\title{
REMOVAL OF BORON FROM PRODUCED WATER \\ BY \\ CO-PRECIPITATION / ADSORPTION FOR \\ REVERSE OSMOSIS CONCENTRATE
}

\author{
A thesis \\ presented to \\ the Faculty of California Polytechnic State University, \\ San Luis Obispo \\ In partial fulfillment \\ of the requirements for the degree \\ Master of Science in Civil and Environmental Engineering
}

By Imran Rahman

June 2009 
(C) 2009

Imran Rahman

ALL RIGHT RESERVED 


\title{
Committee Membership
}

TITLE:

\begin{abstract}
Removal of Boron from Produced Water by Coprecipitation / Adsorption for Reverse Osmosis Concentrate
\end{abstract}

AUTHOR:

Imran Rahman

DATE SUBMITTED: June 2009

COMMITTEE CHAIR:

COMMITTEE CHAIR:

COMMITTEE MEMBER:
Yarrow Nelson

Tryg Lundquist

Corinne Lehr 


\section{Abstract \\ Removal of Boron from Produced Water \\ by Co-precipitation / Adsorption \\ for \\ Reverse Osmosis Concentrate}

Imran Rahman

Co-precipitation and absorption methods were investigated for removal of boron from produced water, which is groundwater brought to the surface during oil and natural gas extraction. Boron can be toxic to many crops and often needs to be controlled to low levels in irrigation water. The present research focused on synthetic reverse osmosis (RO) concentrate modeled on concentrate expected from a future treatment facility at the Arroyo Grande Oil Field on the central coast of California. The produced water at this site is brackish with a boron concentration of $8 \mathrm{mg} / \mathrm{L}$ and an expected temperature of $80^{\circ} \mathrm{C}$. The future overall produced water treatment process will include lime softening, micro-filtration, cooling, ion exchange, and finally RO. Projected boron concentrations in the RO concentrate are 20 to $25 \mathrm{mg} / \mathrm{L}$. Concentrate temperature will be near ambient. This RO concentrate will be injected back into the formation. To prevent an accumulation of boron in the formation, it is desired to reduce boron concentrations in this concentrate and partition the boron into a solid sludge that could be transported out of the area. 
The primary method explored for boron removal during this study was adsorption and co-precipitation by magnesium chloride. Some magnesium oxide tests were also conducted. Jar testing was used to determine the degree of boron removal as a function of initial concentration, $\mathrm{pH}$, temperature, and reaction time. Synthetic RO concentrate was used to control background water quality factors that could potentially influence boron removal. The standard synthetic RO concentrate contained $8 \mathrm{~g} \mathrm{NaCl} / \mathrm{L}, 150 \mathrm{mg}$ $\mathrm{Si} / \mathrm{L}$ and $30 \mathrm{mg} \mathrm{B/L}$. After synthetic RO concentrate was prepared, amendments (e.g. sulfate, sodium chloride) were added and the $\mathrm{pH}$ adjusted to the desired value. Each solution was then carried through a mixing and settling protocol ( 5 min at 200 RPM, 10 min at 20 RPM, followed by 30 min settling and filtration). Boron concentrations from the jar tests were determined using the Carmine colorimetric method.

Boron removal with magnesium chloride was greatest at a $\mathrm{pH}$ of 11.0 . At this $\mathrm{pH} 87 \%$ of boron was removed using $5.0 \mathrm{~g} / \mathrm{L} \mathrm{MgCl}_{2}{ }^{\circ} 6 \mathrm{H}_{2} \mathrm{O}$ at $20^{\circ} \mathrm{C}$. Mixing time did not greatly affect boron removal for mixing periods of 5 to 1321 minutes. This result indicates equilibrium was achieved during the 45-min experimental protocol.

Maximum boron removal was observed in the temperature range of $29^{\circ} \mathrm{C}$ to $41^{\circ} \mathrm{C}$. At $68^{\circ} \mathrm{C}$ boron removal decreased five-fold compared to the reduction observed at $29^{\circ} \mathrm{C}$ to $41^{\circ} \mathrm{C}$. For treatment of the cool concentrate, this relatively low optimal temperature 
range gives magnesium chloride an advantage over magnesium oxide, which is effective only at high temperatures.

Neither sodium chloride nor sodium sulfate affected boron removal by magnesium chloride for the chloride and sulfate concentrations expected in the produced water at this site. In contrast, silica did inhibit boron removal, with removal decreasing from $30 \%$ to $5 \%$ when silica concentration was increased from 0 to $100 \mathrm{mmols} / \mathrm{L}$. This result was unexpected because other researchers have reported silica is necessary for effective removal of boron by magnesium chloride.

To investigate the reasons for the differing boron removal results for magnesium chloride and magnesium oxide, solids produced by the two reagents were compared using X-ray diffraction spectroscopy (XRD). Solids from magnesium chloride contained $30 \%$ amorphous material versus $10 \%$ for magnesium oxide. The crystalline components from the magnesium oxide treatment were for the most part magnesium oxide, whereas magnesium chloride crystalline solids were a combination of brucite $\left(\mathrm{Mg}(\mathrm{OH})_{2}\right)$ and magnesium chloride hydroxide. The greater boron adsorption observed with magnesium chloride could thus either be attributed to the greater surface area of the amorphous precipitate and/or the higher boron affinity of brucite and magnesium chloride hydroxide. 
Adsorption isotherms were plotted for boron removal by magnesium compounds formed during precipitation. Boron adsorption followed a linear isotherm $\left(r^{2}=0.92\right)$ for boron concentrations up to $37.8 \mathrm{mg} \mathrm{B/L}$. While the data also fit Langmuir and Freundlich models the data fell in the linear range of those models. The linearity of the adsorption curves indicates that adsorption sites for boron were not saturated at these concentrations. The linearity means that higher boron concentrations in the RO concentrate will lead to greater mass removal, up to concentrations of at least 37.8 $\mathrm{mg} / \mathrm{L}$ boron.

Using magnesium chloride, boron removal by co-precipitation was more effective than by adsorption to pre-formed precipitate. Removal approximately doubled for a given dose of magnesium chloride. The effectiveness of co-precipitation presumably occurs due to entrapment of boron as the precipitate forms.

This study has shown the potential of magnesium chloride as an agent for boron removal by determining those conditions most effective for boron co-precipitation and adsorption. Magnesium chloride has been shown to be more effective than magnesium oxide. Magnesium chloride also out-performed treatment with slaked quicklime, which was tested previously by others. Two important limitations of boron removal with 
magnesium chloride are the high chemical requirements $\left(5 \mathrm{~g} / \mathrm{L} \mathrm{MgCl}_{2}\right)$ and sludge production ( $1 \mathrm{~g} / \mathrm{g} \mathrm{MgCl}_{2}$ used). These are greatly mitigated by treatment of $\mathrm{RO}$ concentrate rather than the full produced water flow. In addition, reagent use and sludge production might be decreased by recycling sludge from the up-front lime softening process. Compared to magnesium oxide, magnesium chloride removes greater quantities of boron per mole of magnesium added (20 mg B/g MgCl 2$)$. The magnesium chloride isotherm demonstrated that treatment of RO concentrate required less reagent and produced less sludge per mass of boron removed than treatment of the more dilute feed water. 


\section{Acknowledgments}

Thank you to my advisors Dr. Tryg Lundquist and Dr. Yarrow Nelson for their constant advice and encouragement. Your commitment to each student as they bounce their way through Cal Poly is amazing. Thank you Dr. Lehr for introducing me to the world of aquatic chemistry which has become my passion

Thank you to Michael DiFilippo for his guidance on the project and for keeping us up to date on changing requirements of the project.

Thank you to Carrie Esaki for your help with the more tedious parts of boron research. Thank you to Tricia Compas and the other grad students for being in lab to help me maintain my sanity.

Thank you to all my friends for helping me play so much and escapes on the weekends

Thank you to my parents and sister for your support through seven years at Cal Poly 


\section{Table of Contents}

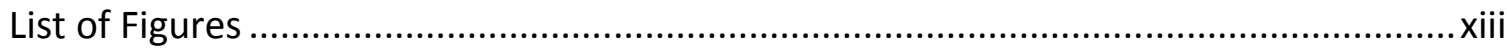

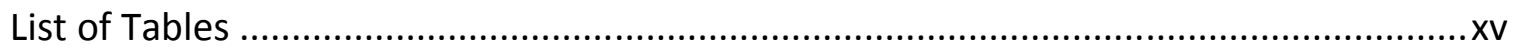

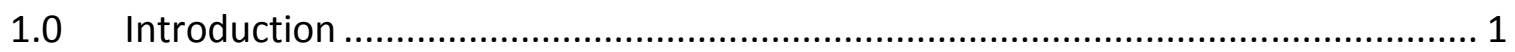

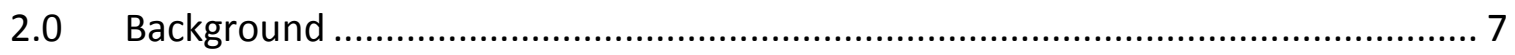

2.1 Boron in the Environment ........................................................................... 7

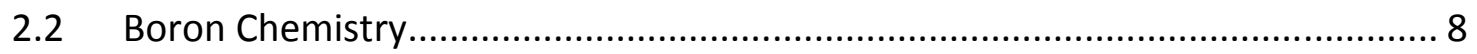

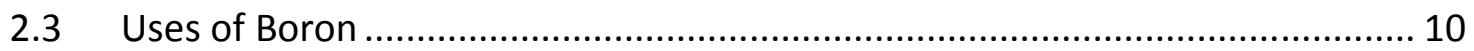

2.4 Effects of Boron on Health and Agriculture ............................................... 11

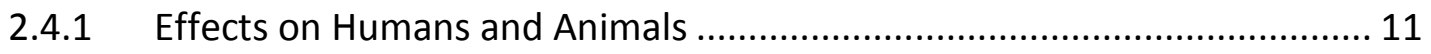

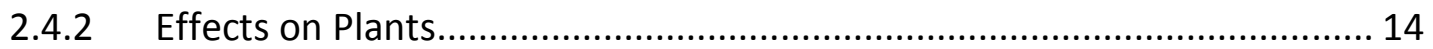

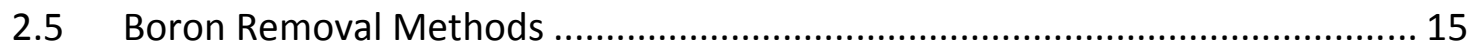

2.5.1 Direct Precipitation ............................................................................ 16

2.5.2 Adsorption and Co- Precipitation ......................................................... 16

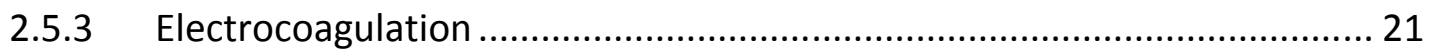

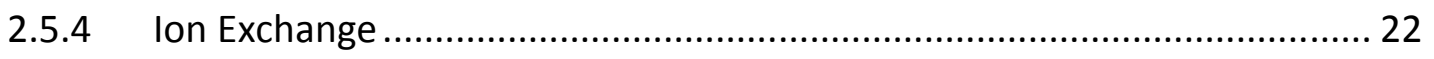

2.5.5 Membrane Filtration................................................................................. 23

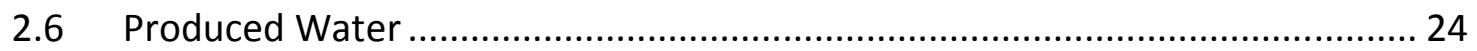

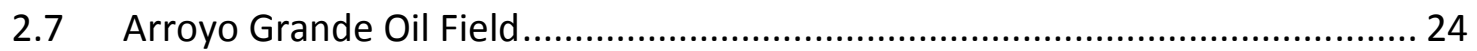

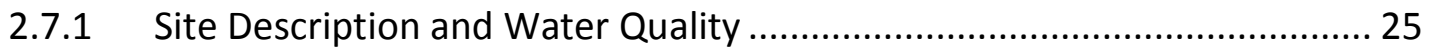

2.7.2 Previous Boron Removal Studies at the Arroyo Grande Oil Field .............. 28

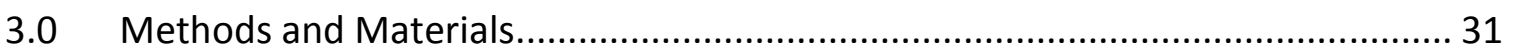

3.1 Experimental Setup and Design ................................................................. 31

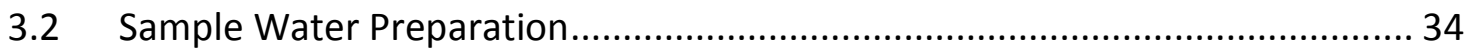

3.3 Analytical Determination of Boron Concentration .......................................... 36

3.3.1 Sodium Chloride Effects on Boron Removal by Aluminum Oxide .............. 38

3.4.2 Sodium Chloride Effect on Boron Removal by Magnesium Oxide ............. 38

3.4.3 Magnesium Carbonate Experiments ..................................................... 39 
3.4.4 Combined Usage of Magnesium Oxide and Aluminum Oxide 40

3.4 Magnesium Chloride Specific Testing Conditions

3.4.1 Boron Removal with Magnesium Chloride under Simulated Site Conditions

3.4.2 Determination of Optimal Initial $\mathrm{pH}$ for Boron Removal by Magnesium Chloride 41

3.5.3 Determination of Optimal Equilibrium $\mathrm{pH}$

3.5.4 Determination of Mixing Time Effects on Boron Removal by Magnesium Chloride.

3.4.5 Preparation of Isotherms for Boron Adsorption by Magnesium Chloride . 44

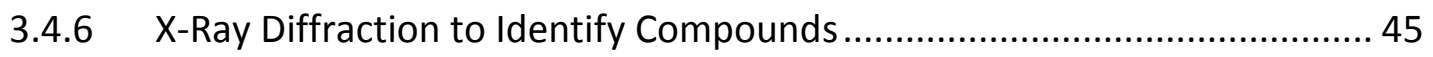

3.4.7 Comparison of Adsorption vs. Co-Precipitation Mechanisms of Boron

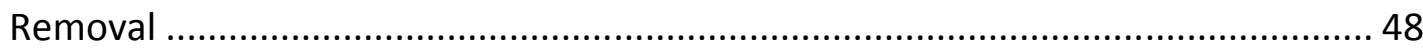

3.4.8 Measurement of Effects of Sodium Chloride on Boron Removal by Magnesium Chloride. 49

3.4.9 Effects of Sulfate on Boron Removal ...................................................... 50

3.4.10 Role of Silica in Boron Removal by Magnesium Chloride ......................... 52

3.4.11 Temperature Effects on Boron Removal by Magnesium Chloride ............. 53

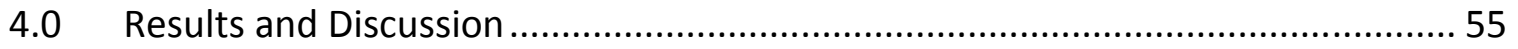

4.1 Initial Experiments of Boron Removal by Magnesium and Aluminum .............. 55

4.1.1 Sodium Chloride Effect on Aluminum Oxide for Boron Removal............... 55

4.1.2 Boron Removal by Magnesium Oxide ................................................... 56

4.1.3 Boron Removal by Magnesium Carbonate .......................................... 57

4.1.4 Combined Use of Aluminum Oxide and Magnesium Oxide ....................... 58

4.2 Boron Removal from Synthetic RO Concentrate Using Magnesium Chloride... 59

4.3 Effects of $\mathrm{pH}$ on Boron Removal Using Magnesium Chloride.......................... 61

4.3.1 Effect of initial pH on boron removal using magnesium chloride .............. 61

4.3.2 Equilibrium pH Effects on Boron Removal by Magnesium Chloride .......... 64

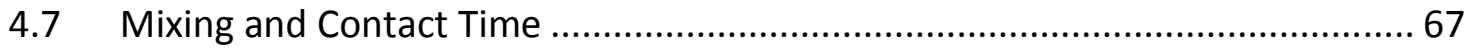

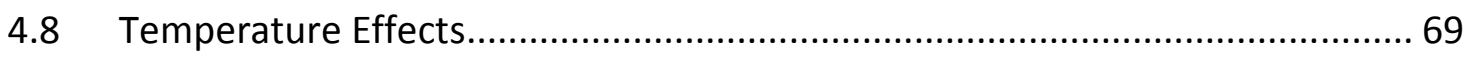




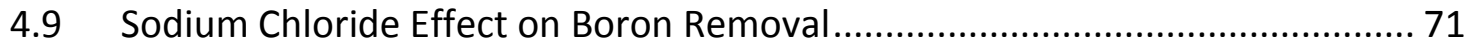

4.10 Effects of Sulfate on Boron Removal........................................................ 74

4.11 Role of Silicon in Boron Removal by Magnesium Chloride ......................... 75

4.12 Adsorption Isotherm for Boron Removal by Magnesium Chloride................ 77

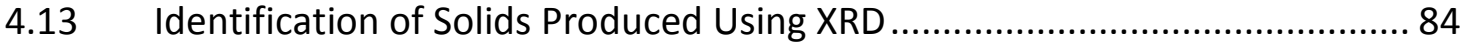

4.14 Adsorption vs. Co-Precipitation Mechanism for Boron Removal with

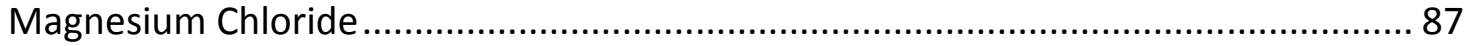

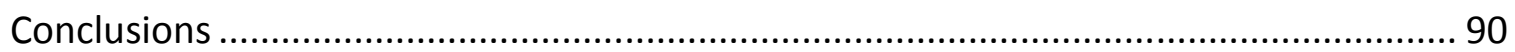

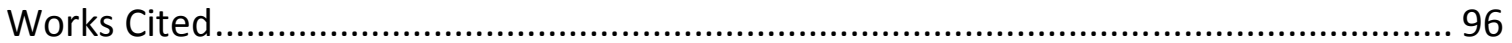




\section{List of Figures}

Figure 1-2 Simplified flow-diagram of the proposed treatment process with proposed boron precipitation treatment system of RO concentrate 3

Figure 1-1 Simplified flow-diagram of the proposed treatment process (without boron treatment components).... 3

Figure 2-1 Distribution of boron species in a solution with $0.01 \mathrm{M}$ total boron conc...... 9

Figure 2-2 White Mulberry tree exhibiting signs of boron toxicity (www.salinitymanagement.org) 15

Figure 2-3 Methyl Glucamine Boron-Specific Ion Exchange Resin (Amberlite IRA 743). 23

Figure 2-4 Arroyo Grande Oil field Site San Luis Obispo County, California (Google Earth). 25

Figure 3-1 - Experimental setup used to conduct jar tests.

Five of the six beaker stations are shown 33

Figure 3-2 Jar after settling period with solids at bottom

Figure 3-3 Example calibration curve used for the determination of boron concentration

Figure 4-1 Percent Boron removal for increasing magnesium chloride doses (8 g/L NaCl, $150 \mathrm{mg} / \mathrm{L} \mathrm{Si}$ )

Figure 4-2 Boron removal by Magnesium Chloride as a function of initial $\mathrm{pH}$ ( $8 \mathrm{~g} / \mathrm{L} \mathrm{NaCl}, 150 \mathrm{mg} / \mathrm{L} \mathrm{Si}, 5 \mathrm{~g} / \mathrm{L} \mathrm{MgCl}_{2}$ ).....

Figure 4-3 Initial and equilibrium $\mathrm{pH}$ values

(5 $\mathrm{g} \mathrm{MgCl}_{2} / \mathrm{L}, 150 \mathrm{mg} \mathrm{Si} / \mathrm{L}, 8 \mathrm{~g} \mathrm{NaCl} / \mathrm{L}$ ) 64

Figure 4-4 Equilibrium $\mathrm{pH}$ for Boron Removal

(5 g/L MgCl $2,8 \mathrm{~g} / \mathrm{L} \mathrm{NaCl}, 150 \mathrm{mg} / \mathrm{L} \mathrm{NaCl}$ )

Figure 4-5 Theoretical titration of synthetic RO concentrate using

Visual MINTEQ ver. 2.53 with percent of $\mathrm{Mg}$ and Si moles precipitated displayed 
Figure 4-6 Changes in boron concentration during extended mixing period

Figure 4-7 Boron removal as a function of temperature

(150 mg Si/L, $8 \mathrm{~g} \mathrm{NaCl} / \mathrm{L}$, and $1.0 \mathrm{~g} \mathrm{MgCl}_{2} \circ 6 \mathrm{H}_{2} \mathrm{O} / \mathrm{L}$ ) 70

Figure 4-8 The effects of sodium chloride on boron removal ..... 73

Figure 4-9 Effects of Sulfate on Boron Removal

(1.0 $\mathrm{g} \mathrm{MgCl}_{2}{ }^{\circ} 6 \mathrm{H}_{2} \mathrm{O} / \mathrm{L}, 8 \mathrm{~g} \mathrm{NaCl} / \mathrm{L}$, and $150 \mathrm{mg} \mathrm{Si} / \mathrm{L}$ ) 75

Figure 4-10 Role of silicon in boron removal with magnesium compounds

(1.0 $\left.\mathrm{g} \mathrm{MgCl}_{2} \circ 6 \mathrm{H}_{2} \mathrm{O}, 8 \mathrm{~g} \mathrm{NaCl} / \mathrm{L}\right)$

Figure 4-11 Isotherm model plots for boron adsorption by magnesium $\left(20^{\circ} \mathrm{C}, \mathrm{pH}=11,150 \mathrm{mg} \mathrm{Si} / \mathrm{L}\right.$ and $\left.8 \mathrm{~g} \mathrm{NaCl} / \mathrm{L}\right)$ 81

Figure 4-12 Plot of adsorption models showing excluded points (pH 11, 20ㄷ, $150 \mathrm{mg} \mathrm{Si} / \mathrm{L}, 8 \mathrm{~g} \mathrm{NaCl} / \mathrm{L})$. 83

Figure 4-13 Boron removal for solutions in which solids were pre-formed (adsorption) versus formed after boron addition (co-precipitation). 89 


\section{List of Tables}

Table 2-1 Summary of human health effects from exposure to boron

(USHHS, 2007).

Table 2-2 Summarized produced water quality data for Arroyo Grande Oil Field 27

Table 3-1 Constituents of synthetic RO concentrate 35

Table 3-2 Amounts of magnesium oxide and aluminum oxide used 40

Table 3-3 Conditions used for comparison of magnesium chloride and magnesium oxide

Table 3-4 Volume of stock solution used for separate reaction conditions. 49

Table 3-5 Weights of $\mathrm{NaCl}$ added to determine effects of $\mathrm{NaCl}$. 50

Table 3-6 Sulfate concentrations used to test effects of sulfate on boron removal........ 51

Table 3-7 Sodium metasilicate weights used to determine role of silicon...................... 52

Table 3-8 - Temperatures used to determine effects on boron removal....................... 54

Table 4-1 Conditions observed during increased $\mathrm{NaCl}$ concentrations in solution ......... 56

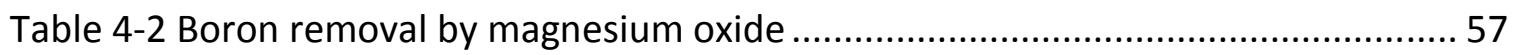

Table 4-3 Boron Removal by Magnesium Carbonate ............................................. 58

Table 4-4 Concentrations of magnesium oxide and aluminum oxide used to determine combination effects on boron removal 58

Table 4-5 Boron removal from synthetic RO reject under approximate site conditions using magnesium chloride 60

Table 4-6 Conditions for determination of optimal initial $\mathrm{pH}$ for boron removal 63

Table 4-7 Conditions used to determine optimal equilibrium $\mathrm{pH}$ 65 
Table 4-8 Changes in boron concentration during extended mixing period (150 mg Si/L, $8 \mathrm{~g} \mathrm{NaCl} / \mathrm{L}, 1.0 \mathrm{~g} \mathrm{MgCl}_{2}{ }^{\circ} 6 \mathrm{H}_{2} \mathrm{O}$ ) 68

Table 4-9 Results of temperature effect experiments .................................................. 70

Table 4-10 Summary of the effects of sodium chloride on boron removal .................... 72

Table 4-11 Sulfate effects on boron removal by $1 \mathrm{~g} / \mathrm{L}$ of Magnesium Chloride............... 74

Table 4-12 Role of silicon in the removal of boron with magnesium compounds........... 76

Table 4-13 Data used to establish isotherms for boron removal.................................... 78

Table 4-14 Isotherm data for boron adsorption by magnesium chloride at $20^{\circ} \mathrm{C}$.......... 79

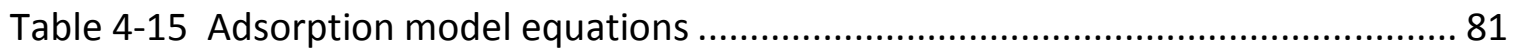

Table 4-16 Observed adsorption data and adsorption predicted from

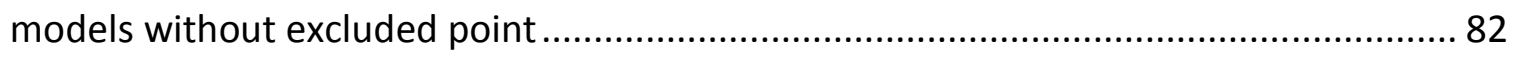

Table 4-17 Model equations for boron adsorption ....................................................... 83

Table 4-18 Solids composition for samples using magnesium oxide and

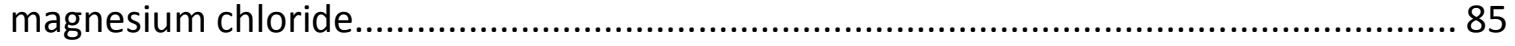

Table 4-19 Elemental composition of solids produced during precipitation .................... 85

Table 4-20 Comparison of Boron Removal by the adsorption versus co-precipitation ... 89 


\subsection{Introduction}

Produced water, water brought to the surface during oil or natural gas production, is the largest waste stream associated with oil and gas production (Veil, Puder, Elcock, \& Redwick Jr., 2004). Given high oil and gas prices and political instability in oil-producing regions of the world, oil and gas production from non-conventional sources such as tar sands and oil shale will continue to expand, resulting in increasing quantities of produced water requiring treatment (Mondal \& Wickramisinghe, 2008). As produced water characteristics and disposal options are site specific, custom treatment process development will most often be required. This project represents part of that development process for the Arroyo Grande Oil Field, San Luis Obispo County, California.

Boron is a common contaminant in produced water. It is a concern for both human health and agricultural reasons. Plants exhibit a range of tolerances to boron. For example blackberries can only handle less than $0.5 \mathrm{mg} \mathrm{B} / \mathrm{L}$ and are considered very sensitive whereas cotton is very tolerant and can be exposed to concentrations as high at $10 \mathrm{mg} \mathrm{B} / \mathrm{L}$. For plants, boron is a necessary nutrient due to its structural role in cell walls; however, at high concentrations, it is toxic and can lead to decreased crop yields (Camacho-Cristobal, Rexach, \& Gonzales-Fontes, 2008). 
The produced water field site for this study was the Arroyo Grande Oil Field on the central coast of California. Currently, the site produces 1500 barrels of oil a day, which is extracted as an oil and water mixture, and the majority of the water is pumped directly back into the formation, while a small portion is treated for use in steam generation. The site owners have proposed to triple oil production at this site by dewatering the formation, which would result in large volumes of produced water that will need to be treated. A proposed treatment system for the site would treat approximately 55,000 barrels of produced water per day ( 8.71 million liters/day) containing $8 \mathrm{mg} / \mathrm{L}$ of boron to provide for steam production, irrigation and/or discharge to Pismo Creek. The proposed treatment train without specific boron removal includes lime-softening, heat exchange, filtration, and reverse osmosis (RO) (Figure 1-2). The reverse osmosis system would be operated at a $\mathrm{pH}>10.5$, and boron removal is expected to be $80-85 \%$. Reverse osmosis concentrate would be re-injected into the formation, but since the RO concentrate would contain approximately $25 \mathrm{mg} / \mathrm{L}$ boron, this reinjection could lead to the accumulation of boron in the formation. In the future, the resulting produced water boron concentrations might increase to a level so high that the RO process would not be able to meet discharge or reuse standards. This risk would be eliminated if the boron were removed prior to RO treatment or if it were removed from the RO concentrate prior to reinjection. An advantage of treating the RO concentrate is that the higher boron concentrations would increase the driving force for adsorption or other separation processes, and thus removal of boron from RO concentrate is the focus of 
this research. A schematic of the revised, proposed treatment process, including the proposed boron removal from RO concentrate, is shown below in Figure 1-1.

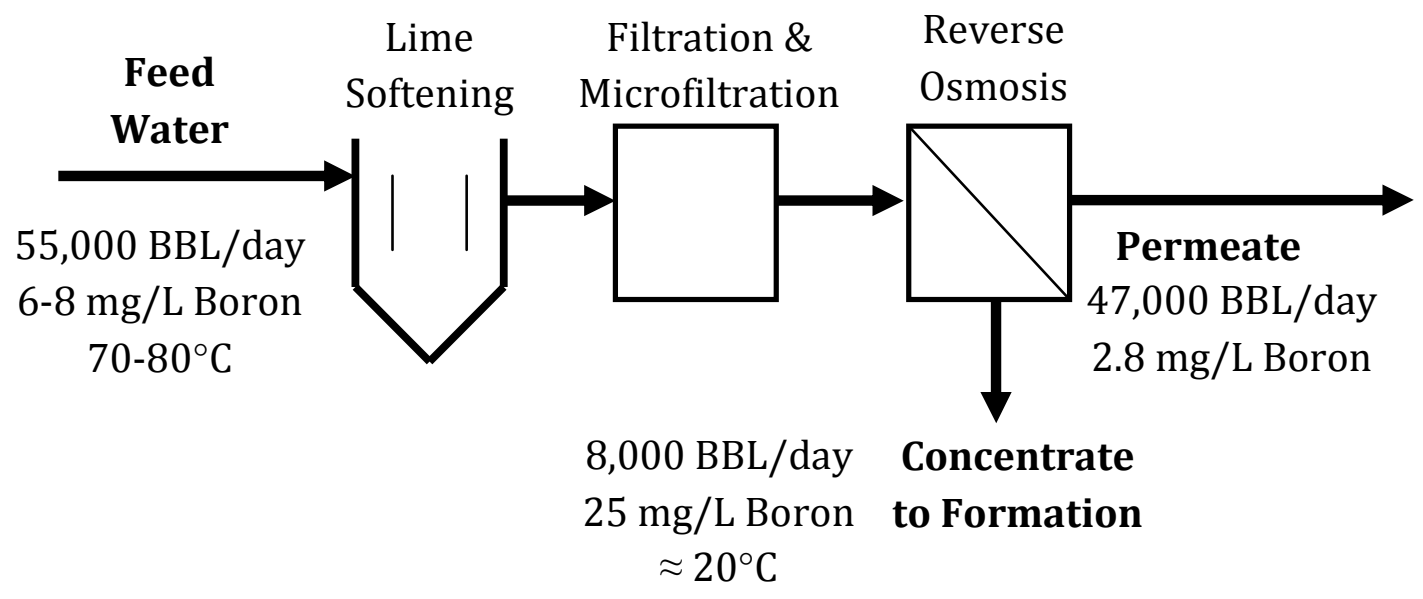

Figure 1-2 Simplified flow-diagram of the proposed treatment process (without boron treatment components) (1 BBL = 42.5 gallons)

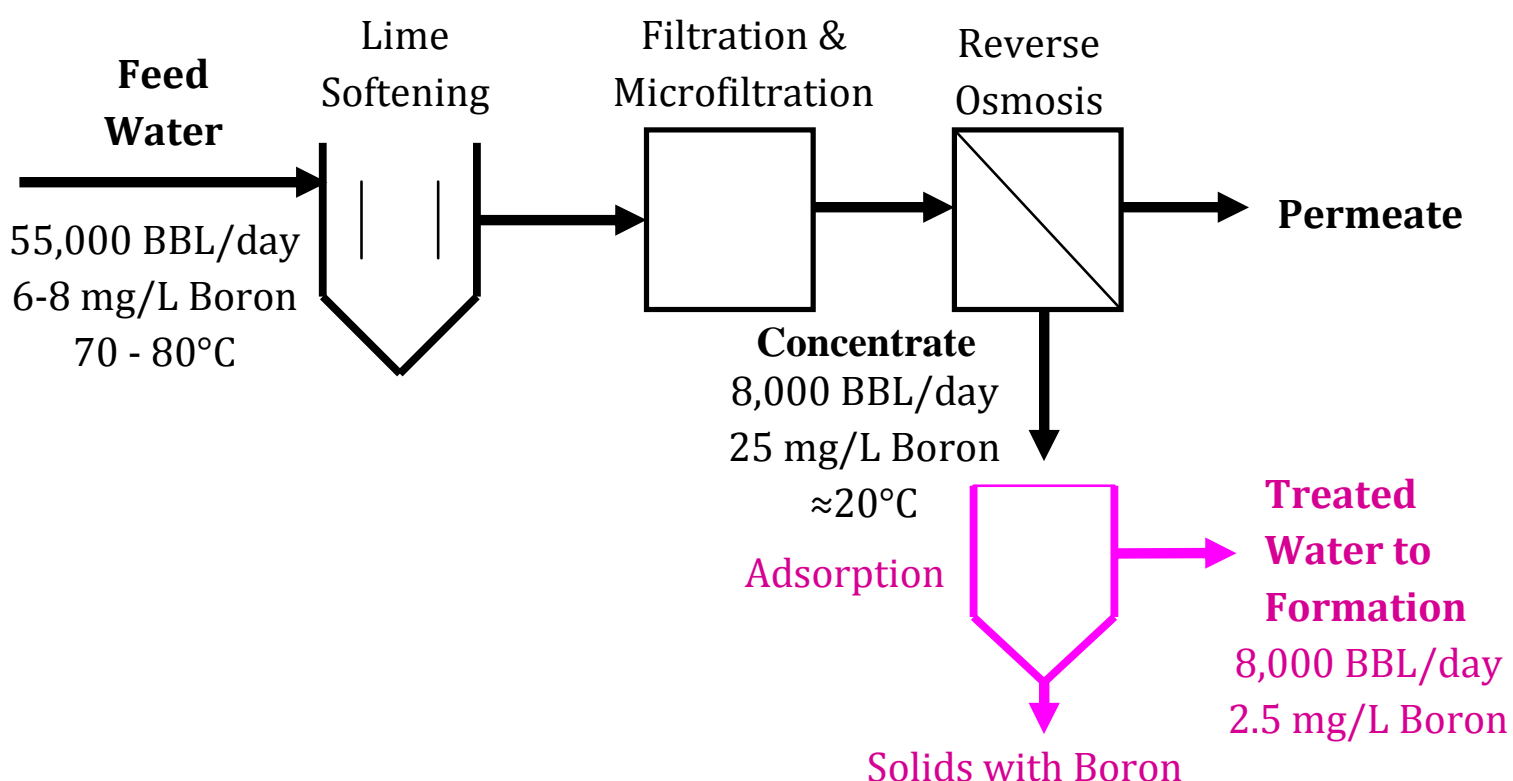

Figure 1-1 Simplified flow-diagram of the proposed treatment process with proposed boron precipitation treatment system of RO concentrate 
The present research focused on synthetic RO concentrate modeled on that expected from the above treatment process. The goal was to decrease concentrations in RO concentrate to a point where accumulation in the formation due to reinjection on concentrate into the formation will not become problematic for continued treatment.

Conventional methods for boron removal include ion exchange, reverse osmosis, and adsorption/precipitation (Parks \& Edwards, 2005). A drawback of ion exchange and RO is that the boron concentrates in a regenerate solution or RO concentrate which are difficult to treat and dispose of. Adsorption/precipitation methods offer the advantage that boron waste is incorporated into a solid, which might be disposed of more easily. However, reported boron absorption/precipitation methods using magnesium, aluminum and various other metal hydroxides typically require large volumes of adsorbent and produce large quantities of sludge, making them uneconomical for many industries (Parks \& Edwards, 2005; Turek, Piotr, Trojanowska, \& Campen, 2006; Remy, Muhr, \& Ouerdiane, 2005; Garcia-Soto \& Camacho, 2006). A promising alternative to adsorption is co-precipitation in which a contaminant is removed during the formation of solids instead of attaching to solids already produced. Several studies showed better boron removal for co-precipitation compared to adsorption (Parks and Edwards 2007, Remy, Muhr and Ouerdiane 2005, Turek, et al. 2006). 
Preliminary work as a part of this project focused on boron removal using magnesium and aluminum oxide during the lime softening process. All work was conducted using site produced water. It was found that lime softening itself did not result in any significant boron removal. To achieve $90 \%$ removal using magnesium oxide $30 \mathrm{~g} / \mathrm{L}$ was necessary and using aluminum oxide $47 \%$ removal was achieved using $35 \mathrm{~g} / \mathrm{L}$ (Worlen 2008).

The goal of boron removal to a solid phase for disposal, led to absorption/precipitation removal was the treatment method selected for development for the Arroyo Grande Oil Field. The preexisting need for lime-softening clarifiers, which might be adapted for boron removal in addition to hardness removal, also contributed to focus on adsorption co-precipitation. Planned use of RO at the site made investigating treatment of the RO concentrate more economical that addition of a further ion exchange treatment step.

Magnesium chloride has shown higher removal potential for boron than adsorption onto magnesium oxide (on a molar basis), based on preliminary experiments with raw produced water from the Arroyo Grande site (Worlen, 2008). To have a greater driving force for adsorption/precipitation, the present research aimed to apply the use of magnesium chloride to treatment of RO concentrate, rather than feed water. Magnesium chloride was selected based on initial experiments demonstrating boron 
removal from the raw produced water at double that of all other reagents explored (Wörlen, 2008). The advantage of focusing on reverse osmosis concentrate is two-fold. First, the waste flow is considerably decreased so that even when using high doses, the overall reagent use and sludge production is potentially decreased. Second, higher concentrations of boron in solution provide a greater driving force for adsorption, potentially increasing the boron content in sludge, and reducing sludge disposal costs. In this research, conditions for boron removal were optimized for the effects of $\mathrm{pH}$, temperature, and mixing time. Adsorption isotherms were constructed to provide a better understanding of the adsorption process to aid in possible full-scale design of the treatment system. In addition, co-precipitation of boron was compared to boron adsorption to an already precipitated magnesium hydroxide. X-ray diffraction analysis was used to determine the mineralogy of the magnesium precipitates. Potential effects of sulfate, chloride, and silica were investigated. 


\subsection{Background}

Boron is an element with a myriad of adverse interactions and beneficial uses in the environment. A summary of literature on these interactions and removal methods is presented in the following sections.

\subsection{Boron in the Environment}

Boron occurs as a trace element in most soil and is estimated to constitute approximately $0.001 \%$ of the earth's crust. Even though boron is widespread, large deposits are uncommon and confined to a few locations (Adams, 1964). The boron concentration in the world's oceans ranges between $1-10 \mathrm{mg} / \mathrm{L}$, with an average of 5 $\mathrm{mg} / \mathrm{L}$. Boron's presence in water is often a result of weathering of boron-containing minerals and soils (Parks \& Edwards, 2005). Another significant source of boron is boric acid, which is released through volcanic eruptions (Muetterties, 1967.) Boron is also released into water from anthropogenic sources such as mining of boron oxide (Parks and Edwards 2005).

Boron has a high affinity for oxygen so in nature it is almost always found associated with oxygen as either boric acid $\left(\mathrm{H}_{3} \mathrm{BO}_{3}\right)$, borates $\left(\mathrm{BO}_{3}{ }^{3-}\right)$, or borosilicates (Wiberg, 
Wiberg, \& Holleman, 2001). Other polyborate ions exist but their presence in nature is negligible (Parks \& Edwards, 2005).

High concentrations of boron are found in Death Valley, California and are often the result of extinct springs where boron was leached from minerals in the ground into surface water. The surface water then evaporated leaving behind large deposits of minerals; such is the case in the mountains east of Death Valley and areas in the Mojave Desert (Adams, 1964).

\subsection{Boron Chemistry}

Two isotopes of boron occur naturally, ${ }^{10} \mathrm{~B}(20 \%)$ and ${ }^{11} \mathrm{~B}(80 \%)$, with ${ }^{11} \mathrm{~B}$ being the predominant isotope (Muetterties, 1967). The elemental form of boron is unstable in nature, but as mentioned above, it is often found in combination with oxygen forming a variety of borate salts and borosilicates (Ross \& Edwards, 1967). Boron appears in group 13 (IIIA) in the periodic table and is the only non metal of this group.

Boric acid, $\mathrm{B}(\mathrm{OH})_{3}$ forms an equilibrium in water with its conjugate base as follows:

$$
B(\mathrm{OH})_{3}+\mathrm{H}_{2} \mathrm{O}=\mathrm{B}(\mathrm{OH})_{4}^{-}+\mathrm{H}^{+} ; \quad p k a=9.24 ; k_{a}=5.8 * 10^{-10}
$$


As can be seen in Equation 1, boric acid does not dissociate in solution but ionizes to form the hydroxyborate ion (tetraborate) in a reaction with a pKa of 9.24. When hydroxyborate and boric acid exist in an aqueous solution, polymerization with the additional formation of water can occur (Ross \& Edwards, 1967).

For total concentrations of boric acid under $0.01 \mathrm{M}$, boric acid and its conjugate base form the only significant species in equilibrium, as determined using Visual Minteq version 2.53. Their relative concentrations in a solution of total concentration 0.01 molar can be seen in Figure 2-1. At a pH above 9.24 the tetraborate $\left(\mathrm{B}(\mathrm{OH})_{4}\right)$ dominates and represents almost all of the boric acid above a $\mathrm{pH}$ of 11 .

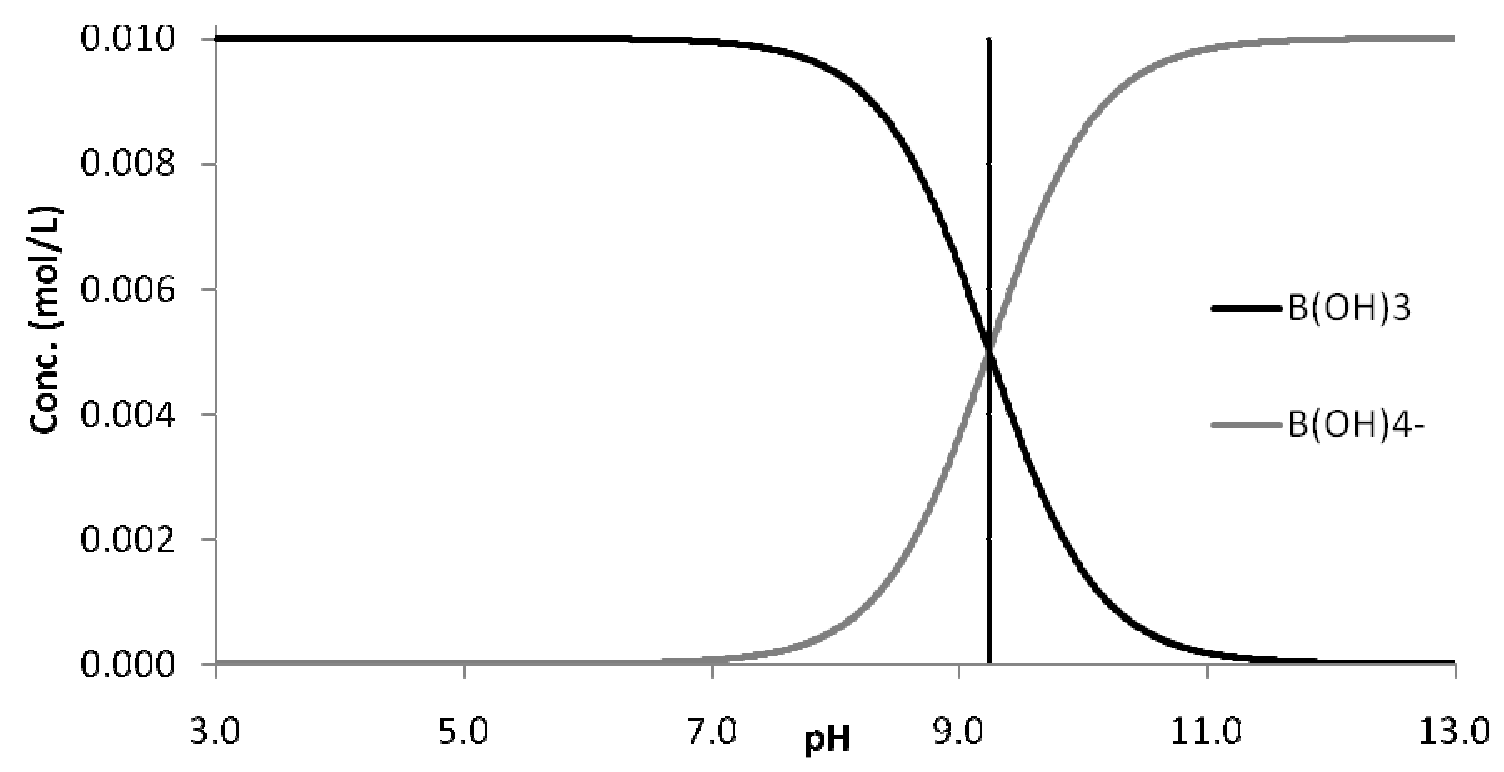

Figure 2-1 Distribution of boron species in a solution with $0.01 \mathrm{M}$ total boron conc. 


\section{$2.3 \quad$ Uses of Boron}

The most abundant boron-containing mineral in the US is tourmaline $\left(\mathrm{NaMg}_{3} \mathrm{Cr}_{6} \mathrm{Si}_{6} \mathrm{O}_{18}\right.$ $\left.\left(\mathrm{BO}_{3}\right)_{3}(\mathrm{OH})_{4}\right)$. However, the boron ores of greatest economic significance are borax (tincal), $\mathrm{Na}_{2} \mathrm{~B}_{4} \mathrm{O}_{5}(\mathrm{OH})_{2}{ }^{\circ} 8 \mathrm{H}_{2} \mathrm{O}$, and kernite, $\mathrm{Na}_{2} \mathrm{~B}_{4} \mathrm{O}_{5}(\mathrm{OH})_{4}{ }^{\circ} 2 \mathrm{H}_{2} \mathrm{O}$ (Muetterties, 1967), which are mainly mined from dry salt lakes (Ross \& Edwards, 1967). Some of the major uses of boron are in the production of glass products (borosilicates), fire retardants, ferroboron, and detergents. Agriculture also consumes significant quantities of boron as fertilizer. In 2007, 4.3 million tons of boron as boric oxide was produced in the United States (Kostick, 2008).

Boron is one of 16 essential nutrients for plant growth. Its use as a fertilizer is common and can quadruple corn yields (Camacho-Cristobal, Rexach, \& Gonzales-Fontes, 2008). The steel industry uses ferroboron as an additive to steel to increase its hardness. It is also used in the semiconductor industry to modify electrical conductivity. Zinc borate is used in many plastics as a fire retardant. Glass is the major use of boron in the United States and internationally (Polyak, 2007). 


\subsection{Effects of Boron on Health and Agriculture}

Although, boron is an essential nutrient for both plants and animals it has toxic effects depending on the concentration and duration of exposure, as described below. Plants are affected by boron both in the soil and in irrigation water, necessitating treatment before they are consumed if boron concentrations are too high.

\subsubsection{Effects on Humans and Animals}

The average daily intake of boron for humans is one milligram per person in the United States, with the most common route of intake being through food (USHHS, 2007). The USEPA determined from a survey of 989 public water systems across 49 states that $81.9 \%$ contained boron $(>0.005 \mathrm{mg} / \mathrm{L})$. However, as would be expected, boron concentrations in groundwater are much higher in areas near large natural boron mineral deposits (USEPA, Drinking Water Health Advisory for Boron, 2008). A summary of various health effects on humans is presented below in 


\section{Table 2-1.}

Boron has a lifetime health advisory for adults of $5 \mathrm{mg} / \mathrm{L}$ and a 10-day health advisory of $2.0 \mathrm{mg} / \mathrm{L}$ for children, and these concentrations are often exceeded in drinking water (USEPA 2008). A lifetime or 10 day, health advisory is the concentration of chemical not expected to cause any adverse noncarcinogenic effects during the given time period (EPA 2006) The World Health Organization has set the maximum total daily intake (TDI) for boron to be $0.5 \mathrm{mg} / \mathrm{L}$ (WHO, 1998). However, as of July 2008, the USEPA has not placed boron on the list of contaminants needing to be regulated since few public water supplies contain high boron concentrations (USEPA, 2008). 
Table 2-1 Summary of human health effects from exposure to boron (USHHS, 2007)

\begin{tabular}{|c|c|c|c|c|}
\hline $\begin{array}{l}\text { Mode of } \\
\text { Exposure }\end{array}$ & $\begin{array}{l}\text { Boron } \\
\text { Form }\end{array}$ & Acute Effects & Chronic Effects & Conc. \\
\hline Inhalation & $\begin{array}{l}\text { Borate } \\
\text { Dust }\end{array}$ & $\begin{array}{l}\text { Acute respiratory and ocular } \\
\text { irritation } \\
\text { No noticeable change in lung } \\
\text { function }\end{array}$ & None & $\begin{array}{l}0.44-3.1 \\
\mathrm{mg} \mathrm{B} / \mathrm{m}^{3}\end{array}$ \\
\hline Ingestion & $\begin{array}{l}\text { Boric } \\
\text { Acid }\end{array}$ & $\begin{array}{l}\text { Lethal Dose: } 15-20 \text { grams in } \\
\text { adults } \\
\text { Reproductive system and } \\
\text { developing fetus most } \\
\text { sensitive areas. Decrease in } \\
\text { fetal body weight. Increase in } \\
\text { occurrence of external and } \\
\text { cardiovascular malformations. }\end{array}$ & & $\begin{array}{l} \\
44 \mathrm{mg} \\
\mathrm{B} / \mathrm{kg} / \text { day }\end{array}$ \\
\hline & & & $\begin{array}{l}\text { Decrease in } \\
\text { hemoglobin } \\
\text { levels and } \\
\text { splenic } \\
\text { hematopoesis }\end{array}$ & $\begin{array}{l}\geq 60 \mathrm{mg} \\
\mathrm{B} / \mathrm{kg} / \mathrm{day}\end{array}$ \\
\hline Dermal & Borax & Irritation of eyes and skin & & \\
\hline
\end{tabular}

The Agency for Toxic Substances and Disease Registry (ATSDR) has determined an acute duration inhalation minimum risk level $(\mathrm{MRL})$ of $0.01 \mathrm{mg}$ boron $/ \mathrm{m}^{3}$ based on a lowest observed adverse effect level (LOAEL) of $0.44 \mathrm{mg}$ boron $/ \mathrm{m}^{3}$ for eye, nasal and throat irritation with an uncertainty factor of 30 . An uncertainty factor is a number used to 
account for variations in human sensitivity, using animal data for human cases, and the uncertainty found when using no observed effect level based on effects observed at low levels. An acute duration oral MRL of $0.2 \mathrm{mg}$ boron/ $\mathrm{kg} /$ day is based on a no-observable adverse effect level (NOAEL) of $22 \mathrm{mg} / \mathrm{kg} /$ day with an uncertainty factor of 100 (USHHS, 2007). The World Health Organization (WHO) has set a drinking water standard for boron of $0.5 \mathrm{mg} / \mathrm{L}(\mathrm{WHO}, 1998)$.

\subsubsection{Effects on Plants}

Boron is regarded as a necessary plant nutrient (Eaton, 1940). One of the primary functions of boron is to form borate esters, which are essential to cell wall structure and function of plants (Camacho-Cristobal, Rexach, \& Gonzales-Fontes, 2008). However, both high and low boron exposure can harm plant growth.

Boron toxicity in plants typically is evident in mature portions of a plant such as older leaves, which become chlorotic, produce insufficient chlorophyll, or wither and die (Tanaka \& Fujiwara, 2008). An example is depicted below in Figure 2-2. 


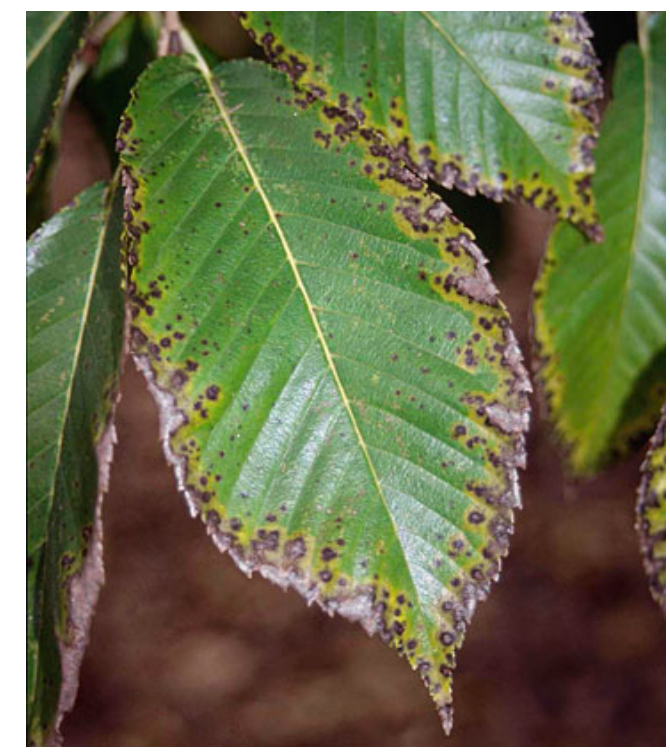

Figure 2-2 White Mulberry tree exhibiting signs of boron toxicity (www.salinitymanagement.org)

Tolerance to boron ranges for different plant species. For example blackberries starts to wilt with less than $0.5 \mathrm{mg} \mathrm{B} / \mathrm{L}$ and are considered very sensitive, whereas cotton is very tolerant and can be exposed to concentrations as high at $10 \mathrm{mg} \mathrm{B} / \mathrm{L}$.

\subsection{Boron Removal Methods}

This section describes the major treatment methods for boron removal from water and their strengths and weaknesses in various contexts. 


\subsubsection{Direct Precipitation}

To date, no sparingly soluble, inorganic borate compounds have been found that are practical in the water treatment industry. Known insoluble boron compounds result in higher removal per mole of treatment chemical than adsorption, but require prohibitive temperature, $\mathrm{pH}$ or chemical requirements (McNeill and Edwards). For example, whereas adsorption typically requires $10-100$ moles of sorbent per mol contaminant removed, direct precipitation removes 0.3 to 3 mol contaminant per mol cation added]. Higher removal efficiencies translate into lower operating costs for both the treatment and waste disposal aspects of a water treatment facility (Parks \& Edwards, 2005).

\subsubsection{Adsorption and Co- Precipitation}

Boron adsorption and co-precipitation to a variety of amorphous or crystalline minerals has been demonstrated (Parks and Edwards 2007, Turek, et al. 2006). Many of these processes have been used as portions of existing water treatment facilities. For example, Turek, et al. (2006) used iron, nickel and aluminum hydroxides on landfill leachate RO concentrate to remove boron to levels less than $1 \mathrm{mg} \mathrm{B/L}$.

Boron can be removed during the formation of magnesium silicate solids in precipitative lime softening (Parks and Edwards, 2007). Parks and Edwards conducted experiments to 
determine the role of magnesium, calcium, silicon, and $\mathrm{pH}$ in boron removal. The mechanism of boron removal was found to be either co-precipitation or adsorption, but the specific mechanism was not determined. Parks and Edwards also determined that calcium played no significant role in boron removal. They showed $70 \%$ of initial boron was removed when both silica and magnesium were present before solids formation. By comparison, only $10 \%$ was removed when only magnesium was present prior to precipitation. An optimal $\mathrm{pH}$ for boron removal was determined to be 10.8 . They concluded that silica was removed from solution by co-precipitation with magnesium, while boron was removed by sorption to amorphous magnesium silicate. From an initial boron concentration of $100 \mu \mathrm{g} / \mathrm{L}$, a maximum of $80 \%$ removal was observed. Initial concentrations of magnesium and silicon were approximately $50 \mathrm{mg} / \mathrm{L}$ and $12 \mathrm{mg} / \mathrm{L} \mathrm{Si}$, respectively. Sorption on boron followed a Freundlich isotherm.

Boron adsorption by magnesium oxide and aluminum oxide was researched by Konstantinou, Kasseta and Pashalidis (2006). A periodically mixed batch technique was used for all their adsorption experiments under atmospheric conditions at $25^{\circ} \mathrm{C}$ with the ionic strength maintained at $0.1 \mathrm{M}$. For $25 \mathrm{~g} / \mathrm{L}$ magnesium oxide, a maximum boron removal of $90 \%$ was achieved from a solution containing an initial concentration of 2.2 $\mathrm{mg} / \mathrm{L} \mathrm{B}$. In contrast, aluminum oxide removed just over $50 \%$ of boron from the same solution using the same concentration of adsorbent. Konstaniou et al. determined that the optimal $\mathrm{pH}$ levels for boron adsorption on magnesium and aluminum oxide are 8 
and 10, respectively. Steep decreases in boron adsorption were observed outside of these optimal $\mathrm{pH}$ values. They postulated that optimum conditions for boron removal on aluminum oxide occur when surface charge is neutralized and tetraborate is the dominate species in solution. Based on this conclusion, Konstantinou et al. postulated that the mechanism for adsorption is proton dissociation of boric acid at the surface of the aluminum oxide and subsequent reaction of dissociated protons with surface hydroxyl groups of sites to form water, which is then displaced by the boric acid anion. For magnesium, they postulated that adsorption is driven by a coulombic interaction between borate anions and positively-charged sites on the surface. At high $\mathrm{pH}$, they suggested carbonate anions compete for positively-charged sites. The maximum adsorption capacity for aluminum oxide was $0.4 \mathrm{mg} \mathrm{B} / \mathrm{g}$ adsorbent and $4 \mathrm{mg} \mathrm{B} \mathrm{/} \mathrm{g}$ adsorbent for 25g magnesium oxide. Both adsorbents could be modeled with Freundlich isotherms. Konstantinou et al. also studied temperature effects. It was shown that for magnesium oxide, increased temperature led to greater boron removal. The opposite effect was found for aluminum oxide.

An adsorption / co-precipitation plus reverse osmosis system for boron removal was explored by Turek, Piotr, Trojanowska, and Campen (2006). The influence of initial boron concentration on boron removal by various metal hydroxides present at $2.4 \mathrm{~g} / \mathrm{L}$ was investigated. Turek et al. concluded that boron adsorption by metal hydroxides decreased in the following order $\mathrm{Ni}>\mathrm{Al}>\mathrm{Co}>\mathrm{Fe}>\mathrm{Zn} \approx \mathrm{Mg}$. For $2.4 \mathrm{~g} / \mathrm{L}$ of magnesium 
chloride and initial boron concentrations ranging from 50 to $300 \mathrm{mg} / \mathrm{L}$ of boron, a consistent $40 \%$ removal was observed indicating that no saturation occurred in the range explored.

A further study on boron removal by adsorption on magnesium oxide was conducted by Garcia-Soto and Camacho (2006). They carried out their study on two solutions, one with a high concentration $(500 \mathrm{mg} \mathrm{B} / \mathrm{L})$ and one with low concentration $(50 \mathrm{~g} \mathrm{~B} / \mathrm{L})$. The removal yield was quantified by the $\mathrm{Mg}$ / $\mathrm{B}$ ratio so that the amount of additional boron removal achieved per additional amount of magnesium oxide added could be quantified. Removal yield correlated with $\mathrm{Mg}$ / B ratio up to a ratio of 20. Higher ratios did not increase removal yield significantly. Contact time was also explored. Initially boron removal increased rapidly, after which the trend became asymptotic. Optimum contact time was found to be 6-10 hours. Temperature was shown to have a large influence on boron removal, with higher temperatures leading to greater boron removal. Optimum $\mathrm{pH}$ for boron removal was observed around $\mathrm{pH}$ 10. These data also led the researchers to believe that boron is removed via a complexation reaction with hydroxide groups on the surface of the adsorbent. At higher $\mathrm{pH}$, competition between borate ions and hydroxyl groups for adsorption sites led to a decrease in boron removal. 
Boron adsorption to aluminum oxide, as well as removal by reverse osmosis was investigated by Bouguerra, Mnif, Hamrouni, and Dhabi (Bouguerra, Mnif and Dhahbi 2008). Equilibrium was reached after 30 minutes of contact time. Maximum adsorption was observed at $\mathrm{pH}$ values of $8.0-8.5$. Bouguerra et al. also found that boron removal decreased in the presence of sulfate, fluoride, nitrate, carbonate, or silica. Two solutions were tested for boron removal, one with $5 \mathrm{mg} \mathrm{B} / \mathrm{L}$ and one with $50 \mathrm{mg} / \mathrm{L}$. Removal peaked at $40 \%$ for the low boron solution and $65 \%$ for the high boron solution.

Remy, Muhr, Plasari, and Ouerdiane (2005) studied the removal of boron from wastewater by precipitation with calcium hydroxide. Boron was removed from $700 \mathrm{mg} / \mathrm{L}$ to less than $50 \mathrm{mg} / \mathrm{L}$. Synthetic waste solution was prepared with conditions similar to industrial waste. Conditions were $90^{\circ} \mathrm{C}$ using $50 \mathrm{~g} / \mathrm{L}$ of calcium hydroxide and a 2-hr contact time. Sulfuric acid was also added at a concentration of $0.7 \mathrm{~g} / \mathrm{L}$. Influences of $\mathrm{pH}$ were not investigated. Increased temperatures were found to lead to increased boron removal.

Boron co-precipitation with calcium carbonate was researched by Kitano, Okumura, and Idogaki (1978). Calcium carbonate was added to solutions containing various ratios of sodium chloride, magnesium chloride, and boric acid. This study found that boron removal correlated with magnesium concentration $(1.27 \mathrm{~g} / \mathrm{L})$ in the parent solutions, 
leading to the formation of the aragonite form of calcium carbonate instead of the calcite form. Higher initial sodium concentrations corresponded to lower boron removal. The $\mathrm{pH}$ of all solutions was maintained at $7.5-8.2$. A wide range of initial boron concentrations were tested for removal.

Parks and Edwards (2006) did a broad range study investigating removal of a variety of individual inorganic contaminants using sodium carbonate. In their study, effective boron removal was not observed by sodium carbonate alone during these experiments.

\subsubsection{Electrocoagulation}

Yilmaz, Boncukcuoglu, and Kocakerim (2007) compared electrocoagulation and chemical coagulation for boron removal. Specifically, aluminum chloride addition was compared with aluminum electrocoagulation. Aluminum doses were equal for both methods ( 7.45 $\mathrm{g} / \mathrm{L}$ ). Optimal pH was found to be the same for both coagulation methods at a $\mathrm{pH}$ of 8.0. It was also found that removal saturated for both methods above $100 \mathrm{mg} \mathrm{B} / \mathrm{L}$ initial concentration. Electrocoagulation was much more effective, with boron removal reaching $94 \%$ versus $24 \%$ for chemical coagulation alone. Temperatures between 20 and $40^{\circ} \mathrm{C}$ were tested for electrocoagulation and between 20 and $80^{\circ} \mathrm{C}$ for chemical coagulation. Temperature was also shown to have an important effect on removal efficiency, with more boron being removed at higher temperatures. 
The mechanisms of boron removal by electrocoagulation were investigated by Jiang, $\mathrm{Xu}$, Quill, Simon, and Shettle (2006). Maximum removal was observed at a current density of $62.1 \mathrm{~A} / \mathrm{m}^{2}$. Above this current density, removal efficiency decreases as well as requiring a higher working potential, which led to higher energy consumption. The maximum adsorption capacity of the aluminum flocs produced by electrocoagulation was $200 \mathrm{mg}$ of B per $\mathrm{g}$ of Al. Freshly produced aluminum flocs from aluminum sulfate, by comparison, had a maximum adsorption capacity of about $20 \mathrm{mg}$ B per g of Al. Boron removal of $70 \%$ was achieved through electrocoagulation for aluminum to boron ratios of four to one.

\subsubsection{Ion Exchange}

While general ion exchange resins do not remove boron well, the development of boron specific resins in the 1970s (Jacob, 2007) has led to an increase in the applicability of ion exchange to boron removal. When a non-specific ion exchange resin is used all anions are retained on the resin leading to very high regeneration costs, but less regeneration is required when using boron specific resins.

Amberlite IRA 743 Boron Specific Resin (Figure 2-3) only removes boron when the $\mathrm{pH}<8$.

The resin is then regenerated with strong mineral acids (Receoglu \& Beker, 1991). Jacob (2007) compared a single-pass RO system combined with ion exchange to a second-pass 
reverse osmosis system The total estimated operating costs was $\$ 0.06 / \mathrm{m}^{3}$ and $\$ 0.03$ / $\mathrm{m}^{3}$, respectively. Boron in RO concentrate is typically removed by ion exchange to less than $50 \mu \mathrm{g} / \mathrm{L}$, with this value increasing with the number of bed volumes treated (Jacob, 2007).

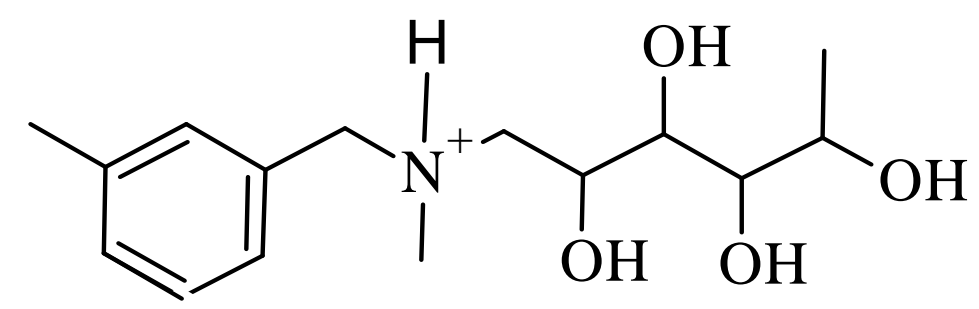

Figure 2-3 Methyl Glucamine Boron-Specific Ion Exchange Resin (Amberlite IRA 743)

\subsubsection{Membrane Filtration}

Reverse osmosis is commonly used for the treatment of produced water throughout the United States, presenting several advantages over other technologies. For example, the variation in feed water does not necessarily lead to a variation in permeate quality (Mondal \& Wickramisinghe, 2008). The boron rejection by a standard reverse osmosis operation ranges from $40-60 \%$, which does not produce concentrate that meets drinking water standards (Pastor, Ruiz, Chillon, \& Rico, 2001). For reverse osmosis to be more effective in rejecting boron, $\mathrm{pH}$ must be raised, and higher than usual driving pressures must be used. With feed water $\mathrm{pH}$ elevated to 10 , boron rejection reaches $90 \%$, and with $\mathrm{pH} 11$, rejection can reach $99 \%$. Multi-stage reverse osmosis systems 
have also been proposed in order to lessen scaling, and membrane degradation that occur due to operating at conditions required for boron rejection (Magara, Tabata, Kohki, Kawasaki, \& Hirose, 1998).

\subsection{Produced Water}

Produced water is water that is trapped in underground formations and brought to the surface with oil or gas production. A produced solution is brought to the surface that consists of liquid or gaseous hydrocarbons, dissolved and suspended solids and fluids injected into the formation to assist with resource extraction. Produced water is by far the largest waste stream association with oil production. Approximately 15-20 billion barrels (42 US gallons per barrel) of produced water are generated each year in the US alone from almost one million oil wells (Veil, Puder, Elcock, \& Redwick Jr., 2004). In the oil and gas industry over $90 \%$ of produced water is reinjected into the ground (Hayes \& Arthur, 2004).

\subsection{Arroyo Grande Oil Field}

The site relevant to this research is located in Price Canyon of San Luis Obispo County California outside the town of Arroyo Grande. 


\subsubsection{Site Description and Water Quality}

The site lies in close proximity to Pismo Creek, evident by the dense line of trees at the bottom right of Figure 2-4.

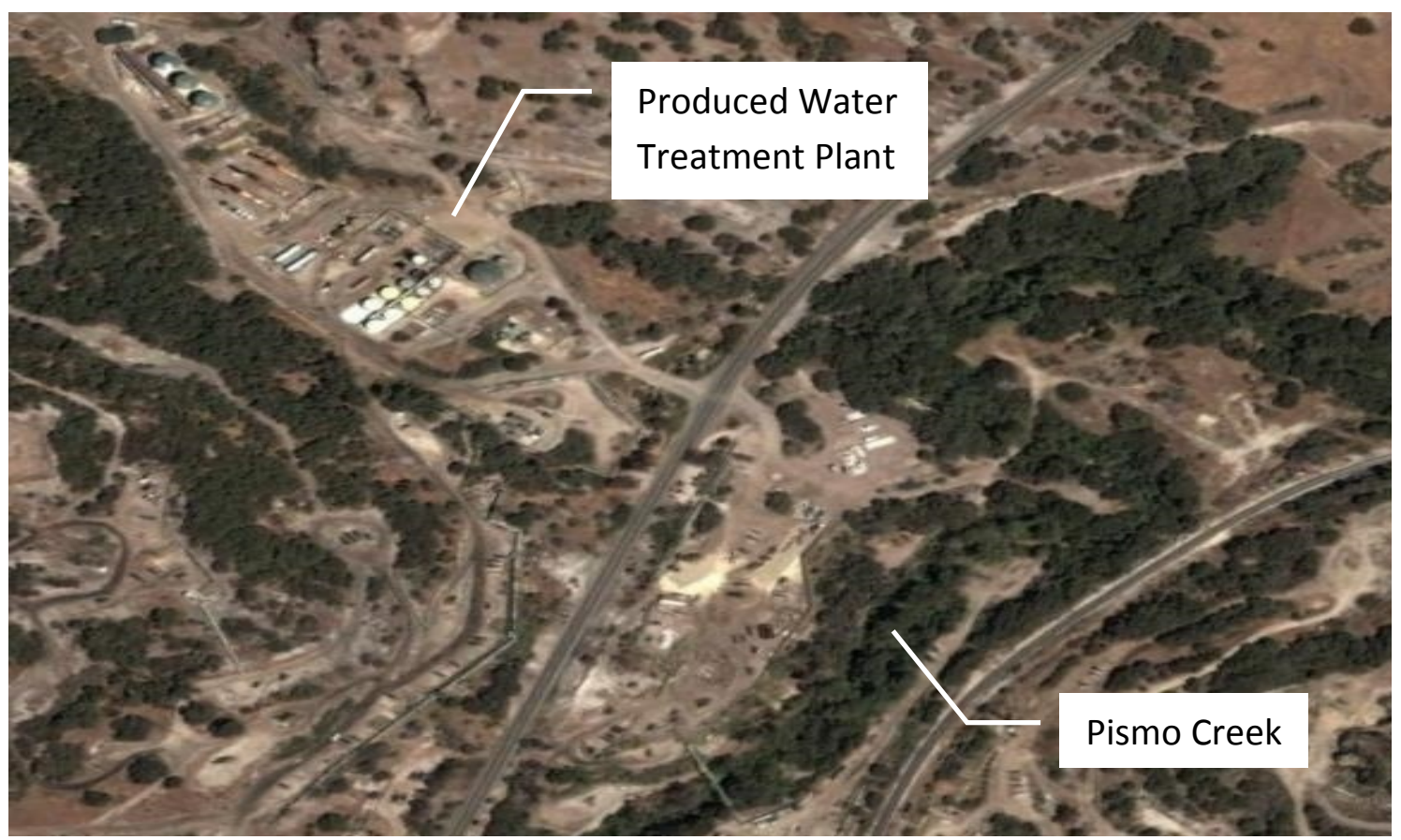

Figure 2-4 Arroyo Grande Oil field Site, San Luis Obispo County, California (Google Earth)

The current water treatment scheme involves a set of oil-water separators, after which the majority of the water is reinjected into the formation from which the oil was extracted. The remainder of the water is sent through a set of filters and treated by ion exchange for use in steam generation for injection for further oil extraction. The raw produced water is characterized as a brackish and comes out of the ground at $70-80^{\circ} \mathrm{C}$. 
The typical water chemistry of the produced water is summarized below in Table 2-2 (data provided by site owner). The proposed water treatment schemes for the site are summarized in Figure 1-2 and Figure 1-1 in the introduction. 
Table 2-2 Summarized produced water quality data for Arroyo Grande Oil Field

\begin{tabular}{|c|c|c|}
\hline \multirow{2}{*}{ Constituent } & \multicolumn{2}{|c|}{ Concentration } \\
\hline & $(m M)$ & $(m g / L)$ \\
\hline $\mathrm{Na}$ & 20.59 & 473 \\
\hline K & 1.22 & 37 \\
\hline $\mathrm{Ca}$ & 1.41 & 56 \\
\hline Mg & 0.74 & 18 \\
\hline Sr & 0.02 & 1 \\
\hline B & 0.68 & 7 \\
\hline Alkalinity, as $\mathrm{CaCO}_{3}$ & - & 495 \\
\hline $\mathrm{Cl}$ & 15.87 & 563 \\
\hline $\mathrm{SO}_{4}$ & 0.05 & 5 \\
\hline $\mathrm{F}$ & 0.07 & 1 \\
\hline $\mathrm{NH}_{3}$ & 0.98 & 17 \\
\hline Total S & 0.76 & 24 \\
\hline Calc'd $\mathrm{CO}_{2}$ & - & 316 \\
\hline Si (total) & 3.51 & 98 \\
\hline Si (soluble) & 3.37 & 95 \\
\hline Calc'd $\mathrm{SiO}_{2}$ (soluble) & - & 203 \\
\hline $\mathrm{EC}$ & - & 2600 \\
\hline $\mathrm{pH}$ & - & 7 \\
\hline TSS & - & 4 \\
\hline Calc'd TDS & - & 1988 \\
\hline Oil & - & 76 \\
\hline TOC & - & 179 \\
\hline $\mathrm{CH}_{4}$ & 0.072 & 1 \\
\hline Acetone & 0.071 & 4 \\
\hline 2-Butanone & 0.016 & 1 \\
\hline Propionic Acid & 0.204 & 15 \\
\hline Butyric Acid & 0.150 & 13 \\
\hline
\end{tabular}




\subsubsection{Previous Boron Removal Studies at the Arroyo Grande Oil Field}

Graduate student Cecilia Wörlen, previously worked on the problem of boron removal at the Arroyo Grande Oil Field for her MS thesis work conducted at Cal Poly (Worlen, 2008). Her research focused on boron removal during the lime softening process with addition of magnesium oxide $(\mathrm{MgO})$ and aluminum oxide $\left(\mathrm{Al}_{2} \mathrm{O}_{3}\right)$ for silica and boron removal. Her study was conducted using Arroyo Grande (AG) produced water. Initial research determined that AG water did not have significant buffering, and that alkalinity measured only $200 \mathrm{mg} / \mathrm{L}$ as $\mathrm{CaCO}_{3}$ (Worlen 2008). This value for alkalinity was measured consistently during Wörlen's research. An optimum lime dose of $500 \mathrm{mg} / \mathrm{L}$ for softening was determined after exploratory experiments. However, silica removal was also a goal of the lime softening process, and lime doses exceeding $1000 \mathrm{mg} / \mathrm{L}$ were necessary to reach $90 \%$ silica removal. Addition of soda ash with the lime decreased the lime dose needed for silica removal.

High doses of lime $(2.7 \mathrm{~g} / \mathrm{L})$ alone resulted in up to $20 \%$ boron removal at $70^{\circ} \mathrm{C}$. Magnesium oxide (MgO) doses of 0-30 g/L were tested. The maximum boron removal of $90 \%$ was observed with lime softening and $30 \mathrm{~g}$ magnesium oxide per liter.

Boron removal was temperature dependent. Boron removal was five times higher when temperatures were higher increased from $50^{\circ} \mathrm{C}$ to $90^{\circ} \mathrm{C}$. Magnesium addition 
contributed to silica removal; when adding $5 \mathrm{~g} / \mathrm{L}$ of $\mathrm{MgO}$ with $500 \mathrm{mg} / \mathrm{L}$ of lime, $70 \%$ of silica was removed. Temperature also played a critical role in silica removal. Silica removal was higher $(75 \%$ vs $97 \%)$ when the temperature was higher $\left(70^{\circ} \mathrm{C}\right.$ vs $\left.80^{\circ} \mathrm{C}\right)$ with $5 \mathrm{~g} / \mathrm{L}$ of $\mathrm{MgO}$ and $500 \mathrm{mg} / \mathrm{L}$ of lime.

A control experiment was conducted using boron solutions in DI water in place of AG water. Boron removal was better from DI water for a given lime and $\mathrm{MgO}$ dose than in the AG water.

Aluminum oxide doses of 0 to $35 \mathrm{~g} / \mathrm{L}$ were tested. A maximum of $38 \%$ boron was removed when $35 \mathrm{~g} / \mathrm{L}$ of aluminum oxide was added.

Wörlen also ran a preliminary investigation using magnesium chloride which demonstrated that five times more boron was removed per mole of magnesium using magnesium chloride than magnesium oxide.

Wörlen found magnesium oxide and aluminum oxide required large doses to achieve significant boron removal making this method of boron removal uneconomical. The effective removal of boron by magnesium and aluminum oxide for site water was 
demonstrated. The greater potential of magnesium chloride over magnesium oxide and aluminum oxide was also demonstrated. 


\subsection{Methods and Materials}

\subsection{Experimental Setup and Design}

Jar test experiments were set up to measure boron removal under simulated site conditions. There were two potential scenarios explored for boron removal: Removal during the initial lime softening or removal from RO concentrate. A reactor clarifier was envisioned as the reactor in both cases. To emulate a reactor clarifier in the lab, a jar testing apparatus (Phipps and Baird, Model 7790-400) was used. A few tests were run with raw produced water from the field site, but most tests were carried out using a synthetic reverse osmosis concentrate. Synthetic RO concentrate allowed for easier control of constituents added to the water.

Prior to focusing the experiments on magnesium chloride, preliminary experiments were conducted using magnesium oxide and aluminum oxide with synthetic RO concentrate. As discussed in the background section of this report, both of these compounds had been explored previously for treatment of raw AG water, but large ( $\geq 30$ $\mathrm{g} / \mathrm{L}$ doses were required to achieve $90 \%$ removal (Worlen, 2008). These preliminary experiments were conducted to confirm previous results (Parks and Edwards 2007, Worlen 2008). 
The focus of the remainder of this research became magnesium chloride treatment in a series of jar tests conducted on synthetic RO concentrate. Based on these results, $\mathrm{pH}$, mixing time, silica, sodium chloride and sulfate concentration as well as temperature was optimized by varying adsorbent dose, initial and final $\mathrm{pH}$, temperature, and contact time. The early experiments explored boron removal under the conditions predicted for the RO concentrate from $\mathrm{Ag}$ water $\left(20^{\circ} \mathrm{C}, 150 \mathrm{mg} \mathrm{Si} / \mathrm{L}, 8 \mathrm{~g} \mathrm{NaCl} / \mathrm{L}, 30 \mathrm{mg} \mathrm{B} / \mathrm{L}\right)$. Subsequent experiments were designed to optimize conditions for maximum boron removal.

All experiments in this research followed the same basic protocol. Synthetic RO concentrate was prepared using solid reagents (Section 3.2) and mixing thoroughly. Six 1-L Pyrex ${ }^{\circledR}$ beakers each received a $500-\mathrm{mL}$ aliquot of water. Although evidence suggests boron leaches from borosilicate Pyrex containers over long periods of time, leaching was determined to be negligible for the time necessary to complete an experiment (Worlen, 2008). A sample was then taken from the synthetic RO concentrate to determine initial boron concentration. Each beaker was then placed in the stirring apparatus and rapid mixed at $200 \mathrm{rpm}$. While mixing, the designated quantity of adsorbent was added. After adsorbent addition, rapid mixing continued for 5 min followed by slow mixing at $20 \mathrm{rpm}$ for $10 \mathrm{~min}$ and a settling period of $20 \mathrm{~min}$. All samples were then filtered through a glass fiber filter (Fisher, 55 mm, 934-AH, Grade G6) using a vacuum pump (Barnant Co., Model 400-1901) prior to water quality measurements. It should be noted that all 
removal efficiencies are based on filtered samples and lower removal efficiencies may be observed with settling only. The setup used to conduct jar tests is depicted below in Figure 3-1. An individual jar after the final settling period is presented below in Figure 3-2.

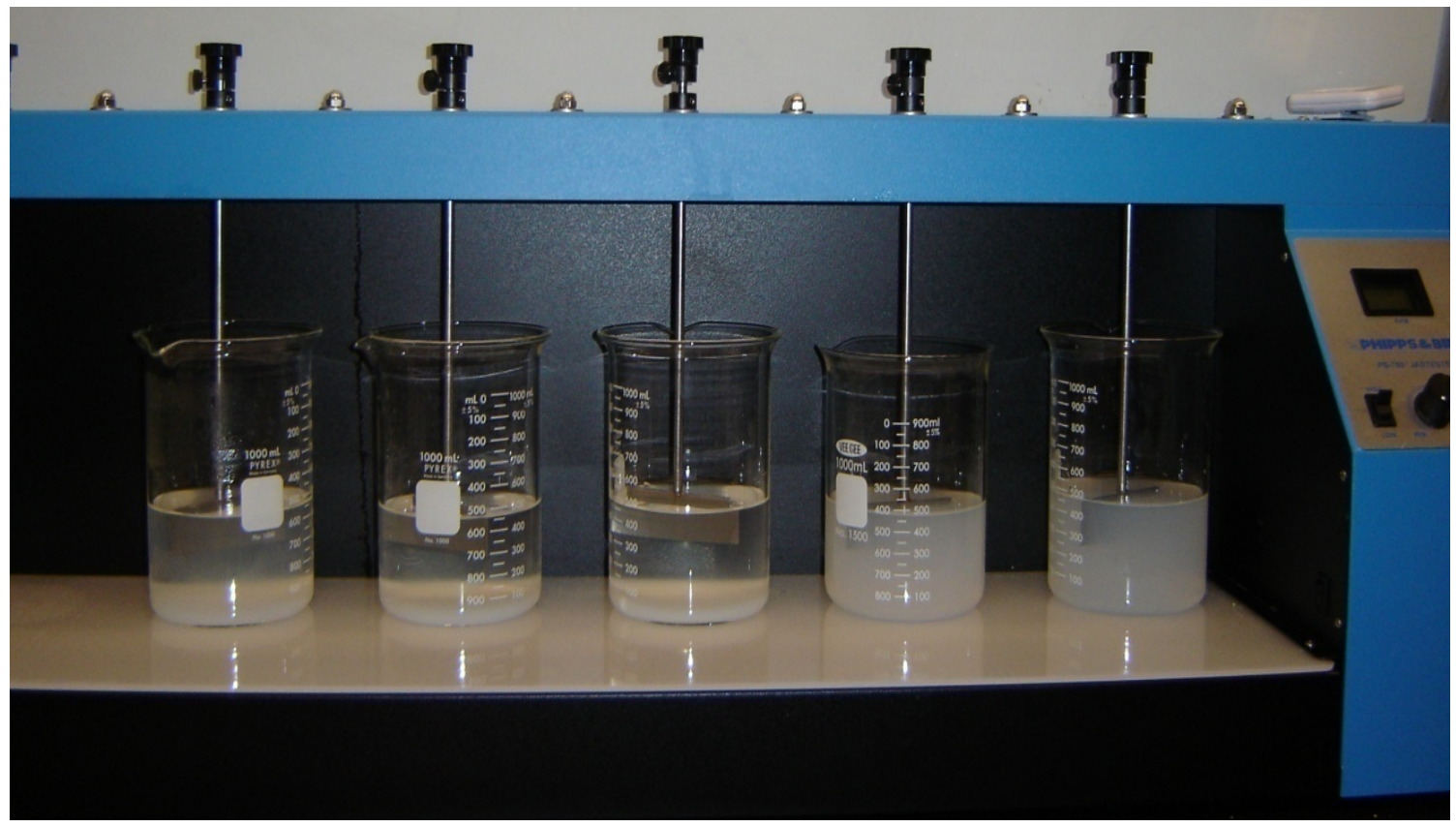

Figure 3-1 - Experimental setup used to conduct jar tests. Five of the six beaker stations are shown. 


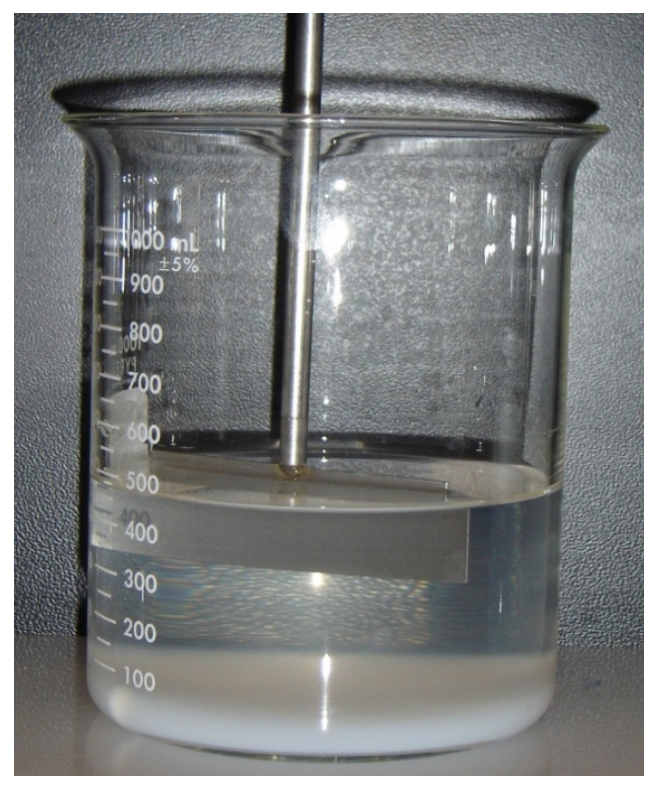

Figure 3-2 Jar after settling period with solids at bottom

The $\mathrm{pH}$ of each sample was measured with a specialty electrode designed for high $\mathrm{pH}$ values at high temperature and high salinity (Broadly James Corporation Process Probe sealed $\mathrm{Ag} / \mathrm{AgCl}$ reference half-cell $\mathrm{pH}$ probe with a glass body). The $\mathrm{pH}$ meter used was a Mettler Toledo SevenEasy S20 with temperature compensation (Mettler-Toledo ATC temperature probe). The $\mathrm{pH}$ standards used were certified $\mathrm{pH}$ 7, $\mathrm{pH} 10,11$ and $\mathrm{pH} 13$ (Fisher Scientific). Standardization was carried out at room temperature.

\subsection{Sample Water Preparation}

Efforts to set up a laboratory-scale reverse osmosis system to treat AG produced water and create RO reject were abandoned early in the project as the needed pretreatments were complex, and the resulting water quality would probably have varied between 
batches, introducing experimental error. Therefore all experiments with RO reject were conducted using a synthetic mixture to simulate the RO concentrate expected at the AG site.

Table 3-1 Constituents of synthetic RO concentrate

\begin{tabular}{cccc} 
Chemical Name & Chemical formula & Manufacturer & Concentration \\
\hline Boric Acid & $\mathrm{H}_{3} \mathrm{BO}_{3}$ & Fisher Scientific & $30 \mathrm{mg} / \mathrm{L}$ \\
Sodium Chloride & $\mathrm{NaCl}$ & Fisher Scientific & $8000 \mathrm{mg} / \mathrm{L}$ \\
Sodium Metasilicate & $\mathrm{Na}_{2} \mathrm{SiO}_{3} \bullet \mathrm{H}_{2} \mathrm{O} ;$ & Fisher Scientific & $150 \mathrm{mg} / \mathrm{L}$ \\
Magnesium Chloride & $\mathrm{MgCl}_{2} \bullet 6 \mathrm{H}_{2} \mathrm{O}$ & Across Chemicals & Various \\
\hline
\end{tabular}

Synthetic reverse osmosis concentrate was prepared by the addition of reagent grade chemicals listed in Table 3-1 to DI water (18mohms, Millpore Q-Gard2, ProGard2). The concentrations were selected to mimic expected site conditions based on AG produced water quality data Table $\mathbf{2 - 2}$ and projections on operation of the AG treatment facility provided by the engineer (Michael DiFilippo). All constituents were allowed to fully dissolve before beginning each experiment. Fresh synthetic RO concentrate was prepared at the beginning of each experiment. 


\subsection{Analytical Determination of Boron Concentration}

Boron concentrations were determined using Standard Method 4500 B - Carmine Method, as described in Standard Methods for the Examination of Water and Wastewater (Eaton, Clesceri, \& Greenberg, 1995). All reagent mixing was carried out in 20-mL HDPE scintillation vials (Fisher Scientific), which were washed between analyses and reused. Boron standards were made at concentrations of $0,2.5,5,7.5,10,15,20$, 25 and $30 \mathrm{mg} / \mathrm{L}$ with crystalline boric acid (Fisher Scientific, ACS certified). Photometric measurements were carried out using a Shimadzu PharmaSpec UV-1700 spectrophotometer. Quartz cuvettes (Elma) were used because of deterioration of plastic cuvettes by the carmine solution. Obtaining accurate photometric measurements required thorough mixing of the carmine reagent. In order to obtain consistent results, quart cuvettes were rinsed out with sample instead of DI water between measurements. When DI water was used to clean cuvettes, residual would interact with the strong acid in the carmine reagent causing the solution to heat up and gas to evolve, thus skewing the reading. To avoid this, a small quantity of sample was used to rinse the cuvette and then disposed of before an actual measurement was taken. This avoided the exothermic reaction between water and strong acid which skewed results previously. Each sample was analyzed by the carmine method in duplicate. Each carmine solution was then measured twice using the spectrophotometer at $585 \mathrm{~nm}$ and the average of these four measurements was reported as the final concentration. Using this

method, a calibration curve was obtained with typical linear regression $r^{2}$ values of 0.99 
(Figure 3-3). A calibration curve was created for each carmine analysis carried out. All analyses were carried out at about $20^{\circ} \mathrm{C}$. All boron samples were typically analyzed within a week of being produced. They were stored in the same scintillation vials used for carmine analysis.

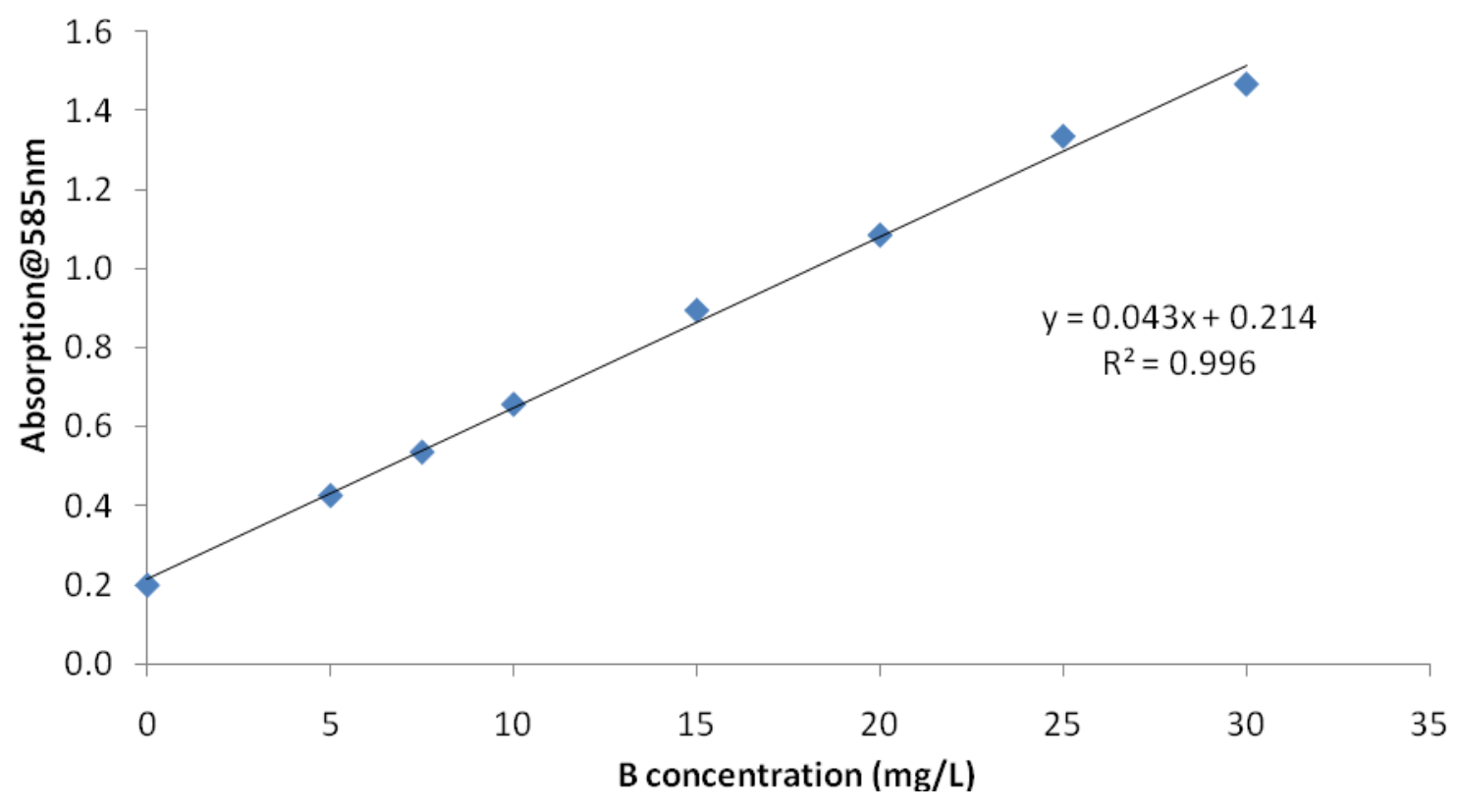

Figure 3-3 Example calibration curve used for the determination of boron concentration

For quality control, matrix spike samples were tested occasionally. The spiking standard contained $5000 \mathrm{mg} / \mathrm{L}$ boron prepared with boric acid (Fisher Scientific). The volume of spikes was $<10 \%$ of the sample volume to prevent dilution of the matrix. The same was done in synthetic RO concentrate. After final carmine analysis the difference in concentration between the two samples should be the concentration of spike added. In some cases it was not possible to test matrix effects by adding boron to synthetic RO concentrate because magnesium and silicon were already present and would result in 
boron removal. Instead, a blank check of DI water was carried out. In this case, boron was analyzed in synthetic RO concentrate to determine whether a false positive for boron was observed. Quality assurance requirements for determination of whether results were accurate or not were set as measured values being within $15 \%$ of calculated values. These values were met for almost all experiments.

\subsection{Initial Experiments of Boron removal by Magnesium and Aluminum}

\subsubsection{Sodium Chloride Effects on Boron Removal by Aluminum Oxide}

The purpose of the first experiment with aluminum oxide was to find the effects of increased sodium chloride on boron removal by aluminum oxide. Temperature and $\mathrm{pH}$ were not explored initially because their effects had previously been investigated (Konstantinou, Kasetta and Pashalidis 2006). The RO concentrate from AG water will be expected to have a high concentration of $\mathrm{NaCl}$. In this first experiment, silica was not added so synthetic RO concentrate was prepared to include approximately $20 \mathrm{mg} / \mathrm{L}$ boron by the addition of $0.5 \mathrm{M} \mathrm{B}$ stock solution. Individual $500-\mathrm{mL}$ jars were then prepared with 0, 1000, 5000, 10000, 25000, and $50000 \mathrm{mg} / \mathrm{L}$ of $\mathrm{NaCl}$ (Fisher Scientific). The $\mathrm{pH}$ of each jar was adjusted to 10.8 using $10-\mathrm{N} \mathrm{NaOH}$. A rapid mix at $200 \mathrm{rpm}$ was initiated and $20 \mathrm{~g} / \mathrm{L}$ of aluminum oxide $\left(\mathrm{Al}_{2} \mathrm{O}_{3}\right)$ was added. The standard mixing protocol (Section 3.1) was then followed. Final pH was measured, and samples were filtered for boron analysis. 


\subsubsection{Sodium Chloride Effect on Boron Removal by Magnesium Oxide}

The effects of increased sodium chloride concentration were also investigated for magnesium oxide removal of boron. A solution with $30 \mathrm{mg} / \mathrm{L}$ of boron was prepared by the addition of boric acid (Fisher Scientific, Certified ACS) to deionized water. The $\mathrm{pH}$ of this solution was increased to 11 using $10-\mathrm{N} \mathrm{NaOH}$. Six $500-\mathrm{mL}$ aliquots were then measured out into 1-L Pyrex ${ }^{\circledR}$ beakers. A rapid mix at $200 \mathrm{rpm}$ was started, and $5 \mathrm{~g} / \mathrm{L}$ of MgO was added to each beaker. The standard mixing protocol was then followed (Section 3.1). The final $\mathrm{pH}$ was then measured and samples were filtered for boron analysis.

\subsubsection{Magnesium Carbonate Experiments}

Magnesium carbonate was also investigated for its potential to remove boron. Synthetic RO concentrate was prepared as described in Section 3.2, with silica, sodium chloride and boron. The $\mathrm{pH}$ was adjusted to 11.0 using $10-\mathrm{N} \mathrm{NaOH}$. The synthetic RO concentrate was then divided into six $500-\mathrm{mL}$ aliquots in 1-L Pyrex ${ }^{\circledR}$ beakers. A rapid mix at $200 \mathrm{rpm}$ was then initiated, and $0.1,0.5,1.0,5.0,10.0$ and $20.0 \mathrm{~g} / \mathrm{L}$ of $\mathrm{MgCO}_{3}$ were added to the beakers. The standard mixing protocol (Section 3.1) was then followed. The final pH recorded, and sample was filtered for boron analysis. 


\subsubsection{Combined Usage of Magnesium Oxide and Aluminum Oxide}

Boron removal by a combination of magnesium oxide and aluminum oxide was also tested. In the literature magnesium is better at removing boron at higher boron concentrations, while aluminum works better at low boron concentrations (Konstantinou, Kasetta, \& Pashalidis, 2006). The idea behind using both magnesium oxide and aluminum oxide was that the high initial concentration of boron would be removed by magnesium oxide, and then lower residual concentrations would be further removed by aluminum oxide. Thus, together magnesium and aluminum might increase overall boron removal.

Synthetic RO concentrate was prepared with boron, silicon, and sodium chloride (Section 3.2). The $\mathrm{pH}$ was adjusted to approximately 11.0 using $10-\mathrm{N} \mathrm{NaOH}$. Magnesium oxide and aluminum oxide were then added in various combinations as shown below in Table 3-2. The standard mixing protocol was then followed, final $\mathrm{pH}$ was measured and sample was filtered for boron analysis.

Table 3-2 Amounts of magnesium oxide and aluminum oxide used

\begin{tabular}{cccccc} 
Jar & $\begin{array}{c}\mathbf{A l}_{2} \mathbf{O}_{3} \\
(\mathbf{g} / \mathbf{L})\end{array}$ & $\begin{array}{c}\mathbf{M g O} \\
(\mathbf{g} / \mathbf{L})\end{array}$ & $\begin{array}{c}\mathbf{A l} \\
(\mathbf{m m o l} / \mathbf{L})\end{array}$ & $\begin{array}{c}\mathbf{M g} \\
(\mathbf{m m o l} / \mathbf{L})\end{array}$ & $\begin{array}{c}\mathbf{M g} / \mathbf{A l} \\
\text { Molar } \\
\text { Ratio }\end{array}$ \\
\hline 1 & 0.1 & 0.1 & 1.96 & 2.48 & 1.265 \\
2 & 2.0 & 2.0 & 39.20 & 49.60 & 1.265 \\
3 & 5.0 & 5.0 & 98.10 & 124.00 & 1.265 \\
4 & 0.1 & 1.0 & 1.96 & 24.80 & 12.653 \\
5 & 1.0 & 0.1 & 19.60 & 2.48 & 0.127 \\
6 & 2.0 & 0.1 & 39.20 & 2.48 & 0.063 \\
\hline
\end{tabular}




\subsection{Magnesium Chloride Specific Testing Conditions}

Based on results found during the previously described experiments magnesium chloride was selected as the best candidate for boron removal but requires process optimization. The following experiments determined effects of a variety of conditions on boron removal to achieve optimal removal.

\subsubsection{Boron Removal with Magnesium Chloride under Simulated Site Conditions}

Standard synthetic RO concentrate was prepared with silica (150 mg Si/L), sodium chloride (8 $\mathrm{g} \mathrm{NaCl} / \mathrm{L})$, and boron (27.6 mg B/L). Initial pH was adjusted to 11 using 10-N

$\mathrm{NaOH}$. Varying doses of magnesium chloride hexahydrate $(0.1,0.5,1.0,5.0,10.0$ and $20.0 \mathrm{~g} / \mathrm{L}$ ) were added in the solid form and the above mentioned mixing regimen was followed (Section 3.1). After mixing a sample was removed and filtered for boron analysis. Initial and final pH values were also measured.

\subsubsection{Determination of Optimal Initial $\mathrm{pH}$ for Boron Removal by Magnesium Chloride}

Preliminary experiments were run to find the optimal initial $\mathrm{pH}$ for boron removal followed by more detailed $\mathrm{pH}$ experiments. Synthetic RO concentrate was prepared 
with boron, sodium chloride, and sodium meta-silicate as per Section 3.1. The $\mathrm{pH}$ was then adjusted to the desired value by the addition of $10-\mathrm{N} \mathrm{NaOH}$. Magnesium chloride was then added, and the previously described mixing and settling regimen followed (Section 3.2). Two runs were necessary in order to find the peak boron adsorption. A first run with an initial $\mathrm{pH}$ ranging from 11.5 - 12.5 was followed by a second experiment using $\mathrm{pH}$ from $12.0-13.0$. Both initial and final $\mathrm{pHs}$ were measured in this experiment.

\subsubsection{Determination of Optimal Equilibrium pH}

During the preliminary $\mathrm{pH}$ experiments described above, final $\mathrm{pH}$ was measured but not used as a factor during experimental protocol. In this experiment, an adsorption isotherm was determined, which is based on final equilibrium $\mathrm{pH}$. A fixed concentration magnesium chloride was used along with a range of boron concentrations to get different absorbent to adsorbate ratios.

The optimal equilibrium $\mathrm{pH}$ for boron removal by magnesium chloride was determined. Synthetic RO reject (Section 3.2) was prepared (3.5 L) with sodium chloride and sodium meta-silicate, and $1.0 \mathrm{~g} / \mathrm{L}$ magnesium chloride hexahydrate was added. The $\mathrm{pH}$ of the solution was then dropped to 3.5 , at which point all the constituents dissolved. With thorough mixing, $600.6 \mathrm{mg}$ of boric acid was added to the solution, for a boron 
concentration of $30 \mathrm{mg} \mathrm{B} / \mathrm{L}$. Aliquots of $500 \mathrm{~mL}$ were then placed in $1000-\mathrm{mL}$ beakers. The $\mathrm{pH}$ of each beaker was then adjusted to the desired value using $10-\mathrm{N} \mathrm{NaOH}$. The standard mixing regimen was followed (Section 3.1), and a final $\mathrm{pH}$ measurement was then taken for each beaker. Samples were filtered for boron determination.

\subsubsection{Determination of Mixing Time Effects on Boron Removal by Magnesium Chloride}

The effect of mixing time on boron removal was determined because mixing time is an important operational parameter to establish whether or not equilibrium is reached during an experiment. This is important for the construction of accurate adsorption isotherms which should be based on equilibrium conditions. To determine the effect of mixing time on boron removal, $500-\mathrm{mL}$ of standard synthetic RO reject was prepared with $1 \mathrm{~g} / \mathrm{L}$ of magnesium chloride hexahydrate. The $\mathrm{pH}$ of this solution was then dropped using concentrated hydrochloric acid until all compounds were dissolved $(\mathrm{pH} \approx 6.0)$. Then $3.0 \mathrm{~mL}$ of $5000 \mathrm{mg} \mathrm{B} / \mathrm{L}$ boric acid stock solution was

added to the solution to provide $30 \mathrm{mg} \mathrm{B} / \mathrm{L}$. Sodium hydroxide $(10 \mathrm{~N})$ was then used to adjust the $\mathrm{pH}$ to 11.07 . The solution was then mixed at $200 \mathrm{rpm}$ using the jar tester for a total of $1321 \mathrm{~min}$. During the mixing period, 10-mL samples were removed and filtered for boron measurement. 


\subsubsection{Preparation of Isotherms for Boron Adsorption by Magnesium Chloride}

To prepare adsorption isotherms several experiments were required. Using results from the determination of optimal equilibrium $\mathrm{pH}$, a $\mathrm{pH}$ of 11 was used. Initial boron concentrations from 5 to $50 \mathrm{mg} / \mathrm{L}$ were used for the first experiment. When isotherm saturation was not observed in the first experiment, a second experiment was conducted with higher boron to magnesium ratios. Both experiments used synthetic RO concentrate (Section 3.2).

The first isotherm experiment was conducted using synthetic RO reject and suspensions of $1.0 \mathrm{~g} / \mathrm{L}$ magnesium chloride. The $\mathrm{pH}$ of this solution was adjusted to 11.10 , and solids were observed in suspension. Six 500- $\mathrm{mL}$ aliquots of this suspension were placed in six beakers. A 5000-mg B/L boric acid stock solution was added to provide boron concentration of $5.0,10.0,15.0,20.0,30.0$, and $50 \mathrm{mg} \mathrm{B} / \mathrm{L}$. The $\mathrm{pH}$ of these suspensions was then adjusted to 11.01 using $10-\mathrm{N} \mathrm{NaOH}$ and concentrated hydrochloric acid. Each suspension was then carried through the standard mixing protocol. Final pH values were measured and samples were filtered for boron measurement.

The second experiment was carried out following the same protocol except the concentration of magnesium chloride in the synthetic RO concentrate was made to be

$0.5 \mathrm{~g} / \mathrm{L}$ and higher boron concentrations were tested. The concentrations of boron in 
each of the six beakers were 5, 10, 20, 30, 50 and $100 \mathrm{mg} \mathrm{B/L}$. With the lower magnesium chloride dose and higher maximum boron concentration, larger boron to magnesium ratios were attained. Again, final $\mathrm{pH}$ was measured and samples were filtered for final boron analysis.

Each of the models used for isotherms, namely Freundlich, Langmuir and Linear isotherms hold different implications for adsorption. The Langmuir isotherm assumes a single layer of adsorption sites, which become saturated beyond a certain concentration (Weber, Mcginley and Katz 1991). Neither Freundlich nor linear isotherms are based on the adsorption mechanism. The primary difference between them is that Freundlich isotherms follow a logarithmic pattern (Stumm and Morgan 1996).

\subsubsection{X-Ray Diffraction to Magnesium Solids}

X-Ray diffraction (XRD) was used to qualitatively identify crystalline compounds in magnesium oxide and magnesium chloride precipitates. This analysis was expected to provide insight on the differences between adsorption efficiencies found for these solids. 
To provide samples for the XRD analysis, magnesium chloride precipitates and magnesium oxide were prepared side by side. Two adsorbents with different starting $\mathrm{pH}$ were used to match testing conditions used in adsorption experiments (Table 3-3). The initial concentrations were silica (150 mg Si/L), sodium chloride (8 $\mathrm{g} \mathrm{NaCl} / \mathrm{L}$ ) and boron (30 mg B/L). Room temperature was maintained for each test.

Table 3-3 Conditions used for comparison of magnesium chloride and magnesium oxide

\begin{tabular}{|c|c|c|c|c|c|c|c|c|}
\hline \multirow{2}{*}{ Jar } & \multicolumn{2}{|c|}{$p H$} & \multirow{2}{*}{$\begin{array}{c}\text { Temp } \\
\left({ }^{\circ} \mathrm{C}\right)\end{array}$} & \multirow{2}{*}{$\begin{array}{c}\text { Silica } \\
(\mathrm{mg} / \mathrm{L})\end{array}$} & \multirow{2}{*}{$\begin{array}{l}\mathrm{NaCl} \\
(\mathrm{g} / \mathrm{L})\end{array}$} & \multirow{2}{*}{$\begin{array}{l}\mathrm{MgO} / \\
\mathrm{MgCl}_{2}\end{array}$} & \multicolumn{2}{|c|}{ Adsorbent } \\
\hline & Start & Finish & & & & & $(g / L)$ & $(\mathrm{mol} / \mathrm{L})$ \\
\hline 1 & 12.50 & 12.14 & 21.5 & 150 & 8.0 & $\mathrm{MgCl}_{2}$ & 5.0 & 0.025 \\
\hline 2 & 11.00 & 9.74 & 21.5 & 150 & 8.0 & $\mathrm{MgCl}_{2}$ & 5.0 & 0.025 \\
\hline 3 & 9.65 & 10.45 & 21.5 & 150 & 8.0 & MgO & 5.0 & 0.124 \\
\hline 4 & 11.00 & 11.13 & 21.5 & 150 & 8.0 & $\mathrm{MgO}$ & 5.0 & 0.124 \\
\hline 5 & 12.50 & 12.50 & 21.5 & 150 & 8.0 & $\mathrm{MgO}$ & 5.0 & 0.124 \\
\hline
\end{tabular}

After the standard mixing protocol was carried out, as much liquid as possible was decanted from the top of each beaker. The remaining sample was then filtered and the filtered solids were allowed to air dry in a desiccator overnight. The remaining dried solids were then placed in glass vials and transferred to a commercial laboratory (Cal Science Laboratories) for XRD analysis. Only samples from jars 1 and 5 were for analyzed because their pHs matched closely. 
The following procedure was provided by Cal Science Laboratories, which subcontracted out to Mineralogy, Inc., as the protocol for XRD analysis

Mineralogy, Inc. observes the following methodology with respect to the $x$-ray diffraction (XRD) analysis of inorganic precipitates, process control, scale and corrosion products. Following arrival at the laboratory, the samples are assigned a unique laboratory code reference, extracted with toluene solvent (where appropriate to remove hydrocarbon residues) and dried at 120 degrees Fahrenheit. A representative 1.5-gram sample split is subsequently milled (to an approximate mean particle diameter of 30-40 micrometers) utilizing a high $\mathrm{Cr}$ steel milling apparatus and packed into an aluminum XRD sample holder. The bulk powder specimen is then analyzed with a Philips XRG-3100 automated $x$-ray diffraction unit (scan range 4-70 degrees 2-Theta, 0.02 degrees/second, 35kV, $30 \mathrm{~mA}$ ). The procedure outlined above provides the raw digital data (scan intensity vs. degrees 2-Theta) used to graph the x-ray diffractogram for the solid. The resulting spectra are subsequently analyzed with the aid of Philips search/match ("TADD") software and the JCPDS x-ray diffraction database. 


\subsubsection{Comparison of Adsorption vs. Co-Precipitation Mechanisms of Boron Removal}

To compare co-precipitation to adsorption, conditions were created where solids already existed in solution when boron was introduced and where solids were created after the introduction of boron. To do this, $\mathrm{pH}$ was adjusted to dissolve and then reform solids. Synthetic RO concentrate was prepared for this experiment with $1.0 \mathrm{~g} / \mathrm{L}$ of $\mathrm{MgCl}_{2} \circ 6 \mathrm{H}_{2} \mathrm{O}, 150 \mathrm{mg} \mathrm{Si} / \mathrm{L}$ and $8 \mathrm{~g} / \mathrm{L} \mathrm{NaCl}$. Solutions were then prepared in $500-\mathrm{mL}$ volumetric flasks to maintain a total volume of $500 \mathrm{~mL}$. Each boron concentration was prepared by adding the volume of $5000 \mathrm{mg} / \mathrm{L}$ stock solution shown in to maintain a total volume of $500 \mathrm{~mL}$. . Under these conditions, the magnesium chloride remained in solid form. For the first three jars, the $\mathrm{pH}$ was then adjusted to a value of approximately 11 using 10- $\mathrm{N} \mathrm{NaOH}$. For the fourth and fifth jars, the $\mathrm{pH}$ of the synthetic RO was adjusted down to 3.1 using concentrated hydrochloric acid. Stock boron solution was then added to the final two reaction vessels. The $\mathrm{pH}$ was then adjusted back up to approximately 11 using 10-N NaOH. Thus, adsorption and co-precipitation was measured at the same $\mathrm{pH}$ and under the same conditions for all tests. The only difference (other than the chloride ion concentration from the $\mathrm{HCl}$ ) was that boron adsorbed to pre-formed solids for Jars 1-3, but boron adsorbed to solids as they were precipitating for Jars 4 and 5 . Presumably, the solids were mainly magnesium hydroxide based on the XDR tests described above. After final pH adjustment, each beaker was placed in a $500 \mathrm{~mL}$ beaker and carried through the standard mixing regimen. A sample was then filtered for boron analysis. 


\section{Table 3-4 Volume of stock solution used for separate reaction conditions}

\begin{tabular}{ccc} 
Jar \# & Vol. $\mathbf{5 0 0 0} \mathbf{m g}$ B / L Stock $(\mathbf{m L})$ & $\begin{array}{c}\text { Boron Conc. } \\
(\mathbf{m g} / \mathbf{L})\end{array}$ \\
\hline 1 & 1.0 & 10 \\
2 & 2.0 & 20 \\
3 & 3.0 & 30 \\
4 & 1.0 & 10 \\
5 & 2.0 & 20 \\
\hline
\end{tabular}

To determine the amount of sludge produced during this experiment, supernatant was decanted off of each reaction vessel following the settling period. The remaining liquid and solids were then placed in $250-\mathrm{mL}$ Nalgene ${ }^{\circledR}$ polycarbonate centrifuge tubes. The samples were then centrifuged at $5000 \mathrm{rpm}$ for $25 \mathrm{~min}$ in a Fisher Thermo Electron Corp. IEC Multi RF refrigerated centrifuge held at $20^{\circ} \mathrm{C}$. The supernatant was then decanted, and the pellet placed in a crucible. The crucible was dried overnight at $105^{\circ} \mathrm{C}$, and then weighed after cooling.

\subsubsection{Measurement of Effects of Sodium Chloride on Boron Removal by Magnesium Chloride}

The effects of sodium chloride were tested to determine if boron removal is affected by the high sodium chloride concentration in reverse osmosis concentrate. Synthetic RO concentrate was prepared with $1.0 \mathrm{~g} / \mathrm{L} \mathrm{MgCl}{ }^{\circ} \circ \mathrm{H}_{2} \mathrm{O}$, and $150 \mathrm{mg} \mathrm{Si} / \mathrm{L}$, as above. The $\mathrm{pH}$ of this solution was then raised to a value of approximately 11 using $10-\mathrm{N} \mathrm{NaOH}$. Sodium chloride was added to each $500-\mathrm{mL}$ suspension in volumetric flasks, according 
to Table 3-5. To each flask, $3.0 \mathrm{~mL}$ of $5000 \mathrm{mg} \mathrm{B} / \mathrm{L}$ stock solution was added to provide an initial boron concentration of $30 \mathrm{mg} / \mathrm{L}$.

\section{Table 3-5 Weights of $\mathrm{NaCl}$ added to determine effects of $\mathrm{NaCl}$}

\begin{tabular}{cc} 
Jar \# & $\mathrm{NaCl}(g)$ \\
\hline 1 & 0 \\
2 & 0.5038 \\
3 & 4.0016 \\
4 & 10.0026 \\
5 & 17.5027 \\
6 & 25.0057 \\
\hline
\end{tabular}

Each flask was then brought up to volume using synthetic RO concentrate, and the $\mathrm{pH}$ was adjusted to 11 using $10-\mathrm{N} \mathrm{NaOH}$. Each suspension was then carried through the standard mixing regimen, and a sample was filtered for boron analysis. The sludge produced by each reaction condition was then determined as described above (Section 3.5.2).

\subsubsection{Effects of Sulfate on Boron Removal}

Sulfate was not added to the synthetic RO reject for any of the experiments above. However, sulfate has been shown to reduce brucite dissolution (Pokrovsky, Schott, \& Castillo, 2005). To determine the effects of sulfate on boron removal, a standard experiment was carried out over a range of sulfate concentrations. 
Synthetic RO concentrate was again prepared with $1.0 \mathrm{~g} / \mathrm{L} \mathrm{MgCl}_{2} \circ 6 \mathrm{H}_{2} \mathrm{O}, 150 \mathrm{mg} \mathrm{Si} / \mathrm{L}$ and $8 \mathrm{~g} / \mathrm{L} \mathrm{NaCl}$. A 50,001 $\mathrm{mg} \mathrm{SO}_{4}{ }^{2-} / \mathrm{L}$ stock solution was prepared by the addition of 36.9806 $\mathrm{g}$ of anhydrous sodium sulfate to $500 \mathrm{~mL}$ of DI water. Again, $500-\mathrm{mL}$ volumetric flasks were used to prepare individual suspensions with different sulfate concentrations. First, $3.0 \mathrm{~mL}$ of $5000 \mathrm{mg} \mathrm{B} / \mathrm{L}$ stock solution was added to each flask to provide a boron concentration of $30 \mathrm{mg} / \mathrm{L}$ with the volumes of sulfate stock shown in Table 3-6 added.

Table 3-6 Sulfate concentrations used to test effects of sulfate on boron removal

\begin{tabular}{ccc} 
Jar \# & $\begin{array}{c}50,000 ~ \mathrm{mgSO}_{4}{ }^{2-} / \mathrm{L} \\
(\mathrm{mL})\end{array}$ & $\begin{array}{c}\mathrm{SO}_{4}{ }^{2-} \\
(\mathrm{mg} / \mathrm{L})\end{array}$ \\
\hline 1 & 0.0 & 0 \\
2 & 0.5 & 50 \\
3 & 1.0 & 100 \\
4 & 2.0 & 200 \\
5 & 5.0 & 500 \\
6 & 10.0 & 1000 \\
\hline
\end{tabular}

After the addition of both stock solutions, the volume was brought up to $500-\mathrm{mL}$ using synthetic RO concentrate. The contents of each flask were then moved to 1-L beakers, and the $\mathrm{pH}$ was adjusted up to approximately 11.0 using $10-\mathrm{N} \mathrm{NaOH}$. The standard mixing regimen was then followed and samples were filtered for boron analysis. Also, the sludge production was measured for this experiment as in previous experiments. 


\subsubsection{Role of Silica in Boron Removal by Magnesium Chloride}

An experiment was conducted to determine the relationship between silica and boron removal in the synthetic RO reject. Synthetic RO reject was prepared with $1.0 \mathrm{~g} / \mathrm{L}$ $\mathrm{MgCl}_{2}{ }^{\circ} 6 \mathrm{H}_{2} \mathrm{O}, 8 \mathrm{~g} / \mathrm{L} \mathrm{NaCl}$, and $30 \mathrm{mg} \mathrm{B} / \mathrm{L}$. Solutions were prepared in $500-\mathrm{mL}$ volumetric flasks. Sodium metasilicate was added to each of six flasks as described in Table 3-7. The volume was then brought up to $500 \mathrm{~mL}$ using synthetic RO concentrate, and the suspensions were transferred to $1-\mathrm{L}$ Pyrex ${ }^{\circledR}$ beakers where the $\mathrm{pH}$ was adjusted to 11 using $10-\mathrm{N} \mathrm{NaOH}$. For Jars 5 and 6 , the $\mathrm{pH}$ was above 11 after the addition of silicon and was adjusted down to a $\mathrm{pH}$ of 11 using concentrated $\mathrm{HCl}$. The standard mixing regimen was then followed, and samples were filtered for boron analysis. Sludge production was also measured as in previous experiments.

Table 3-7 Sodium metasilicate weights used to determine role of silicon

\begin{tabular}{ccc} 
Jar \# & $\begin{array}{c}\mathrm{Na}_{2} \mathrm{SiO}_{3} \circ 9 \mathrm{H}_{2} \mathrm{O} \\
(\mathrm{mg})\end{array}$ & $\begin{array}{c}\mathrm{Si} \\
(\mathrm{mg} / \mathrm{L})\end{array}$ \\
\hline 1 & 0 & 0 \\
2 & 69.4 & 13.7 \\
3 & 142.4 & 28.1 \\
4 & 359.6 & 71.1 \\
5 & 713.9 & 141 \\
6 & 1421.5 & 281 \\
\hline
\end{tabular}




\subsubsection{Temperature Effects on Boron Removal by Magnesium Chloride}

Determination of temperature effects on boron removal by magnesium chloride is important because the AG produced water comes out of the wells at approximately $80^{\circ} \mathrm{C}$. The expected temperature of the RO reject is approximately $20^{\circ} \mathrm{C}$, The effect of temperature on boron removal by magnesium chloride was investigated by measuring boron removal at six temperatures, ranging from $29.6-68.3^{\circ} \mathrm{C}$ (Table 3-8). Jacketed beakers were used with a re-circulating water bath (VWR Scientific Products Model \# 1162) to provide temperature control. Synthetic RO concentrate was prepared with 150 $\mathrm{mg} \mathrm{Si} / \mathrm{L}, 8 \mathrm{~g} \mathrm{NaCl} / \mathrm{L}$ and $1.0 \mathrm{~g} \mathrm{MgCl}_{2}{ }^{\circ} 6 \mathrm{H}_{2} \mathrm{O} / \mathrm{L}$. The water bath was then brought to temperature with the $500 \mathrm{~mL}$ of synthetic RO concentrate. Once the concentrate reached the appropriate temperature, $3.0 \mathrm{~mL}$ of $5000 \mathrm{mg} \mathrm{B} / \mathrm{L}$ concentrate was added corresponding to $30 \mathrm{mg} \mathrm{B} \mathrm{/} \mathrm{L.} \mathrm{The} \mathrm{pH} \mathrm{was} \mathrm{then} \mathrm{adjusted} \mathrm{to} \mathrm{approximately} 11.0$ using 10$\mathrm{N} \mathrm{NaOH}$. Once the $\mathrm{pH}$ was adjusted, the standard mixing protocol was followed, while maintaining the temperatures. The $\mathrm{pH}$ and temperature were monitored throughout the mixing period. A sample was removed from each beaker and filtered at the end for carmine analysis. 
Table 3-8 - Temperatures used to determine effects on boron removal

\begin{tabular}{cc} 
Jar \# & $\begin{array}{c}\text { Temp } \\
\left({ }^{\circ} \mathrm{C}\right)\end{array}$ \\
\hline 1 & 29.6 \\
2 & 41.4 \\
3 & 50.6 \\
4 & 59.9 \\
5 & 68.3 \\
\hline
\end{tabular}




\subsection{Results and Discussion}

\subsection{Comparison of Boron Removal by Magnesium and Aluminum oxide as well as Magnesium Carbonate}

This section describes the results of separate boron adsorption experiments using aluminum oxide $\left(\mathrm{Al}_{2} \mathrm{O}_{3}\right)$, and magnesium oxide $(\mathrm{MgO})$ and magnesium carbonate. The focus of subsequent experiments was on magnesium chloride after it was determined to be the best candidate for boron removal.

\subsubsection{Sodium Chloride Effect on Aluminum Oxide for Boron Removal}

About $48 \%$ boron removal efficiency was observed with an alumina dose of $20 \mathrm{~g} / \mathrm{L}$ (Table 4-1). These results were observed at ambient temperatures $\left(21^{\circ} \mathrm{C}\right)$. The synthetic RO reject contained $30 \mathrm{mg} / \mathrm{L}$ boron initially, but no added silica. Boron removal was unaffected by greater sodium chloride concentrations. The potential exists for aluminum oxide to be used on RO concentrate. However, greater removal with lower aluminum oxide doses would be necessary for practical operation. 
Table 4-1 Conditions observed during increased $\mathrm{NaCl}$ concentrations in solution

\begin{tabular}{cccccccccc} 
Jar & $\begin{array}{c}\mathrm{NaCl} \\
(\mathrm{mg} / \mathrm{L})\end{array}$ & $p \mathrm{H}_{0}$ & $p \mathrm{H}_{f}$ & $\begin{array}{c}\mathrm{Al}_{2} \mathrm{O}_{3} \\
(\mathrm{~g} / \mathrm{L})\end{array}$ & $\begin{array}{c}\mathrm{Al}_{2} \mathrm{O}_{3} \\
(\mathrm{~mol} / \mathrm{L})\end{array}$ & $B_{0}$ & $B_{f}$ & $B_{\text {removal }}$ & Roron $(\mathrm{mmol} / \mathrm{L})$ \\
\hline 1 & 0 & 10.8 & 7.35 & 20 & 0.196 & 1.30 & 0.673 & 0.629 & 48.3 \\
2 & 1000 & 10.8 & 7.71 & 20 & 0.196 & 1.30 & 0.668 & 0.634 & 48.7 \\
3 & 5000 & 10.8 & 7.62 & 20 & 0.196 & 1.30 & 0.725 & 0.577 & 44.3 \\
4 & 10000 & 10.8 & 7.56 & 20 & 0.196 & 1.30 & 0.696 & 0.607 & 46.6 \\
5 & 25000 & 10.8 & 7.64 & 20 & 0.196 & 1.30 & 0.721 & 0.582 & 44.7 \\
6 & 50000 & 10.8 & 7.67 & 20 & 0.196 & 1.30 & 0.749 & 0.554 & 42.5 \\
\hline
\end{tabular}

\subsubsection{Boron Removal by Magnesium Oxide}

Boron removal by magnesium oxide was investigated earlier in the project (Worlen 2008). However, these early studies used the boron concentration expected in raw produced water, not $\mathrm{RO}$ reject. Thus, in the present study, boron removal by MgO was measured using the higher boron concentrations expected for RO reject. The effect of sodium chloride on boron removal was also measured. Boron removal with $5 \mathrm{~g} / \mathrm{L} \mathrm{MgO}$ was only 1 to $4 \%$ (Table 4-2). On a molar basis, the amount of $\mathrm{MgO}$ used in this experiment was only about $60 \%$ of the aluminum oxide dose, and resulted in at least an order of magnitude less boron removal. Some variation in final boron concentration was observed, but $\mathrm{NaCl}$ showed little consistent effect on overall removal (Table 4-2). Similar to aluminum oxide, magnesium oxide would be impractical due to the high concentrations of $\mathrm{MgO}$ required. Greater boron removal may be possible with $\mathrm{MgO}$ if $\mathrm{pH}$ and other conditions are optimized. The extent of the benefits is not known, and necessitates further research. 
Table 4-2 Boron removal by magnesium oxide

\begin{tabular}{|c|c|c|c|c|c|c|c|c|c|}
\hline \multirow{2}{*}{ Jar } & \multirow{2}{*}{$\begin{array}{c}\mathrm{NaCl} \\
(\mathrm{mg} / \mathrm{L})\end{array}$} & \multirow{2}{*}{$\begin{array}{l}M g O \\
(g / L)\end{array}$} & \multirow{2}{*}{$\begin{array}{c}\mathrm{MgO} \\
(\mathrm{mol} / \mathrm{L})\end{array}$} & \multirow{2}{*}{$p H_{f}$} & \multirow{2}{*}{$p H_{o}$} & \multicolumn{3}{|c|}{ Boron $(\mathrm{mmol} / \mathrm{L})$} & \multirow{2}{*}{$\begin{array}{c}\% \text { B } \\
\text { Remova }\end{array}$} \\
\hline & & & & & & Initial & Final & Removal & \\
\hline 1 & 0 & 5.0 & 0.12 & 11.00 & 11.06 & 0.0036 & 0.00294 & $1.21 \mathrm{E}-04$ & 4.0 \\
\hline 2 & 1000 & 5.0 & 0.12 & 11.00 & 11.03 & 0.0036 & 0.00301 & 4.90E-05 & 1.6 \\
\hline 3 & 5000 & 5.0 & 0.12 & 11.00 & 11.04 & 0.0036 & 0.00297 & 8.97E-05 & 2.9 \\
\hline 4 & 10000 & 5.0 & 0.12 & 11.00 & 10.99 & 0.0036 & 0.00293 & $1.25 \mathrm{E}-04$ & 4.1 \\
\hline 5 & 25000 & 5.0 & 0.12 & 11.00 & 10.97 & 0.0036 & 0.00293 & $1.31 \mathrm{E}-04$ & 4.3 \\
\hline 6 & 50000 & 5.0 & 0.12 & 11.00 & 10.98 & 0.0036 & 0.00302 & 4.07E-05 & 1.3 \\
\hline
\end{tabular}

\subsubsection{Boron Removal by Magnesium Carbonate}

For a magnesium carbonate dose matched on a molar basis to the magnesium oxide dose used above $(0.019 \mathrm{~mol} / \mathrm{L})$, boron removal was similar for magnesium carbonate and magnesium oxide (Table 4-2 and Table 4-3). Boron removal by magnesium carbonate increased with greater concentrations of magnesium carbonate. The maximum removal achieved during this experiment was $<10 \%$ even when large concentrations $(20 \mathrm{~g} / \mathrm{L})$ of magnesium carbonate were used. Since $\mathrm{pH}$ is expected to play a significant role in boron removal, determining the $\mathrm{pH}$ for optimal boron removal should be explored further. Further research would also be required to determine temperature effects. 


\section{Table 4-3 Boron Removal by Magnesium Carbonate}

\begin{tabular}{|c|c|c|c|c|c|c|c|c|}
\hline \multirow[b]{2}{*}{ Jar } & \multirow[b]{2}{*}{$p H_{f}$} & \multirow[b]{2}{*}{$p H_{o}$} & \multirow{2}{*}{$\begin{array}{c}\mathrm{MgCO}_{3} \\
(\mathrm{~g} / \mathrm{L})\end{array}$} & \multirow{2}{*}{$\begin{array}{c}\mathrm{MgCO}_{3} \\
(\mathrm{mmol} / \mathrm{L})\end{array}$} & \multicolumn{3}{|c|}{ Boron $(\mathrm{mmol} / \mathrm{L})$} & \multirow{2}{*}{$\begin{array}{c}\% \text { B } \\
\text { Removal }\end{array}$} \\
\hline & & & & & $B_{o}$ & $B_{f}$ & Removal & \\
\hline 1 & 11.00 & 10.89 & 0.1 & 1.19 & 2.72 & 2.66 & 0.0594 & 2.2 \\
\hline 2 & 11.00 & 10.77 & 1.0 & 11.9 & 2.72 & 2.64 & 0.0797 & 2.9 \\
\hline 3 & 11.00 & 10.72 & 2.0 & 23.7 & 2.72 & 2.61 & 0.1060 & 3.9 \\
\hline 4 & 11.00 & 10.59 & 5.0 & 59.3 & 2.72 & 2.58 & 0.1330 & 4.9 \\
\hline 5 & 11.00 & 10.48 & 10.0 & 119 & 2.72 & 2.55 & 0.1610 & 5.9 \\
\hline 6 & 11.00 & 10.34 & 20.0 & 237 & 2.72 & 2.49 & 0.0230 & 8.5 \\
\hline
\end{tabular}

\subsubsection{Combined Use of Aluminum Oxide and Magnesium Oxide}

The effects of combining both aluminum oxide and magnesium oxide in various ratios on boron removal were tested with no significant advantage observed (Table 4-4). Combinations were used on synthetic RO reject with silica (150 mg Si/L), sodium chloride ( $8 \mathrm{~g} \mathrm{NaCl} / \mathrm{L})$, and boron $(30 \mathrm{mg} / \mathrm{L})$. Boron removal was less than $4 \%$ for all magnesium to aluminum ratios ranging from 1.265 to 0.063 (Table 4-4).

Table 4-4 Concentrations of magnesium oxide and aluminum oxide used to determine combination effects on boron removal

\begin{tabular}{|c|c|c|c|c|c|c|c|c|c|}
\hline \multirow{2}{*}{ Jar } & \multirow{2}{*}{$\begin{array}{c}\text { Alumina } \\
(\mathrm{g} / \mathrm{L})\end{array}$} & \multirow{2}{*}{$\begin{array}{l}\mathrm{MgO} \\
(g / L)\end{array}$} & \multirow{2}{*}{$\begin{array}{c}A l \\
(\mathrm{mmol} / \mathrm{L})\end{array}$} & \multirow{2}{*}{$\begin{array}{c}M g \\
(\mathrm{mmol} / \mathrm{L})\end{array}$} & \multirow{2}{*}{$\begin{array}{c}\mathrm{Mg} / \mathrm{Al} \\
\text { Ratio } \\
\text { (mol/mol) }\end{array}$} & \multicolumn{3}{|c|}{ Boron $(\mathrm{mmol} / \mathrm{L})$} & \multirow{2}{*}{$\begin{array}{c}\% \\
\text { Remova }\end{array}$} \\
\hline & & & & & & Initial & Final & Removal & \\
\hline 1 & 0.1 & 0.1 & 1.96 & 2.48 & 1.265 & 2.58 & 2.56 & 0.016 & 0.6 \\
\hline 2 & 2.0 & 2.0 & 39.2 & 49.6 & 1.265 & 2.58 & 2.52 & 0.059 & 2.3 \\
\hline 3 & 5.0 & 5.0 & 98.1 & 124.0 & 1.265 & 2.58 & 2.47 & 0.106 & 4.1 \\
\hline 4 & 0.1 & 1.0 & 1.96 & 24.8 & 12.653 & 2.58 & 2.53 & 0.051 & 2.0 \\
\hline 5 & 1.0 & 0.1 & 19.6 & 2.48 & 0.127 & 2.58 & 2.53 & 0.0 .44 & 1.7 \\
\hline 6 & 2.0 & 0.1 & 39.2 & 2.48 & 0.063 & 2.58 & 2.52 & 0.055 & 2.1 \\
\hline
\end{tabular}




\subsection{Boron Removal from Synthetic RO Concentrate Using Magnesium Chloride}

Magnesium chloride was added to synthetic RO reject water to first determine a baseline of boron removal without any process optimization. This experiment was carried out at room temperature $\left(21^{\circ} \mathrm{C}\right)$ and an initial $\mathrm{pH}$ of 11.0 . The synthetic $\mathrm{RO}$ reject contained $150 \mathrm{mg} / \mathrm{L}$ of silica and $8 \mathrm{~g} / \mathrm{L}$ of sodium chloride. Boron removal increased with increasing doses of magnesium chloride (Table 4-5). On a molar basis, much greater boron removal was observed with magnesium chloride than with either $\mathrm{MgO}$ or $\mathrm{MgCO}_{3}$. For example, $\mathrm{MgO}$ removed about $4 \%$ boron with a dose of $0.12 \mathrm{~mol} \mathrm{Mg} / \mathrm{L}$ (Table 4-2), and magnesium carbonate removed just $5.9 \%$ boron with $0.12 \mathrm{~mol} \mathrm{Mg} / \mathrm{L}$ (Table 4-3). Magnesium chloride removed $23 \%$ with only $0.098 \mathrm{~mol} \mathrm{Mg} / \mathrm{L}$ (Table 4-5). Thus magnesium chloride was the most promising method for removing boron to date, but the low removal rates and high magnesium doses required still would make this method impractical. Therefore, the next strategy was to increase boron removal by optimizing operating conditions.

One important condition to optimize is $\mathrm{pH}$. Since magnesium chloride causes hydroxide precipitates, it lowers the $\mathrm{pH}$, and thus $\mathrm{pH}$ was depressed more with increasing doses of magnesium chloride (Table 4-4). 
Further indicators of potential boron removal are suggested in Figure 4-1 which shows boron removal by magnesium chloride is a function of magnesium dose. Boron removal increased as the amount of magnesium chloride added increased (Figure 4-1), as expected. However, considering how much additional magnesium chloride was added between points, the resulting boron removal was not proportional. If all added magnesium chloride was removing the same amount of boron (as $\mathrm{mg} \mathrm{B}$ per $\mathrm{mmol} \mathrm{Mg}$ ), then one would expect a straight line in Figure 4-1. However, the trend starts off very steep for low magnesium doses and then saturates with higher magnesium doses. This effect can be partially explained by the reduced driving force for adsorption low boron concentrations (high magnesium doses). A second factor is that $\mathrm{pH}$ decreased with magnesium chloride addition (Figure 4-1and Table 4-5). This reduction in $\mathrm{pH}$ could be the reason for boron removal as well. Further experiments were thus conducted to isolate the reason for different boron removals and to make broader conclusions about conditions affecting boron removal.

Table 4-5 Boron removal from synthetic RO reject under approximate site conditions using magnesium chloride

\begin{tabular}{|c|c|c|c|c|c|c|c|c|c|c|}
\hline \multirow[b]{2}{*}{ Jar } & \multirow[b]{2}{*}{$\mathrm{pH}$} & \multirow{2}{*}{$\begin{array}{c}\mathrm{MgCl}_{2} \\
\bullet 6 \mathrm{H}_{2} \mathrm{O} \\
(\mathrm{g} / \mathrm{L})\end{array}$} & \multirow{2}{*}{$\begin{array}{c}\mathrm{MgCl}_{2} \\
\bullet 6 \mathrm{H}_{2} \mathrm{O} \\
(\mathrm{mmol} / \mathrm{L})\end{array}$} & \multicolumn{3}{|c|}{ Boron (mg/L) } & \multicolumn{3}{|c|}{ Boron (mmol/L) } & \multirow{2}{*}{$\begin{array}{c}\% \text { B } \\
\text { Removed }\end{array}$} \\
\hline & & & & $B_{0}$ & $B_{f}$ & B $_{\text {removed }}$ & $\mathbf{B}_{\mathrm{o}}$ & $B_{f}$ & B $_{\text {removed }}$ & \\
\hline 1 & 10.92 & 0.1 & 0.49 & 27.6 & 27.0 & 0.6 & 2.6 & 2.5 & 0.06 & 2 \\
\hline 2 & 10.30 & 0.5 & 2.5 & 27.6 & 25.7 & 1.9 & 2.6 & 2.4 & 0.18 & 7 \\
\hline 3 & 9.95 & 1.0 & 4.9 & 27.6 & 26.4 & 1.2 & 2.6 & 2.4 & 0.11 & 4 \\
\hline 4 & 9.56 & 5.0 & 25 & 27.6 & 25.0 & 2.6 & 2.6 & 2.3 & 0.24 & 10 \\
\hline 5 & 9.37 & 10.0 & 49 & 27.6 & 22.6 & 5.0 & 2.6 & 2.1 & 0.46 & 18 \\
\hline 6 & 9.23 & 20.0 & 98 & 27.6 & 21.2 & 6.4 & 2.6 & 2.0 & 0.59 & 23 \\
\hline
\end{tabular}




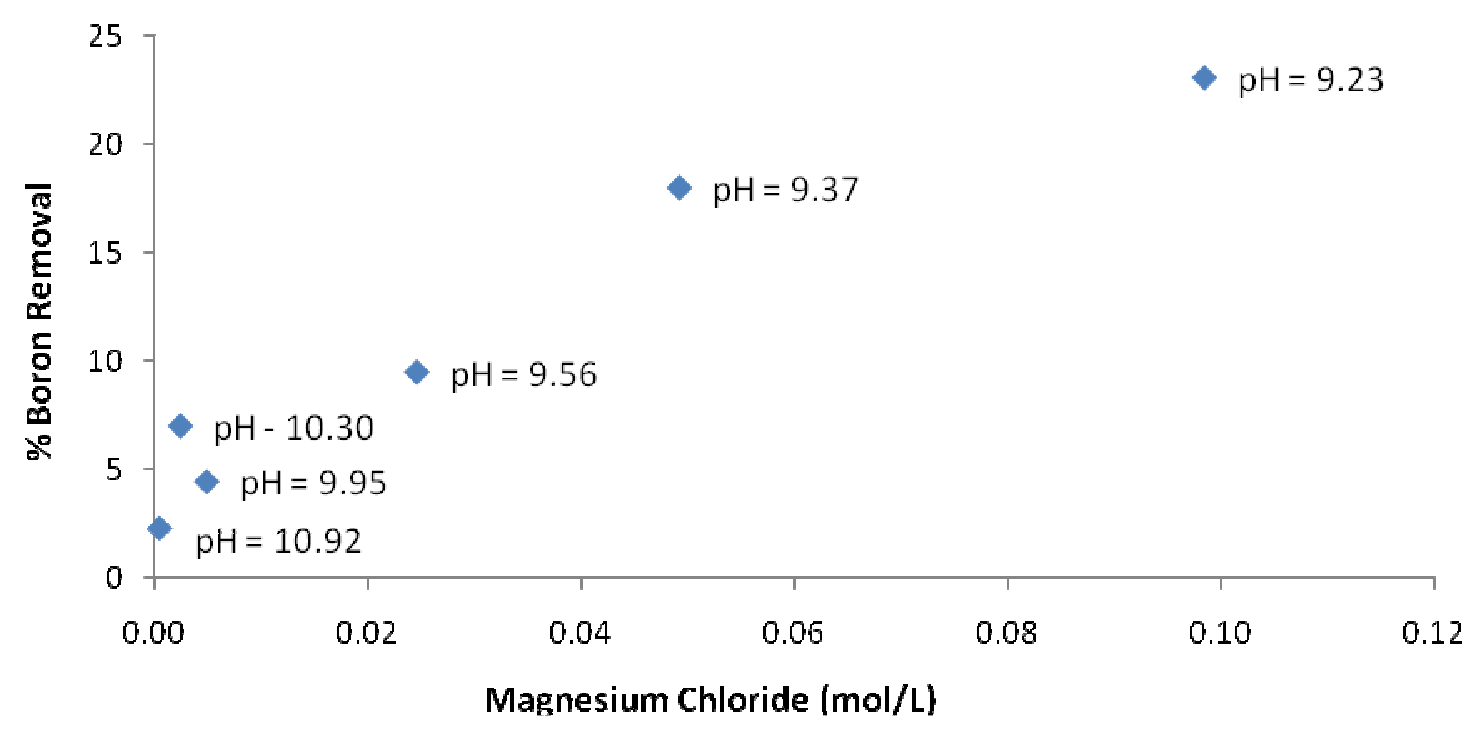

Figure 4-1 Percent Boron removal for increasing magnesium chloride doses $(8 \mathrm{~g} / \mathrm{L} \mathrm{NaCl}, 150 \mathrm{mg} / \mathrm{L} \mathrm{Si}$ )

\subsection{Effects of pH on Boron Removal Using Magnesium Chloride}

The effects of $\mathrm{pH}$ were broken up into experiments concerning initial and equilibrium $\mathrm{pH}$ values. In the end, equilibrium $\mathrm{pH}$ proved to be the more practical parameter for process optimization.

\subsubsection{Effect of initial pH on boron removal using magnesium chloride}

The goal of this series of experiments was to determine the optimal initial $\mathrm{pH}$ for boron removal. As described above, the addition of magnesium chloride lowers the $\mathrm{pH}$, so the final equilibrium adsorption occurs at a lower $\mathrm{pH}$. However, optimal initial $\mathrm{pH}$ should be established to provide for the most boron removal for a given magnesium dose. One 
problem with this approach is it is difficult to separate $\mathrm{pH}$ effects and dose effects. A subsequent experiment was done to determine the optimum equilibrium $\mathrm{pH}$, which is described below in Section 4.3.2.

A magnesium chloride concentration of $5.0 \mathrm{~g} / \mathrm{L}$ was used for these experiments. Although this $\mathrm{Mg}$ dose is too high to be practical, it was used so that potential differences in removal would be more discernable. Boron removal climbs with increasing initial $\mathrm{pH}$ values. A maximum boron removal for this experiment is observed at a $\mathrm{pH}$ of 12.5 (Figure 4-2).

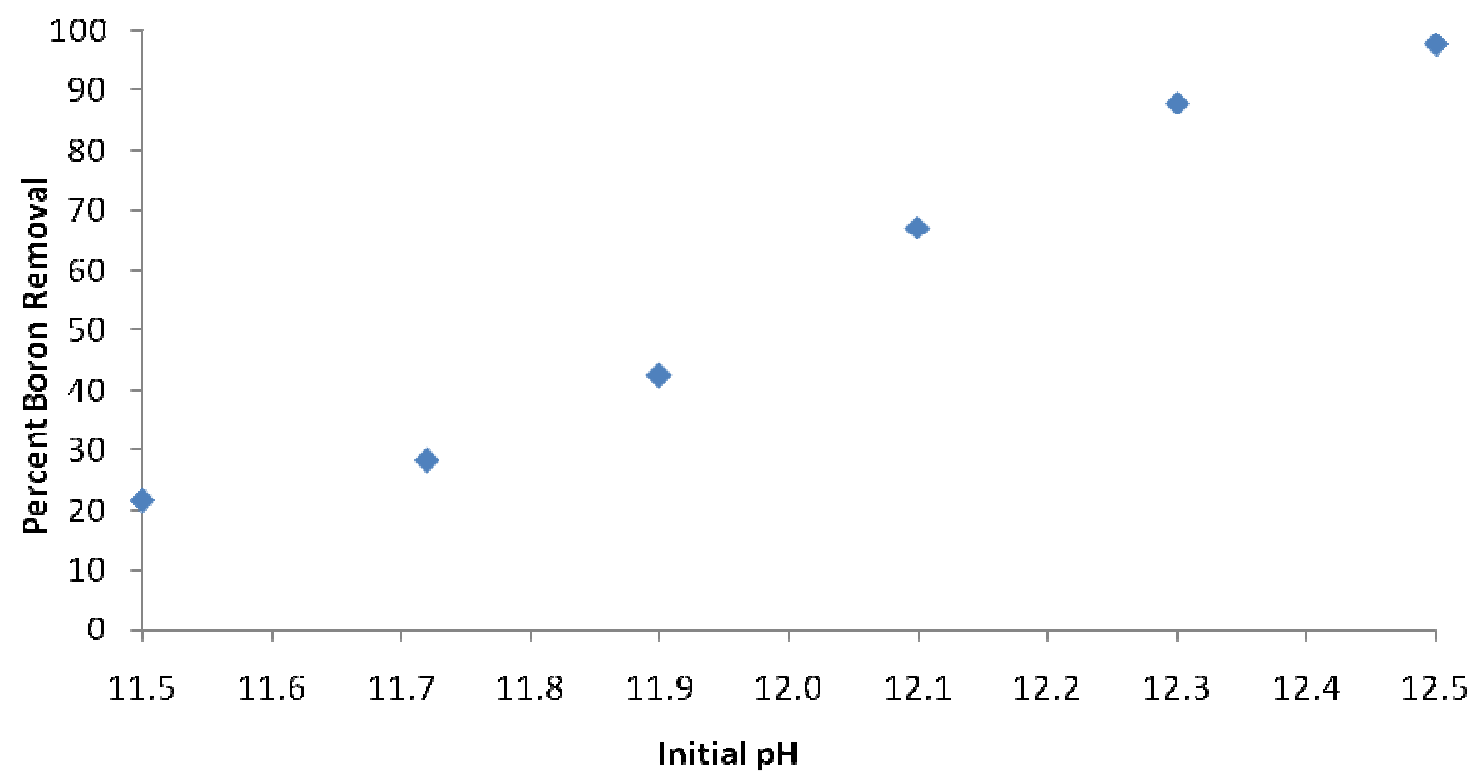

Figure 4-2 Boron removal by Magnesium Chloride as a function of initial $\mathrm{pH}$ ( $8 \mathrm{~g} / \mathrm{L} \mathrm{NaCl}, 150 \mathrm{mg} / \mathrm{L} \mathrm{Si}, 5 \mathrm{~g} / \mathrm{L} \mathrm{MgCl}_{2}$ ) 
Since no decrease in boron removal was observed at higher $\mathrm{pH}$ the optimum $\mathrm{pH}$ was not reached. Thus a further experiment was conducted over a higher $\mathrm{pH}$ range. Table 4-6 gives the conditions for the experiment investigating the effect of initial $\mathrm{pH}$ between 12.0 and 13.0. Boron removal peaks at an initial $\mathrm{pH}$ of 12.5 (Figure 4-3). Boron removal dropped off steeply on both sides of this peak, revealing a narrow range of optimal initial $\mathrm{pH}$ leading to maximum boron removal. Boron removal is also plotted as a function of final equilibrium $\mathrm{pH}$ in Figure 4-3. Maximum boron removal was observed at an equilibrium $\mathrm{pH}$ of 10.9 .

Optimization of $\mathrm{pH}$ resulted in boron removals up to $80 \%$, which is significantly greater than that observed previously. However, the amount of magnesium chloride $(5 \mathrm{~g} / \mathrm{L})$ used is still beyond practical application.

Table 4-6 Conditions for determination of optimal initial pH for boron removal

\begin{tabular}{|c|c|c|c|c|c|c|c|c|}
\hline \multirow{2}{*}{ Jar } & \multicolumn{2}{|c|}{$p H$} & \multirow{2}{*}{$\begin{array}{c}\mathrm{MgCl}_{2} \\
\bullet 6 \mathrm{H}_{2} \mathrm{O} \\
(\mathrm{mmol} / \mathrm{L})\end{array}$} & \multicolumn{3}{|c|}{$\begin{array}{c}\text { Boron Concentration } \\
(\mathrm{mmol} / \mathrm{L})\end{array}$} & \multirow{2}{*}{$\begin{array}{l}\text { \% Boron } \\
\text { Removal }\end{array}$} & \multirow{2}{*}{$\begin{array}{c}\text { mmol B } \\
\text { Removed / } \\
\text { mmol } \\
\mathrm{MgCl}_{2} \bullet 6 \mathrm{H}_{2} \mathrm{O}\end{array}$} \\
\hline & Start & Finish & & Initial & Final & Removed & & \\
\hline 1 & 12.00 & 9.85 & 24.6 & 2.41 & 2.04 & 0.38 & 15.6 & 15.3 \\
\hline 2 & 12.25 & 10.07 & 24.6 & 2.43 & 1.57 & 0.86 & 35.4 & 34.9 \\
\hline 3 & 12.50 & 10.89 & 24.6 & 2.43 & 0.50 & 1.95 & 80.1 & 79.2 \\
\hline 4 & 12.75 & 12.37 & 24.6 & 2.44 & 1.25 & 1.18 & 48.6 & 48.1 \\
\hline 5 & 13.00 & 12.75 & 24.6 & 2.44 & 1.57 & 0.087 & 35.5 & 35.2 \\
\hline Control & 12.00 & 12.84 & 24.6 & 2.47 & 2.43 & 0.004 & 1.5 & 1.47 \\
\hline
\end{tabular}




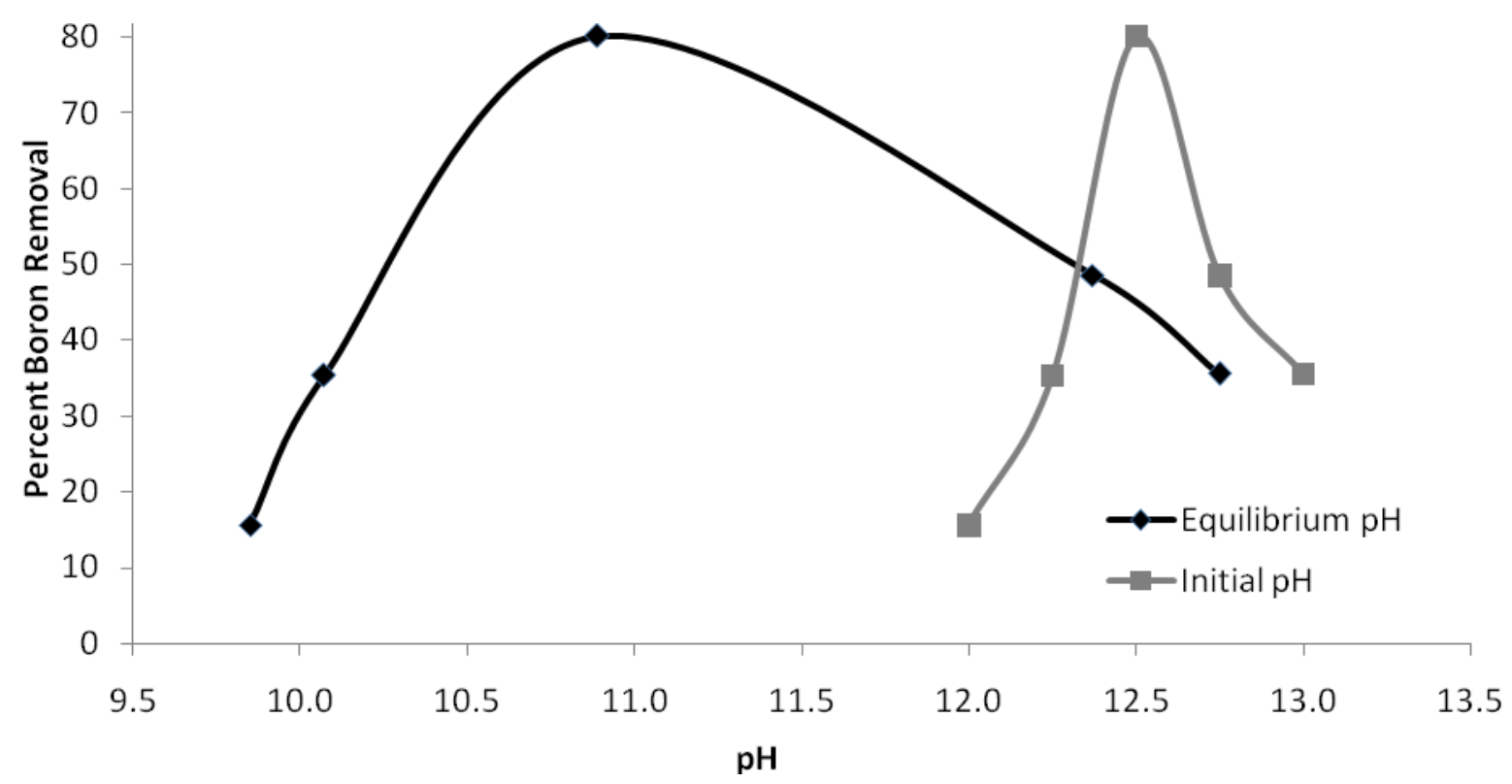

Figure 4-3 Initial and equilibrium $\mathrm{pH}$ values

(5 $\mathrm{g} \mathrm{MgCl}_{2} / \mathrm{L}, 150 \mathrm{mg} \mathrm{Si} / \mathrm{L}, 8 \mathrm{~g} \mathrm{NaCl} / \mathrm{L}$ )

Since equilibrium $\mathrm{pH}$ was determined to be a more practical parameter for optimizing boron removal, further experiments were run to determine it. For equilibrium $\mathrm{pH}, \mathrm{a}$ data gap existed between pH 10.9 and 12.8 (two orders of magnitude separate these two data points).

\subsubsection{Equilibrium pH Effects on Boron Removal by Magnesium Chloride}

The conditions used to determine optimal equilibrium $\mathrm{pH}$ are shown in Table 4-7. Large amounts of boron were removed from solution at all pHs with maximum removal at a $\mathrm{pH}$ of 11.10 (Figure 4-4 and Table 4-7). At this optimum $\mathrm{pH}$, a boron removal efficiency 
of $86 \%$ was observed. Boron removal per mole magnesium added was similar to that observed in the previous experiment, where equilibrium pH was 10.89.

Table 4-7 Conditions used to determine optimal equilibrium pH

\begin{tabular}{|c|c|c|c|c|c|c|c|c|}
\hline \multirow[b]{2}{*}{ Jar } & \multirow[b]{2}{*}{$\mathrm{pH}$} & \multicolumn{2}{|c|}{$\mathrm{MgCl}_{2} \bullet 6 \mathrm{H}_{2} \mathrm{O}$} & \multicolumn{3}{|c|}{ Boron (mmol/L) } & \multirow{2}{*}{$\begin{array}{c}\text { B }_{\text {removed }} / \\
\text { Mgadded }_{\text {(mol/mol) }} \\
\text { (mol }\end{array}$} & \multirow{2}{*}{$\begin{array}{l}\text { \% Boron } \\
\text { Removed }\end{array}$} \\
\hline & & (g/L) & (mol/L) & $\mathrm{B}_{\mathrm{o}}$ & $B_{f}$ & B $_{\text {removed }}$ & & \\
\hline 1 & 10.23 & 5.0 & $2.46 \mathrm{E}-02$ & 2.40 & 1.39 & 1.00 & 0.0407 & 41.8 \\
\hline 2 & 10.47 & 5.0 & 2.46E-02 & 2.40 & 0.81 & 1.58 & 0.0644 & 66.1 \\
\hline 3 & 10.78 & 5.0 & $2.46 \mathrm{E}-02$ & 2.40 & 0.44 & 1.95 & 0.0794 & 81.5 \\
\hline 4 & 11.10 & 5.0 & 2.46E-02 & 2.40 & 0.33 & 2.07 & 0.0842 & 86.4 \\
\hline 5 & 11.29 & 5.0 & $2.46 \mathrm{E}-02$ & 2.40 & 0.46 & 1.94 & 0.0789 & 81.0 \\
\hline 6 & 11.54 & 5.0 & $2.46 \mathrm{E}-02$ & 2.40 & 0.58 & 1.82 & 0.0740 & 76.0 \\
\hline
\end{tabular}

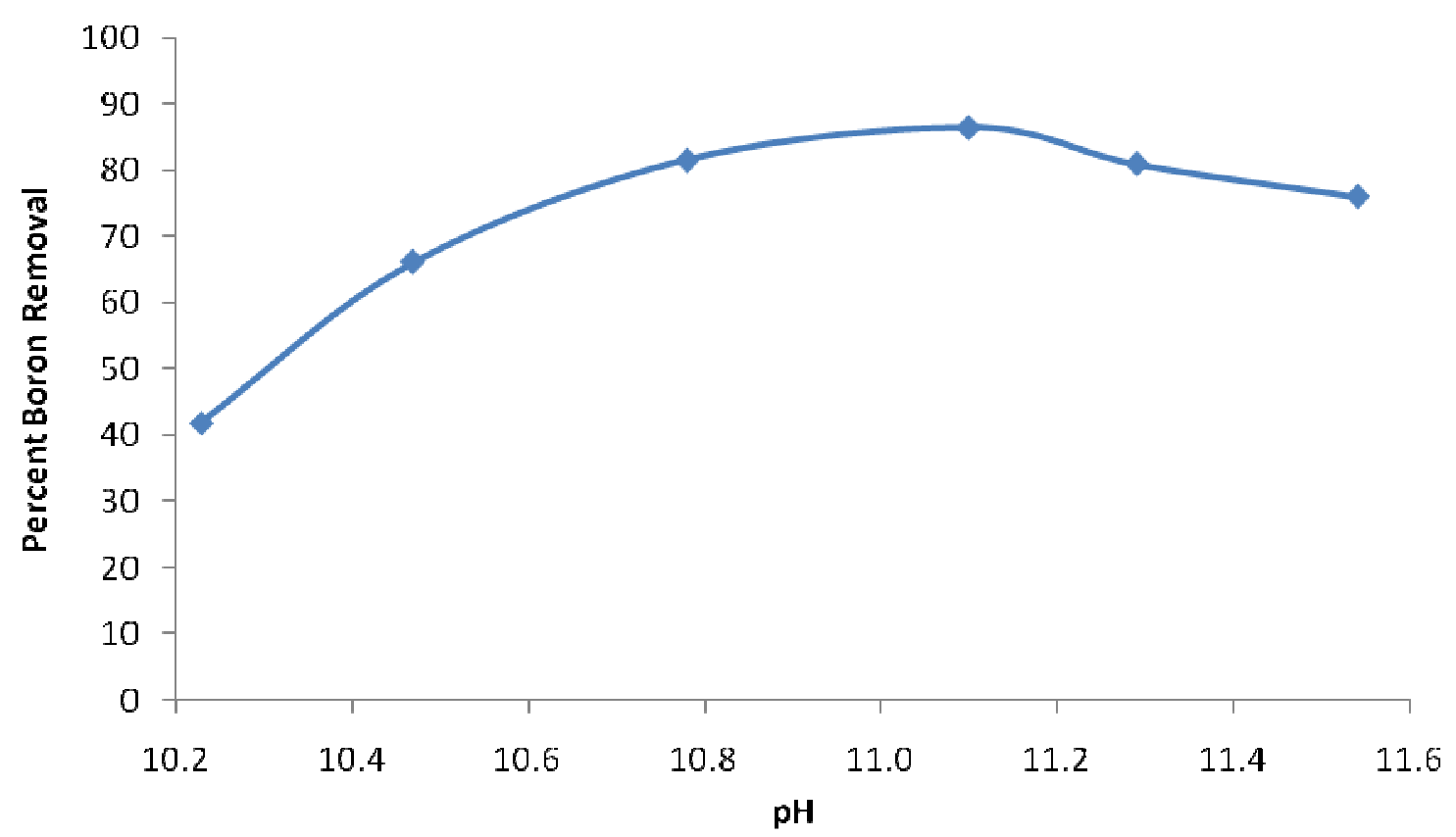

Figure 4-4 Equilibrium pH for Boron Removal

$(5 \mathrm{~g} / \mathrm{L} \mathrm{MgCl} 2,8 \mathrm{~g} / \mathrm{L} \mathrm{NaCl}, 150 \mathrm{mg} / \mathrm{L} \mathrm{NaCl})$ 
Based on the results of this experiment, an optimal equilibrium $\mathrm{pH}$ value of 11 was selected for further experiments. This $\mathrm{pH}$ is also close to the expected initial $\mathrm{pH}$ of reverse osmosis concentrate.

A theoretical titration was carried out on the synthetic RO reject using Visual Minteq ver. 2.53 to determine theoretical speciation of all the components as a function of $\mathrm{pH}$. As can be seen in Figure 4-5, the greatest observed boron removal coincides with the point on the graph where almost all boron is converted into the tetraborate $\left(B(\mathrm{OH})_{4}^{-}\right)$ form. Polyborates (e.g. $\mathrm{B}_{4} \mathrm{O}_{7}{ }^{2-}$ ) form an almost negligible fraction of the boron species in solutions. Magnesium oxide has a pH of zero charge (PZC) and an isoelectric point close to 11 (Pokrovsky, Schott, \& Castillo, 2005). At pH less than $8,>\mathrm{MgOH}_{2}{ }^{+}$dominates, while at $\mathrm{pH}>10,>\mathrm{MgO}^{-}$concentration increases (Pokrovsky \& Schott, 2004). Charge plays a significant role in boron removal (Parks \& Edwards, 2007; Konstantinou, Kasetta, \& Pashalidis, 2006). These results present significant evidence for why adsorption peaked where it did. In this case, it also suggests a mechanism for boron removal: sorption of boron from solution to the surface of the magnesium and silicon solid formed in solution. Removal may decrease above a $\mathrm{pH}$ of 11 , due to the buildup of a negative surface charge on the solids, which repels tetraborate. A further possibility is competition between tetraborate and other negatively charged species in solution for sorption sites. Another result predicted by Figure 4-5 is the precipitation of almost all 
magnesium and silicon solids at $\mathrm{pH} 11$. Thus at $\mathrm{pH}>11$, the maximum quantity of solids would be available for adsorption.

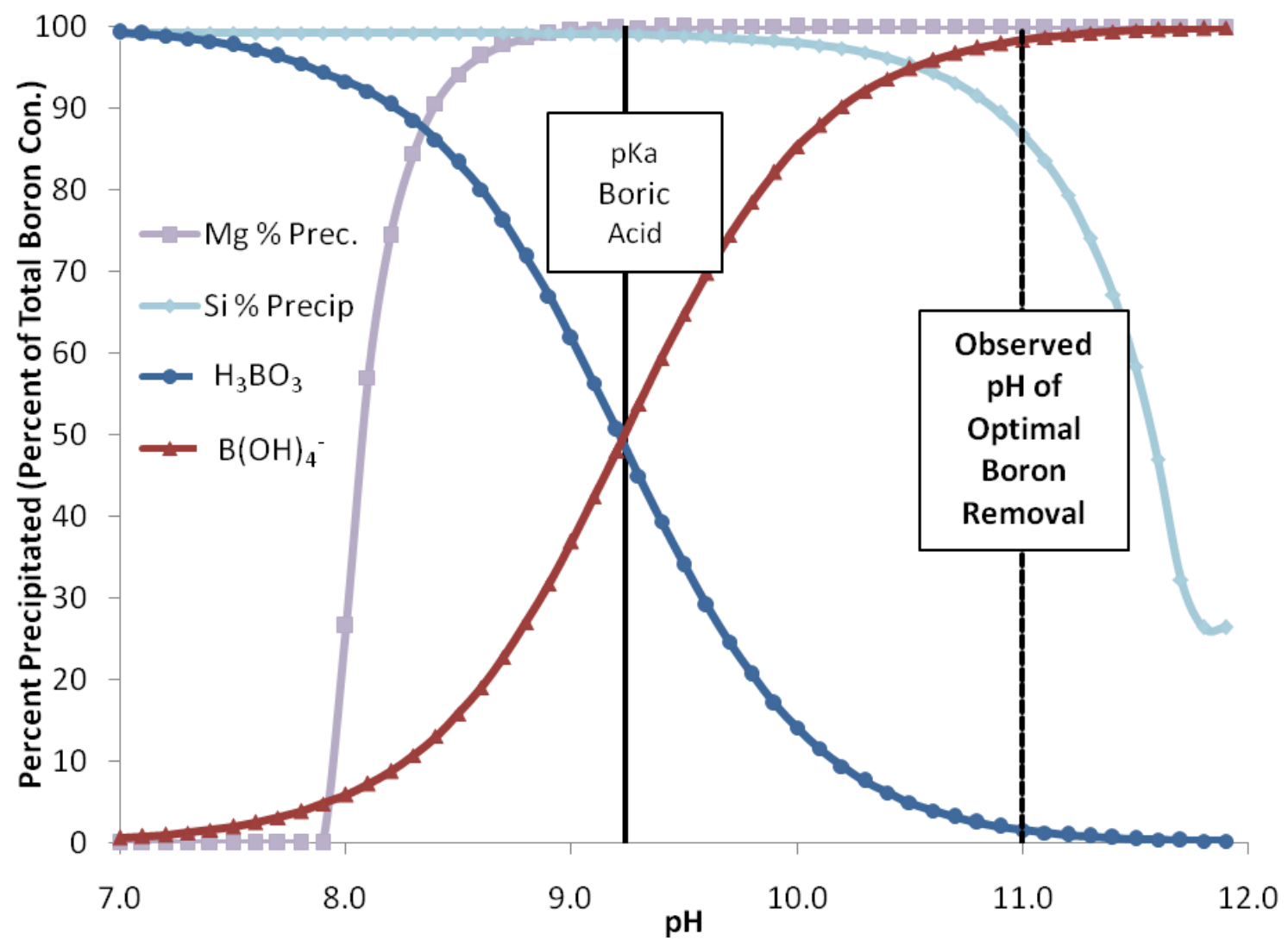

Figure 4-5 Theoretical titration of synthetic RO concentrate using Visual MINTEQ ver. 2.53 with percent of $\mathrm{Mg}$ and Si moles precipitated displayed

\subsection{Mixing and Contact Time}

As discussed previously, the effects of contact time are important for determining mixing requirements for optimal boron removal and determining whether or not equilibrium is reached during the standard experimental protocol. Mixing time and the resulting boron concentrations are displayed in 
- This result demonstrates equilibrium was reached during the mixing time of the standard protocol (45 minutes) used in the experiments of this project.

Table 4-8 Changes in boron concentration during extended mixing period (150 mg Si/L, $8 \mathrm{~g} \mathrm{NaCl} / \mathrm{L}, 1.0 \mathrm{~g} \mathrm{MgCl}_{2} \circ 6 \mathrm{H}_{2} \mathrm{O}$ )

\begin{tabular}{rcc}
$\begin{array}{c}\text { Mixing } \\
\text { Time } \\
\text { (minutes) }\end{array}$ & $\begin{array}{c}p H \\
\text { over } \\
\text { time }\end{array}$ & $\begin{array}{c}\text { Boron } \\
(\mathrm{mg} / \mathrm{L})\end{array}$ \\
\hline 0.00 & 11.07 & 30.00 \\
5.67 & 11.07 & 20.64 \\
12.25 & 11.07 & 23.95 \\
20.63 & 11.07 & 23.63 \\
51.00 & 11.07 & 23.25 \\
80.00 & 11.07 & 23.94 \\
137.00 & 11.07 & 24.60 \\
237.00 & 11.07 & 25.21 \\
427.00 & 11.07 & 24.26 \\
1321.00 & 11.07 & 26.09 \\
\hline
\end{tabular}




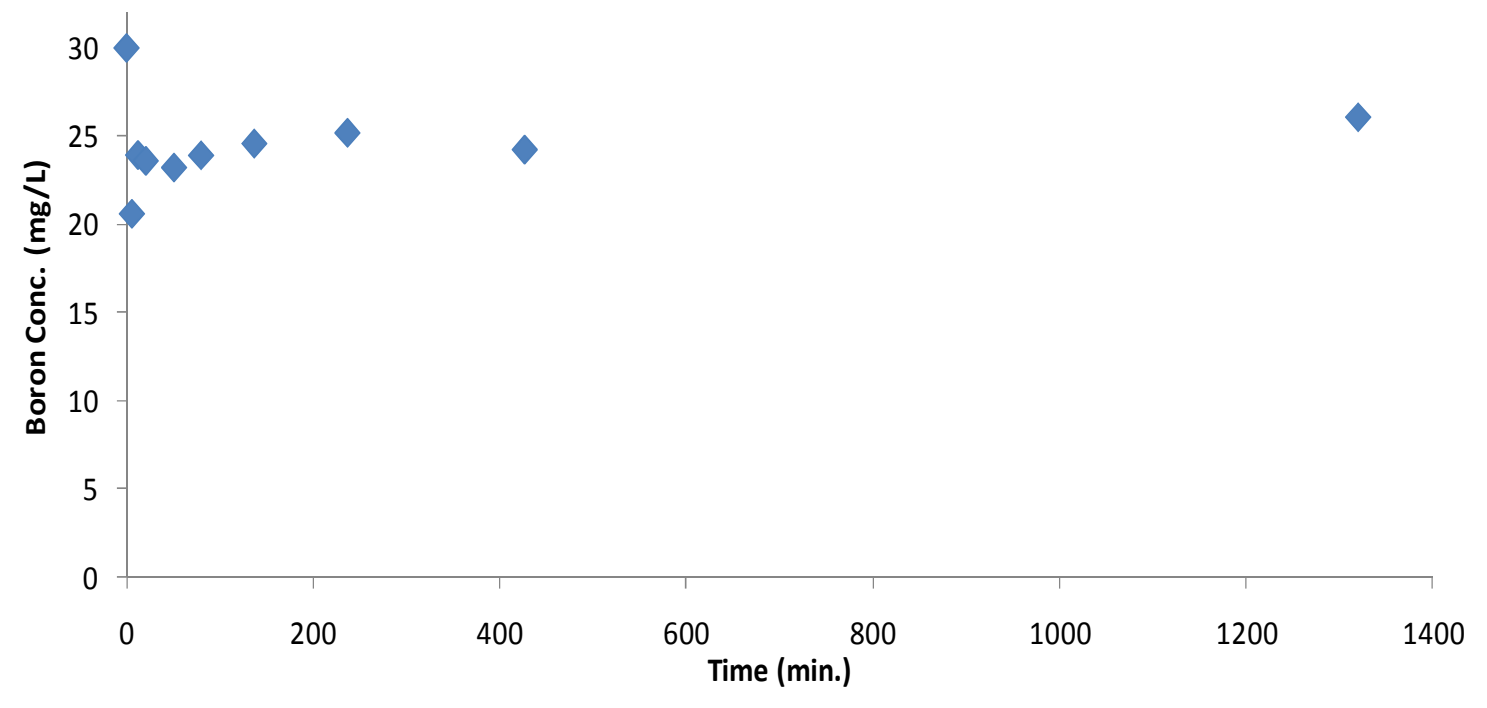

Figure 4-6 Changes in boron concentration during extended mixing period

\subsection{Temperature Effects}

In previous experiment by Wörlen (2008), temperature proved to be a critical factor in boron removal when using magnesium oxide. Boron removal by $\mathrm{MgO}$ was determined to increase from $20 \%$ to $50 \%$ when the temperature was elevated from $70^{\circ} \mathrm{C}$ to $80^{\circ} \mathrm{C}$ (Wörlen, 2008). Temperature effect was revisited because a different reagent was used

in the current study (magnesium chloride versus magnesium oxide) and because conditions representing RO reject are being used. In this study on RO concentrate, high temperature decreased boron removal (

Table 4-9 and Figure 4-7). In addition, turbidity of the final suspension after settling was higher for higher temperatures, indicating that solids became less settleable. Decreased boron removal was thus paired with decreased ability to remove solids from suspension. Magnesium chloride therefore has a major advantage over magnesium oxide in that the optimal temperature for boron removal and solids settling with magnesium chloride 
$\left(\sim 40^{\circ} \mathrm{C}\right)$ is closer to the expected RO reject temperature $\left(20^{\circ} \mathrm{C}\right)$ than the optimum temperature for magnesium oxide $\left(80^{\circ} \mathrm{C}\right)$. A further advantage of magnesium chloride is less sludge production, which is discussed later.

Table 4-9 Results of temperature effect experiments

\begin{tabular}{|c|c|c|c|c|c|c|c|c|c|c|}
\hline \multirow{2}{*}{$\begin{array}{c}J a r \\
\#\end{array}$} & \multirow{2}{*}{$P h$} & \multirow{2}{*}{$\begin{array}{c}\text { Temp } \\
\left({ }^{\circ} \mathrm{C}\right)\end{array}$} & \multirow{2}{*}{$\begin{array}{c}\mathrm{MgCl}_{2}^{\circ} \\
6 \mathrm{H}_{2} \mathrm{O} \\
(\mathrm{mmol} / \mathrm{L})\end{array}$} & \multicolumn{2}{|c|}{ Initial Boron } & \multicolumn{2}{|c|}{ Final Boron } & \multicolumn{2}{|c|}{ Boron Removed } & \multirow{2}{*}{$\begin{array}{c}\% \\
B_{\text {removed }}\end{array}$} \\
\hline & & & & $(\mathrm{mg} / \mathrm{L})$ & $(\mathrm{mmol} / \mathrm{L})$ & $(\mathrm{mg} / \mathrm{L})$ & $(\mathrm{mmol} / \mathrm{L})$ & $(\mathrm{mg} / \mathrm{L})$ & $(\mathrm{mmol} / \mathrm{L})$ & \\
\hline $\begin{array}{l}1 \\
2\end{array}$ & $\begin{array}{l}11.05 \\
11.02\end{array}$ & $\begin{array}{l}29.6 \\
41.4\end{array}$ & $\begin{array}{l}4.92 \\
4.92\end{array}$ & $\begin{array}{l}30.0 \\
30.0\end{array}$ & $\begin{array}{l}2.78 \\
2.78\end{array}$ & $\begin{array}{l}28.03 \\
26.71\end{array}$ & $\begin{array}{l}2.59 \\
2.47\end{array}$ & $\begin{array}{l}1.97 \\
3.29\end{array}$ & $\begin{array}{l}0.18 \\
0.30\end{array}$ & $\begin{array}{c}6.6 \\
11.0\end{array}$ \\
\hline 3 & 11.02 & 50.6 & 4.92 & 30.0 & 2.78 & 27.17 & 2.51 & 2.83 & 0.26 & 9.4 \\
\hline 4 & 11.01 & 59.9 & 4.92 & 30.0 & 2.78 & 27.94 & 2.58 & 2.06 & 0.19 & 6.9 \\
\hline 5 & 11.02 & 68.3 & 4.92 & 30.0 & 2.78 & 29.34 & 2.71 & 0.66 & 0.06 & 2.2 \\
\hline
\end{tabular}

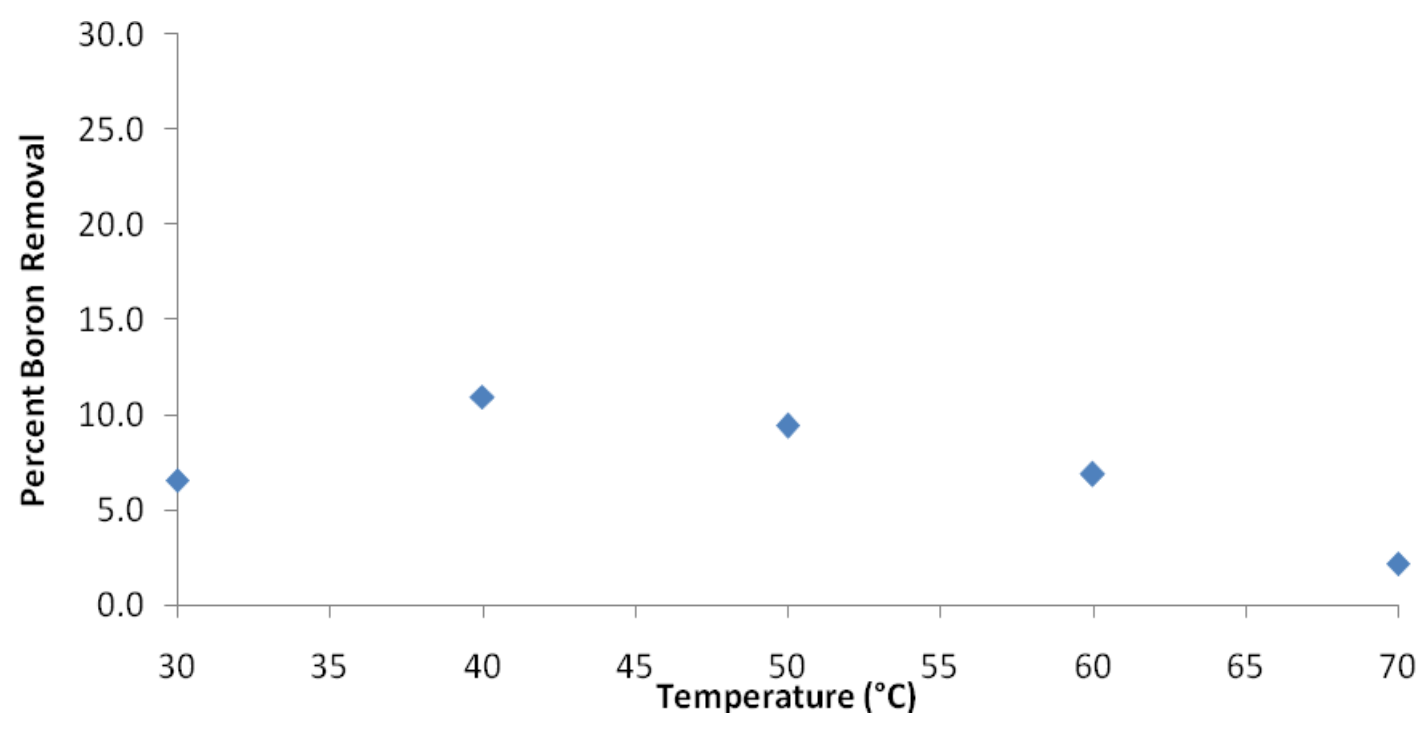

Figure 4-7 Boron removal as a function of temperature (150 mg Si/L, $8 \mathrm{~g} \mathrm{NaCl} / \mathrm{L}$, and $1.0 \mathrm{~g} \mathrm{MgCl}_{2}{ }^{\circ} 6 \mathrm{H}_{2} \mathrm{O} / \mathrm{L}$ ) 


\subsection{Sodium Chloride Effect on Boron Removal by Magnesium Chloride}

The effects of sodium chloride on boron removal by magnesium chloride were explored using synthetic RO concentrate. Increasing sodium chloride concentrations correspond to greater solutions ionic strengths and activity coefficients deviating farther and farther away from one. An activity coefficient of one corresponds to an ideal solution. A value either greater or less than a value of one leads to a solution becoming less and less ideal. A calculation of the ionic strength uses the following equation [1].

$$
I=\frac{1}{2} \sum_{\mathrm{i}=1}^{n} c_{\mathrm{i}} z_{\mathrm{i}}^{2}
$$

\section{Equation 1 - Equation used for calculation of ionic strength}

Where $c_{i}$ is the molar concentration of each ion and $z_{i}$ is the charge of each ion. Ionic strength is then used to calculate the activity coefficient using the Debye-Hückel equation.

The results of this experiment are presented below in Table 4-10 and Figure 4-8. Minimal effects of sodium chloride on boron removal were observed, except for the first jar in which no sodium chloride was present. Sodium chloride concentrations were selected to emulate conditions seen for various types of water: Jar 1 was intended as a control; Jar 2 held brackish water; and Jar 3 held the simulated produced water RO 
concentrate resulting from feed water treatment. Jar 4 represents a more concentrated RO concentrate. Jars 5 and 6 represent sea water and the reverse osmosis concentrate that would result from its treatment, respectively.

After an initial drop, boron removal increases slightly with greater sodium chloride concentrations (Figure 4-8). The minimum boron removal was observed at the $\mathrm{NaCl}$ concentration expected for site RO concentrate $(8 \mathrm{~g} / \mathrm{L})$. The difference in removal between site feed water and reverse osmosis concentrate is minimal. The turbidity of Jars 1 and 2, with low $\mathrm{NaCl}$ concentrations, was higher than in the other beakers. This observation could be the result of greater electric double layer compression in the high ionic strength solutions (Ravina, 1993). Both sodium and chloride only have +1 and -1 charge respectively and thus do not contribute greatly to changes in ionic strength except for at high concentrations. This can explain why the change in boron removal is so gradual even with greatly increased sodium chloride concentrations.

Table 4-10 Summary of the effects of sodium chloride on boron removal

\begin{tabular}{ccccccccc} 
Jar & $\mathbf{p H}$ eq & $\begin{array}{c}\mathrm{NaCl} \\
(\mathbf{g} / \mathbf{L})\end{array}$ & $\begin{array}{c}\text { Initial } \\
\text { Boron } \\
(\mathbf{m m o l} / \mathbf{L})\end{array}$ & $\begin{array}{c}\text { Final } \\
\text { Boron } \\
(\mathbf{m m o l} / \mathbf{L})\end{array}$ & $\begin{array}{c}\text { Boron } \\
\text { Removed } \\
(\mathbf{m m o l} / \mathbf{L})\end{array}$ & $\begin{array}{c}\text { Mol Boron } \\
\text { Removed }\end{array}$ & $\begin{array}{c}\text { Removed } \\
\text { / Mol Mg } \\
\text { Added }\end{array}$ & $\begin{array}{c}\text { Solids } \\
\text { (g/L) }\end{array}$ \\
\hline $\mathbf{1}$ & 11.13 & 0.00 & 2.78 & 1.95 & 0.82 & 29.67 & 0.0167 & 0.6650 \\
$\mathbf{2}$ & 11.10 & 1.01 & 2.78 & 2.61 & 0.16 & 5.90 & 0.0333 & 0.8406 \\
$\mathbf{3}$ & 11.16 & 8.00 & 2.78 & 2.66 & 0.11 & 4.10 & 0.0231 & 0.8566
\end{tabular}




\begin{tabular}{lllllllll}
$\mathbf{4}$ & 11.12 & 20.01 & 2.78 & 2.54 & 0.23 & 8.30 & 0.0468 & 2.4592 \\
$\mathbf{5}$ & 11.12 & 35.01 & 2.78 & 2.51 & 0.26 & 9.47 & 0.0534 & 1.2460 \\
$\mathbf{6}$ & 11.11 & 50.01 & 2.78 & 2.38 & 0.39 & 14.10 & 0.0796 & 3.0952 \\
\hline
\end{tabular}

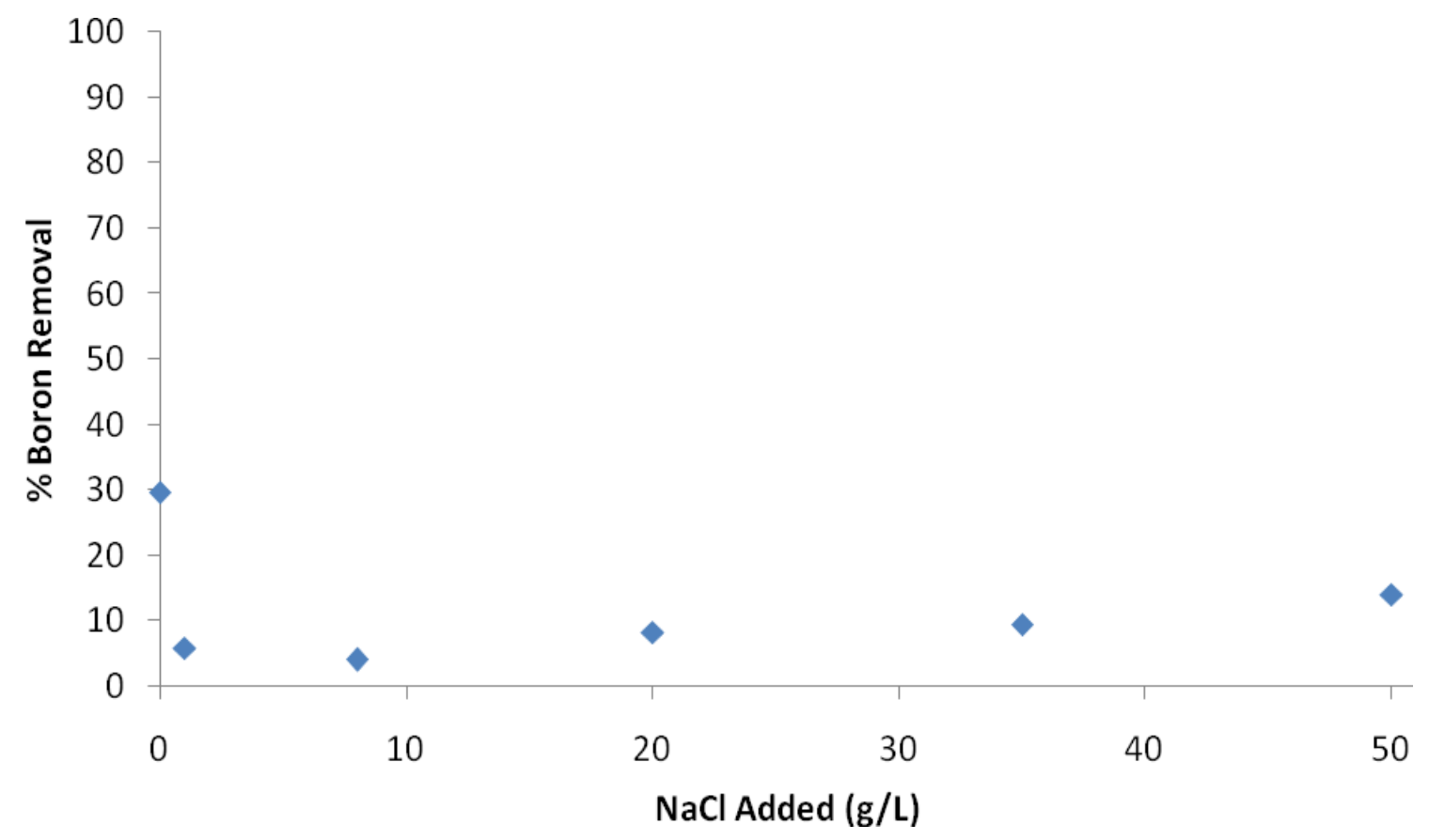

Figure 4-8 The effects of sodium chloride on boron removal

Previous studies have indicated that adsorption sites for boron are specific and are not inhibited by competing anions (Goldberg, Forster, Lesch, \& Heick, 1996). Thus it is not surprising that chloride ion had little effect on boron adsorption. The XRD analysis (Section 4.1.3) indicated that chloride is incorporated into the mineral structure of the solids formed during precipitation. How chloride affects boron binding during precipitate is not clear. Due 


\subsection{Effects of Sulfate on Boron Removal}

Sulfate had no significant effect on boron removal (Figure 4-9 and Table 4-11). Pokrovsky et al. (2005) indicated that sulfate inhibits brucite dissolution. However, Goldberg et al. (1996) suggested sulfate and phosphate both display minimal effects on boron removal by various clays and soils. The results of the sulfate experiment suggest little sulfate effect, if any. Combined with the $\mathrm{NaCl}$ results, anion competition does not represent a problem for boron adsorption under the conditions expected in reverse osmosis concentrate at the site.

Table 4-11 Sulfate effects on boron removal by $1 \mathrm{~g} / \mathrm{L}$ of Magnesium Chloride

\begin{tabular}{ccccccccc} 
Jar & pH & $\begin{array}{c}\text { Sulfate } \\
\left(\mathbf{S O}_{4}{ }^{2-}\right) \\
(\mathbf{m m o l} / \mathbf{L})\end{array}$ & $\begin{array}{c}\text { Initial } \\
\text { Boron } \\
(\mathbf{m m o l} / \mathbf{L})\end{array}$ & $\begin{array}{c}\text { Initial } \\
\text { Boron } \\
(\mathbf{m o l} / \mathbf{L})\end{array}$ & $\begin{array}{c}\text { Boron } \\
\text { Removed } \\
(\mathbf{m o l} / \mathbf{L})\end{array}$ & $\begin{array}{c}\text { \% Boron } \\
\text { Remove } \\
\mathbf{d}\end{array}$ & $\begin{array}{c}\text { Mol B } \\
\text { Removed } \\
/ \mathbf{M o l ~ M g} \\
\text { Added }\end{array}$ & $\begin{array}{c}\text { Solids } \\
\text { Produce } \\
\mathbf{d}(\mathbf{g} / \mathbf{L})\end{array}$ \\
\hline $\mathbf{1}$ & 10.94 & 0 & 2.78 & 2.38 & 0.391 & 14.1 & 0.080 & 1.1026 \\
$\mathbf{2}$ & 10.90 & 0.52 & 2.78 & 2.56 & 0.217 & 7.8 & 0.044 & 0.7484 \\
$\mathbf{3}$ & 11.13 & 1.04 & 2.78 & 2.58 & 0.191 & 6.9 & 0.039 & 0.7758 \\
$\mathbf{4}$ & 11.09 & 2.08 & 2.78 & 2.54 & 0.238 & 8.6 & 0.048 & 0.7520 \\
$\mathbf{5}$ & 11.05 & 5.21 & 2.78 & 2.42 & 0.354 & 12.8 & 0.072 & 0.8044 \\
$\mathbf{6}$ & 11.21 & 10.4 & 2.78 & 2.52 & 0.259 & 9.3 & 0.053 & 0.8978 \\
\hline
\end{tabular}




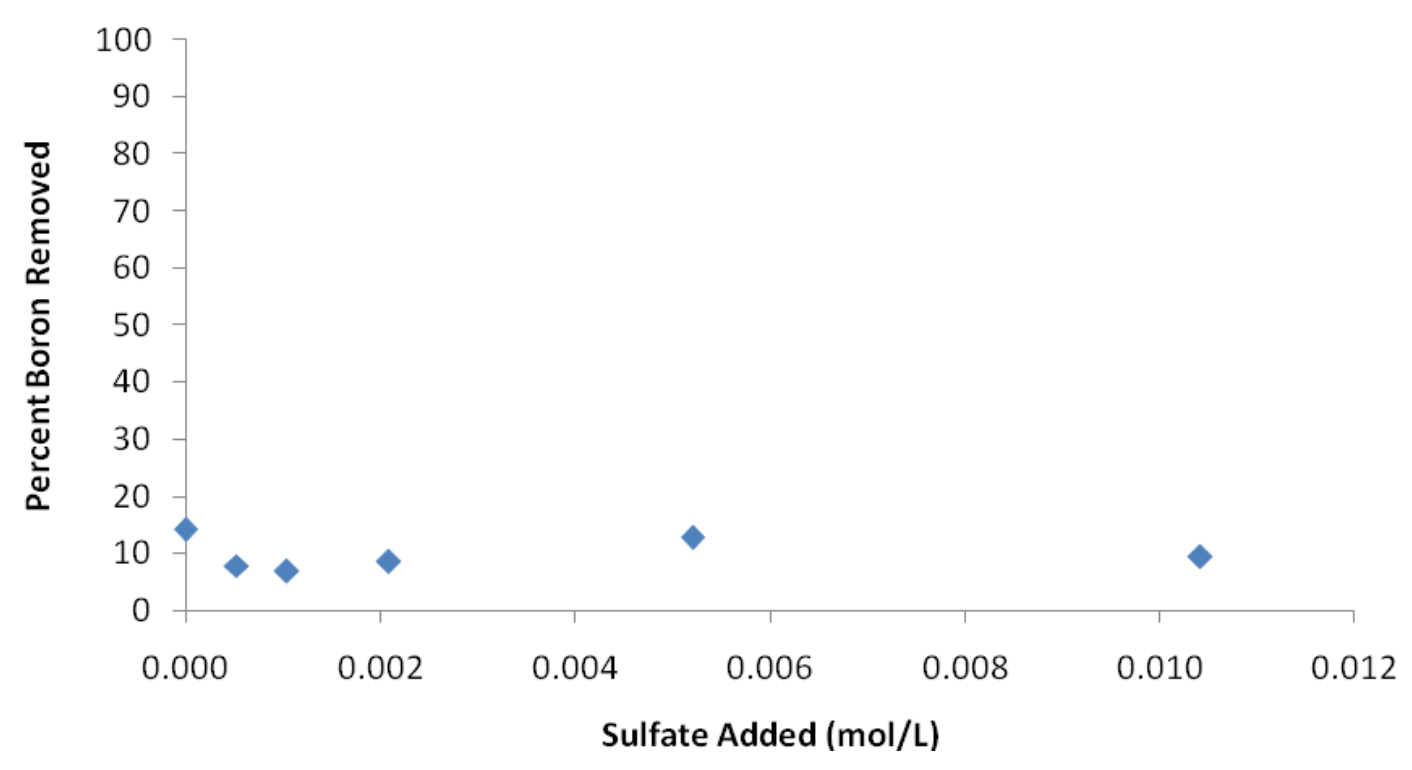

Figure 4-9 Effects of Sulfate on Boron Removal (1.0 $\mathrm{g} \mathrm{MgCl}_{2} \circ 6 \mathrm{H}_{2} \mathrm{O} / \mathrm{L}, 8 \mathrm{~g} \mathrm{NaCl} / \mathrm{L}$, and $150 \mathrm{mg} \mathrm{Si} / \mathrm{L}$ )

\subsection{Role of Silicon in Boron Removal by Magnesium Chloride}

Silica, as sodium metasilicate $\left(\mathrm{Na}_{2} \mathrm{SiO}_{3} \cdot \mathrm{nH}_{2} \mathrm{O}\right)$, in concentrations ranging from 0 to 10 $\mathrm{mmol} \mathrm{Si}$, was added to synthetic RO concentrate containing $8 \mathrm{~g} \mathrm{NaCl} / \mathrm{L}$ and $30 \mathrm{mg} \mathrm{B} / \mathrm{L}$. Silica decreased boron removal from $33 \%$ in the control to $5 \%$ in the $10 \mathrm{mM} \mathrm{Si}$ suspension (Figure 4-10and Table 4-12). The Si concentration expected in the RO reject is represented by Jar 5 and is the concentration used in most of the synthetic RO reject experiments in this study. The Jar $5 \mathrm{Si}$ concentration resulted in significantly decreased boron removal compared to lower initial Si concentrations. This result may not correspond with Parks and Edwards (2007), who suggested that boron is more 
effectively removed when magnesium and silicon are allowed to co-precipitate. Parks and Edwards also concluded that silicon is removed more effectively when magnesium and silicon are allowed to co-precipitate.

Decreasing boron removal suggests removal does not rely specifically on the presence of silica. In fact, boron removal seems to be hindered by the addition of silicon to solution. Boron and silica bind to specific adsorption sites through ligand exchange with hydroxyl groups (Goldberg \& Glaubig, 1985). There is conflicting evidence as to whether this leads to competitive inhibition of boron adsorption caused by silica $\left(\mathrm{SiO}_{3}{ }^{2}\right)$. Our research indicates that silica does act competitively with boron for adsorption sites.

Table 4-12 Role of silicon in the removal of boron with magnesium compounds

\begin{tabular}{|c|c|c|c|c|c|c|c|c|c|}
\hline \multirow[b]{2}{*}{ Jar } & \multirow[b]{2}{*}{$p H_{e q}$} & \multicolumn{2}{|c|}{ Si } & \multirow{2}{*}{$\begin{array}{c}B_{o} \\
(\mathrm{mmol} / \mathrm{L})\end{array}$} & \multirow{2}{*}{$\begin{array}{c}B_{f} \\
(\mathrm{mmol} / \mathrm{L})\end{array}$} & \multirow{2}{*}{$\begin{array}{l}B_{\text {removed }} \\
(\mathrm{mmol} / \mathrm{L})\end{array}$} & \multirow[b]{2}{*}{$\begin{array}{c}\% \\
B_{\text {Removed }}\end{array}$} & \multirow{2}{*}{$\begin{array}{c}\text { Mol B } \\
\text { Removed } \\
\text { / Mol Mg } \\
\text { Added }\end{array}$} & \multirow[b]{2}{*}{$\begin{array}{c}\text { Solids } \\
\text { (g/L) }\end{array}$} \\
\hline & & $\mathrm{mmol} / \mathrm{L}$ & $m g / L$ & & & & & & \\
\hline 1 & 10.92 & 0.00 & 0.00 & 2.78 & 1.87 & 0.90 & 32.5 & 0.183 & 1.1026 \\
\hline 2 & 10.86 & 0.49 & 13.7 & 2.78 & 1.90 & 0.88 & 31.7 & 0.179 & 0.7484 \\
\hline 3 & 10.96 & 1.00 & 28.1 & 2.78 & 2.00 & 0.77 & 27.8 & 0.157 & 0.7758 \\
\hline 4 & 10.97 & 2.53 & 71.1 & 2.78 & 2.02 & 0.76 & 27.3 & 0.154 & 0.7520 \\
\hline 5 & 11.01 & 5.02 & 141.0 & 2.78 & 2.35 & 0.43 & 15.4 & 0.087 & 0.8044 \\
\hline 6 & 11.14 & 10.00 & 281.0 & 2.78 & 2.63 & 0.15 & 5.2 & 0.030 & 0.8978 \\
\hline
\end{tabular}




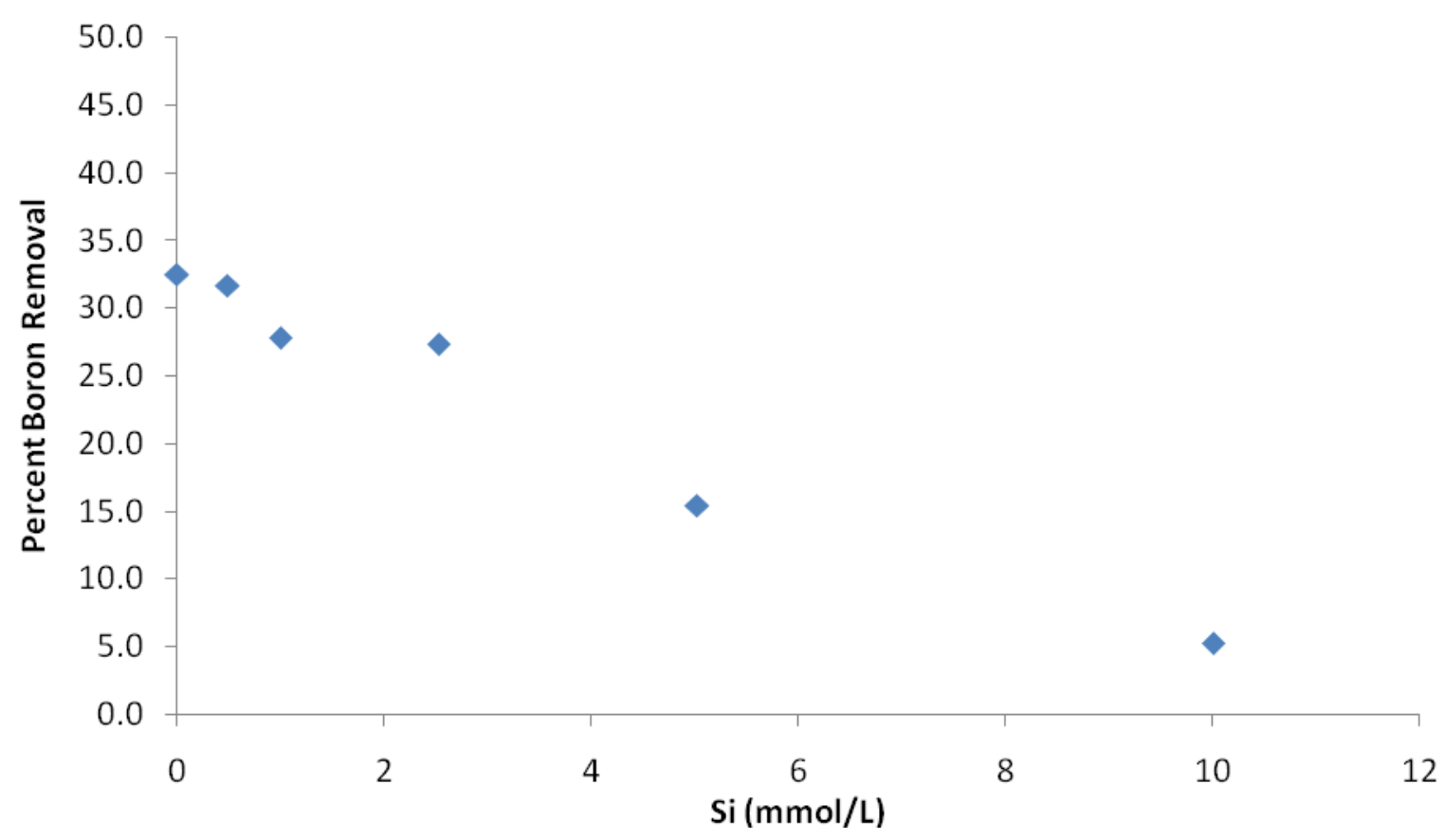

Figure 4-10 Role of silicon in boron removal with magnesium compounds (1.0 $\mathrm{g} \mathrm{MgCl}_{2} \circ 6 \mathrm{H}_{2} \mathrm{O}, 8 \mathrm{~g} \mathrm{NaCl} / \mathrm{L}$ )

\subsection{Adsorption Isotherm for Boron Removal by Magnesium Chloride}

To further characterize boron adsorption, isotherms were created for experimental results. Two experiments were conducted to establish an adsorption isotherm at room temperature. The results of these experiments are summarized below in Table 4-13. High boron removal was observed during both experiments, but a trend of decreasing boron removal was observed as equilibrium concentration of boron decreased. This trend holds true for both experiments except jar 6 from the February $17^{\text {th }}$ experiment. 
Table 4-13 Data used to establish isotherms for boron removal

\begin{tabular}{|c|c|c|c|c|c|c|c|c|}
\hline \multirow{2}{*}{ Experiment } & \multirow{2}{*}{ Jar } & \multicolumn{2}{|c|}{$\mathrm{pH}$} & \multirow{2}{*}{$\begin{array}{c}\mathrm{Mg} \\
(\mathrm{mmol} / \mathrm{L})\end{array}$} & \multirow{2}{*}{$\begin{array}{c}B_{\text {initial }} \\
\text { (mmol) }\end{array}$} & \multirow{2}{*}{$\begin{array}{c}B_{f} \\
(\mathrm{mmol} / \mathrm{L})\end{array}$} & \multirow{2}{*}{$\begin{array}{c}\text { B }_{\text {removed }} \\
(\mathrm{mmol} / \mathrm{L})\end{array}$} & \multirow{2}{*}{$\begin{array}{c}\% \text { B } \\
\text { Removed }\end{array}$} \\
\hline & & Start & final & & & & & \\
\hline \multirow{6}{*}{$\begin{array}{c}\text { February } \\
\text { 7th }\end{array}$} & 1 & 11.01 & 11.11 & 4.92 & 0.46 & 0.23 & 0.23 & 50.7 \\
\hline & 2 & 11.01 & 11.01 & 4.92 & 0.93 & 0.64 & 0.29 & 30.8 \\
\hline & 3 & 11.01 & 11.03 & 4.92 & 1.39 & 1.12 & 0.27 & 19.4 \\
\hline & 4 & 11.01 & 11.02 & 4.92 & 1.85 & 1.43 & 0.42 & 22.8 \\
\hline & 5 & 11.01 & 10.99 & 4.92 & 2.78 & 2.15 & 0.63 & 22.6 \\
\hline & 6 & 11.01 & 11.01 & 4.92 & 4.63 & 3.49 & 1.14 & 24.6 \\
\hline \multirow{6}{*}{$\begin{array}{c}\text { February } \\
\text { 17th }\end{array}$} & 1 & 11.02 & 11.01 & 2.46 & 0.463 & 0.32 & 0.14 & 30.0 \\
\hline & 2 & 11.02 & 11.02 & 2.46 & 0.93 & 0.73 & 0.19 & 20.8 \\
\hline & 3 & 11.03 & 11.05 & 2.46 & 1.85 & 1.45 & 0.40 & 21.8 \\
\hline & 4 & 10.99 & 11.01 & 2.46 & 2.78 & 1.87 & 0.90 & 32.5 \\
\hline & 5 & 11.03 & 11.05 & 2.46 & 4.63 & 3.47 & 1.16 & 25.1 \\
\hline & 6 & 10.99 & 10.98 & 2.46 & 9.25 & 5.01 & 4.24 & 45.8 \\
\hline
\end{tabular}

Adsorption isotherms can give clues as to whether an adsorption process reaching saturation, or more potential for removal exists. The data presented in Table 4-13 were fit to linear, Langmuir and Freundlich isotherm models. The equations for each of these models are as follows:

Linear Adsorption Model: $\mathrm{q}_{\mathrm{e}}=\mathrm{KC}$

Langmuir Adsorption Model: $q_{\mathrm{e}}=Q^{\circ}\left(b C_{\mathrm{e}} / 1+b C_{e}\right)$

Freundlich Isotherm Model: $q_{e}=K_{f} C_{e}{ }^{n}$

(Stumm \& Morgan, 1996) 
Where $\mathrm{q}_{\mathrm{e}}$, is the moles adsorbate per mol adsorbent, $C_{e}$, is the equilibrium concentration of adsorbate in solution. Typically, $\mathrm{q}_{\mathrm{e}}$ is measured as moles adsorbate per kg adsorbent, but in this case since the exact composition of the solid is not known, moles of adsorbent are a more appropriate unit. In the Langmuir isotherm [Eq. 3] $\mathrm{Q}^{\circ}$ represents the sorbed solute corresponding to complete monolayer coverage or a limiting capacity. The parameter $b$ is an adsorption coefficient relating to the enthalpy of adsorption. (Weber, Mcginley, \& Katz, 1991). In the Freundlich model [Eq. 4], $K_{f}$ is referred to as the Freundlich constant and is a measure of nonlinearity involved (Stumm \& Morgan, 1996). The data resulting from regression analysis using all three models is presented below in Table 4-14. A plot of the all three models can be seen below in

Figure 4-11, along with observed data.

Table 4-14 Isotherm data for boron adsorption by magnesium chloride at $20^{\circ} \mathrm{C}$

\begin{tabular}{|c|c|c|c|c|c|}
\hline \multirow[t]{2}{*}{ Jar } & \multirow{2}{*}{$\begin{array}{c}q \\
(\mathrm{mmol} / \mathrm{mmol})\end{array}$} & \multirow{2}{*}{$\begin{array}{c}c \\
(\mathrm{mmol} / \mathrm{L})\end{array}$} & $\begin{array}{c}\text { Linear } \\
\text { Analysis }\end{array}$ & $\begin{array}{c}\text { Freundlich } \\
\text { Analysis }\end{array}$ & $\begin{array}{c}\text { Langmuir } \\
\text { Analysis }\end{array}$ \\
\hline & & & $q_{\text {predicted }}$ & $q_{\text {predicted }}$ & $q_{\text {predicted }}$ \\
\hline 1 & 0.047 & 0.229 & 0.045 & 0.000 & 0.063 \\
\hline 2 & 0.058 & 0.638 & 0.126 & 0.002 & 0.157 \\
\hline 3 & 0.055 & 1.118 & 0.220 & 0.012 & 0.247 \\
\hline 4 & 0.086 & 1.429 & 0.282 & 0.026 & 0.295 \\
\hline 5 & 0.128 & 2.147 & 0.423 & 0.101 & 0.386 \\
\hline 6 & 0.231 & 3.488 & 0.687 & 0.501 & 0.505 \\
\hline 1 & 0.564 & 0.324 & 0.064 & 0.000 & 0.087 \\
\hline 2 & 0.786 & 0.732 & 0.144 & 0.003 & 0.176 \\
\hline 3 & 0.164 & 1.447 & 0.285 & 0.027 & 0.297 \\
\hline 4 & 0.368 & 1.871 & 0.369 & 0.064 & 0.354 \\
\hline 5 & 0.472 & 3.465 & 0.683 & 0.490 & 0.503 \\
\hline 6 & 1.720 & 5.013 & 0.987 & 1.662 & 0.595 \\
\hline
\end{tabular}


As can be seen both experiments coincide with one another well except for Jar 6 from the February $17^{\text {th }}$ experiment. This point forces all of the graphs higher to compensate even though most of the points are grouped at the other end of the graph. Also, it can be seen that the Freundlich model predicts adsorption behavior most accurately followed by the linear and then Langmuir models. The Freundlich isotherm has a problem with the shape of the curve. Due to its convex up curve, if data were to extend out further it would asymptotically approach a given equilibrium boron concentration coinciding to almost infinite boron removal. The data point forcing this shape on the curve is again Jar 6 from the February $17^{\text {th }}$. This point is suspected to be inaccurate because it was necessary to dilute it to bring it within the accurate range for the carmine method. The data was recalculated and re-plotted excluding this point below in Figure 4-12 and Table 4-16. 


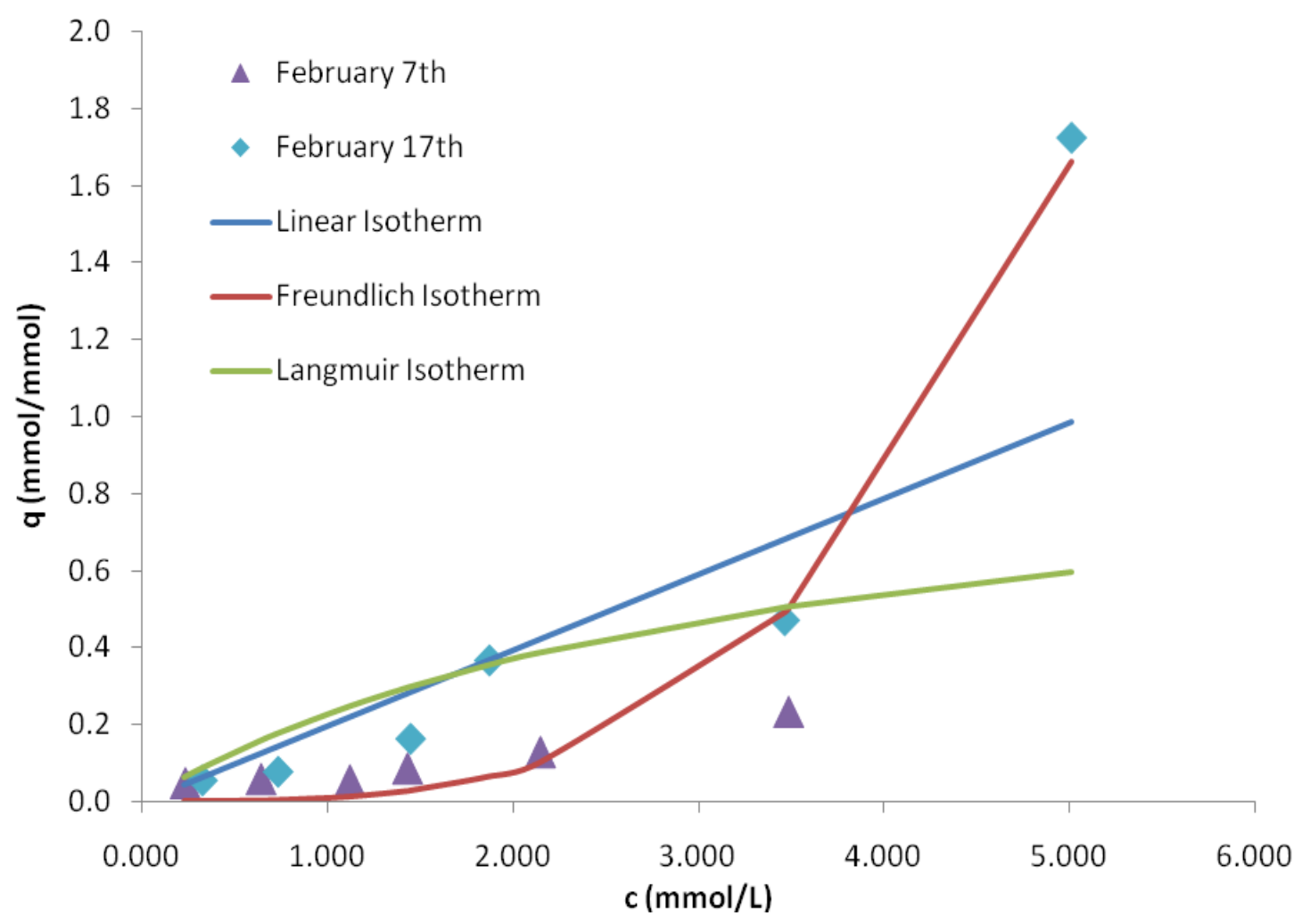

Figure 4-11 Isotherm model plots for boron adsorption by magnesium $\left(20^{\circ} \mathrm{C}, \mathrm{pH}=11,150 \mathrm{mg} \mathrm{Si} / \mathrm{L}\right.$ and $\left.8 \mathrm{~g} \mathrm{NaCl} / \mathrm{L}\right)$

Table 4-15 shows the fitted equations for each model and their coefficients of determination $\left(r^{2}\right)$. The $r^{2}$ for the Freundlich isotherm is higher than the other two models but has two fittable parameters making it easier for it to fit data. The linear model only has one fittable parameter and also has a high $r^{2}$ value.

Table 4-15 Adsorption model equations

\begin{tabular}{c|c|c} 
Linear Model & Langmuir Model & Freundlich Model \\
\hline$q=0.197 c$ & $q=0.293 c /(1+0.293 c)$ & $q=0.00805 c(3.307)$ \\
$r^{2}=0.82$ & $r^{2}=0.49$ & $r^{2}=0.93$
\end{tabular}


When Jar 6 from February $17^{\text {th }}$ is excluded the shape of all the curves changes significantly. All three models produce almost identical results and match the observed results fairly accurately. All three models are in a linear portion of the graph. Thus, saturation is not yet occurring for equilibrium boron concentrations expected in RO concentrate, so working with higher boron concentrations in solution will lead to greater removal for a given quantity of adsorbent. It should also be noted that both Freundlich and Langmuir Isotherms have two fittable parameters, making it easier to for them to fit to data. From Table 4-17 it can be seen that all of the $r^{2}$ are lower than before the point was excluded.

Table 4-16 Observed adsorption data and adsorption predicted from models without excluded point

\begin{tabular}{ccccc}
$q$ & $c$ & $\begin{array}{c}\text { Linear } \\
\text { Analysis }\end{array}$ & $\begin{array}{c}\text { Freundlich } \\
\text { Analysis }\end{array}$ & $\begin{array}{c}\text { Langmuir } \\
\text { Analysis }\end{array}$ \\
\cline { 3 - 5 }$(\mathrm{mmol} / \mathrm{mmol})$ & $(\mathrm{mmol} / \mathrm{L})$ & $q_{\text {predicted }}$ & $q_{\text {predicted }}$ & $q_{\text {predicted }}$ \\
\hline $4.74 \mathrm{E}-02$ & 0.23 & 0.023 & 0.025 & 0.027 \\
$5.642 \mathrm{E}-02$ & 0.32 & 0.033 & 0.035 & 0.038 \\
$5.83 \mathrm{E}-02$ & 0.64 & 0.065 & 0.067 & 0.073 \\
$7.862 \mathrm{E}-02$ & 0.73 & 0.075 & 0.077 & 0.083 \\
$5.47 \mathrm{E}-02$ & 1.12 & 0.114 & 0.116 & 0.124 \\
$8.56 \mathrm{E}-02$ & 1.43 & 0.146 & 0.148 & 0.156 \\
$1.640 \mathrm{E}-01$ & 1.45 & 0.147 & 0.149 & 0.158 \\
$3.675 \mathrm{E}-01$ & 1.87 & 0.191 & 0.192 & 0.199 \\
$1.28 \mathrm{E}-01$ & 2.15 & 0.219 & 0.220 & 0.225 \\
$4.717 \mathrm{E}-01$ & 3.47 & 0.353 & 0.351 & 0.340 \\
$2.31 \mathrm{E}-01$ & 3.49 & 0.355 & 0.353 & 0.341 \\
\hline
\end{tabular}




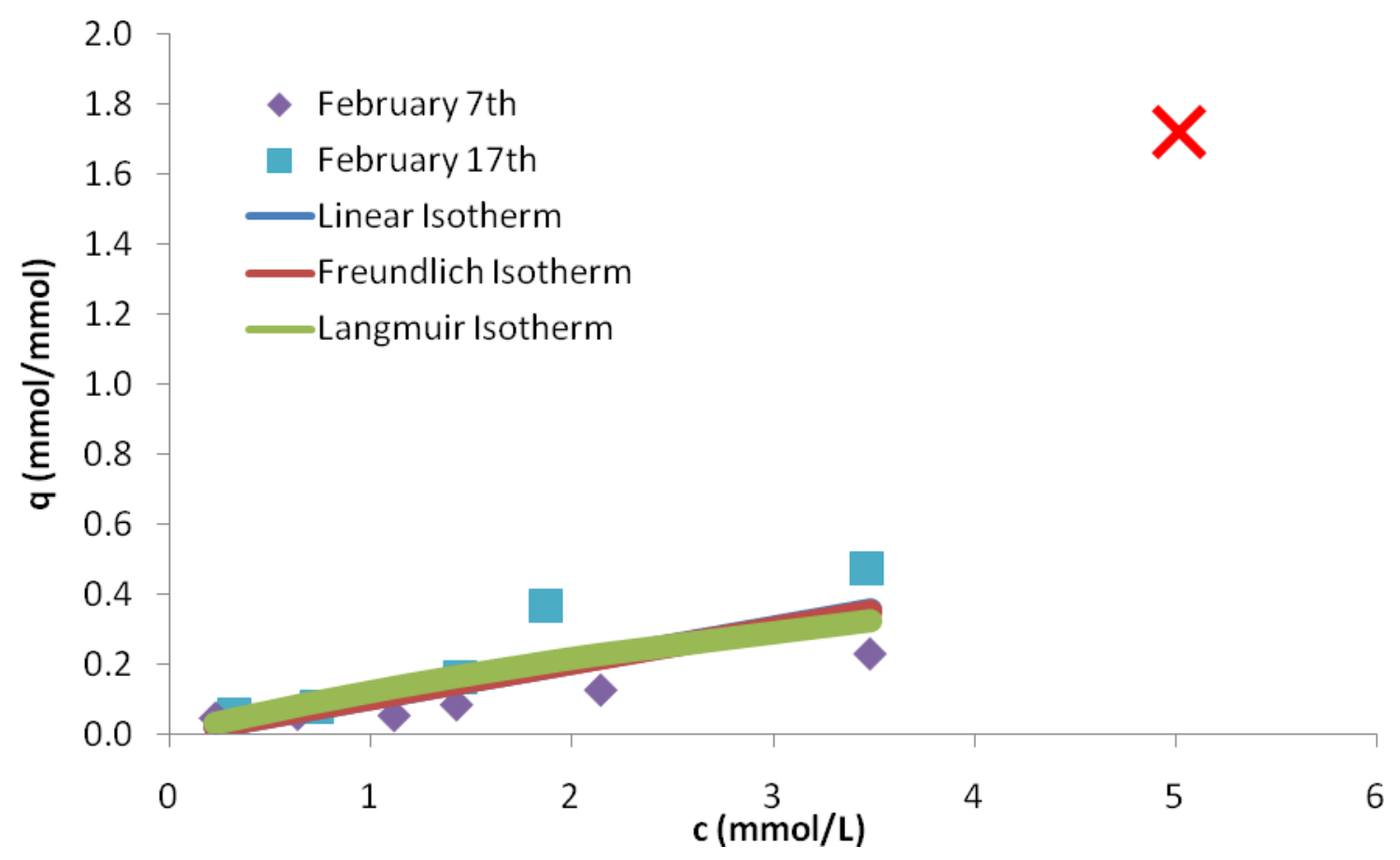

Figure 4-12 Plot of adsorption models showing excluded points (pH 11, 20 ${ }^{\circ} \mathrm{C}, 150 \mathrm{mg} \mathrm{Si} / \mathrm{L}, 8 \mathrm{~g} \mathrm{NaCl} / \mathrm{L}$ )

Table 4-17 Model equations for boron adsorption

\begin{tabular}{ccc} 
Linear Model & Langmuir Model & Freundlich Model \\
\hline$q=0.102 c$ & $q=1.92(0.061 c /(1+0.061 c)$ & $q=0.104 c^{0.978}$ \\
$r^{2}=0.787$ & $r^{2}=0.616$ & $r^{2}=0.619$ \\
\hline
\end{tabular}

Based on this information it is possible to determine how much magnesium chloride would be required to remove a given amount of boron from solution. In the equations above $q$ is equal to the boron removed divided by the moles of magnesium used, and $c$ is the equilibrium concentration of boron. Using this one can substitute desired values into these spots and use the linear equation to then determine the quantity of magnesium required. For example, based on the above results, in order to remove half 
of the boron from a solution containing $30 \mathrm{mg} \mathrm{B} / \mathrm{L}$ a dose of $2 \mathrm{~g} / \mathrm{L}$ of magnesium chloride would be required.

\subsection{Identification of Solids Produced Using XRD}

X-ray diffraction (XRD) analysis was used to determine crystal structures of two solids samples from the experiment. The first sample was precipitate from the use of magnesium chloride for boron removal. To form this precipitate, $5.0 \mathrm{~g} / \mathrm{L}$ magnesium chloride hexahydrate was added to a solution containing $150 \mathrm{mg} \mathrm{Si} / \mathrm{L}$ and $8 \mathrm{~g} \mathrm{NaCl} / \mathrm{L}$. The final $\mathrm{pH}$ was 12.14. The second sample comprised the solids formed using $5.0 \mathrm{~g}$ $\mathrm{MgO} / \mathrm{L}$ for boron removal. The final $\mathrm{pH}$ was also 12.50 . Boron removal for the magnesium chloride was approximately $37 \%$, and for magnesium oxide it $1.3 \%$ with a final $\mathrm{pH}$ of 13. The XRD results are shown in

Table 4-19. Clearly, the solids formed by the addition of these different magnesium compounds differed significantly. The MgO remained $83 \%$ as the magnesium oxide mineral periclase (Table 4-18). In contrast, only $34 \%$ of the magnesium chloride remained in the original $\mathrm{MgCl}$-hydroxide form (Table 4-18). Significant portions of the magnesium chloride were converted to brucite $\left(\mathrm{Mg}(\mathrm{OH})_{2}\right)$ and amorphous solids. Silicon-magnesium compounds did not form during this process unless they are present as part of the amorphous solids. 
Table 4-18 Solids composition for samples using magnesium oxide and magnesium chloride

\begin{tabular}{cccc} 
& & \multicolumn{2}{c}{ Experiment } \\
\cline { 3 - 4 } Mineral Constituent & $\begin{array}{c}\text { Chemical } \\
\text { Formula }\end{array}$ & $\begin{array}{c}\text { Magnesium } \\
\text { Chloride } \\
\text { Added }\end{array}$ & $\begin{array}{c}\text { Magnesium } \\
\text { Oxide Added }\end{array}$ \\
\cline { 3 - 4 } & & Relative Abundance (\%) \\
\hline Cristobalite & $\mathrm{SiO}_{2}$ & - & Trc \\
Aragonite & $\mathrm{CaCO}_{3}$ & - & Trc \\
Dolomite & $\left(\mathrm{Ca}_{7} \mathrm{Mg}\right) \mathrm{CO}_{3}$ & - & Trc \\
Halite & $\mathrm{NaCl}$ & 12 & 5 \\
Periclase & $\mathrm{MgO}$ & - & 83 \\
Brucite & $\mathrm{Mg}(\mathrm{OH})_{2}$ & 24 & - \\
Hydrate & $\mathrm{Mg}(\mathrm{OH})_{3} \mathrm{Cl} \circ 3 \mathrm{H}_{2} \mathrm{O}$ & 34 & - \\
Clay Minerals & - & 2 & - \\
Amorphous & - & 30 & 10
\end{tabular}

Table 4-19 Elemental composition of solids produced during precipitation

\begin{tabular}{ccc} 
Element & $\begin{array}{c}\text { Magnesium } \\
\text { Chloride Added }\end{array}$ & $\begin{array}{c}\text { Magnesium Oxide } \\
\text { Added }\end{array}$ \\
\cline { 2 - 3 } & Concentration (Wt. \%) \\
\hline Sodium (as $\mathrm{Na}_{2} \mathrm{O}$ ) & 6.56 & 1.88 \\
Magnesium (as $\mathrm{MgO})$ & 40.96 & 83.69 \\
Silicon (as $\mathrm{SiO}_{2}$ ) & 25.17 & 3.68 \\
Chlorine (as $\left.\mathrm{Cl}_{2} \mathrm{O}\right)$ & 26.25 & 9.97 \\
Calcium $($ as $\mathrm{CaO}$ ) & 1.05 & 0.78 \\
\hline
\end{tabular}

The elemental analysis shown in

Table 4-19 shows even more clearly the difference in composition of both solids.

Greater quantities of chlorine and silicon were incorporated into the solid resulting from the magnesium chloride. The magnesium oxide solids had a greater percentage of 
magnesium, a probable result of the greater concentration in the original solution: an addition of $5 \mathrm{~g} / \mathrm{L}$ of magnesium oxide versus magnesium chloride hexahydrate corresponds to different molar concentrations of magnesium. The magnesium oxide is equal to $0.124 \mathrm{~mol} / \mathrm{L}$ of magnesium while the magnesium chloride is equal to 0.0246 $\mathrm{mol} / \mathrm{L}$ of magnesium.

These results, in conjunction with the experiment conducted to produce the solids tested, indicate that differences in composition of solids formed have a significant effect on boron removal. This could be the result of how solids are formed in solution. For example, due to the large degree of hydration of magnesium chloride crystals added, magnesium chloride dissociates and reforms solids while boron is present. Magnesium oxide solids seem to remain in the original form. Additional silicon incorporated into the solids potentially leads to a greater removal of boron. Silicon removal by coprecipitation with magnesium has been shown to lead to greater boron removal in previous studies (Parks and Edwards 2007) even though it was not observed during the course of these experiments. 


\subsection{Adsorption vs. Co-Precipitation Mechanism for Boron Removal with Magnesium Chloride}

The purpose of this experiment was to compare boron removal by adsorption to preexisting solids versus a co-precipitation mechanism in which boron adsorbs to solids as they are precipitating. Co-precipitation is an umbrella term which encompasses two specific mechanisms for compound incorporation into a crystal structure, inclusion and occlusion. Inclusion is an impurity whose size and charge are similar to a lattice ion, and can substitute into the lattice structure. Occlusions are impurities that become trapped within a growing precipitate (Harvey, 2000). The literature suggests that for magnesium silicate minerals, boron may adsorb as $\mathrm{B}(\mathrm{OH}){ }_{4}{ }^{-}$onto particle edges. It then migrates into tetrahedral sites where it replaces structural silicon (Goldberg \& Glaubig, 1985). This would suggest that inclusion is the mechanism for boron removal. In this experiment, boron removal was compared in beakers containing an existing suspension of solids versus vessels where solids were formed after the addition of boron. For convenience, when referring to these two different sequences of events, coprecipitation will be used to describe when solids are formed after the addition of boron and adsorption for when solids were already present in solution.

For the results shown in Table 4-20, Jars 1 - 3 had solids formed prior to boron addition (adsorption), while Jars 4 and 5 had solids formed after the addition of boron (coprecipitation). The magnesium chloride addition was $1.0 \mathrm{~g} / \mathrm{L}$ for each beaker. About 
twice as much boron removal was observed via co-precipitation compared to adsorption (Figure 4-13). This experiment shows a significant advantage of forming solids in-situ. It is likely more adsorption sites are available on freshly precipitating or amorphous magnesium solids than on pre-formed solids. The higher removal in co-precipitation conforms to the high amorphous solids content of the magnesium chloride solids observed by XRD. Specific evidence for occlusion or inclusion is not present in the date for this experiment. At high ph, silica exists in a tetrahedral form $\left(\mathrm{SiO}_{4}\right)$ similar to tetraborate and could be substituted for by tetraborate. Boron was also removed from solutions containing no silica although experiments were carried out using a protocol favoring adsorption and not co-precipitation.

Solids production during this experiment is quantified in the last column of Table 4-20. The amount produced varies slightly but in most cases less solids is produced than the quantity of magnesium chloride added. Co-precipitation forms a greater quantity of solids than does adsorption. 
Table 4-20 Comparison of Boron Removal by the adsorption versus co-precipitation

\begin{tabular}{|c|c|c|c|c|c|c|c|c|}
\hline Jar & Mode & $\mathrm{pH}_{\text {final }}$ & $\begin{array}{c}\text { Boron } \\
\text { Initial } \\
\text { (mmol/L) }\end{array}$ & $\begin{array}{c}\text { Boron } \\
\text { Final } \\
\text { (mmol/L) }\end{array}$ & $\begin{array}{c}\text { Boron } \\
\text { Removed } \\
\text { (mmol/L) }\end{array}$ & $\begin{array}{l}\text { \% Boron } \\
\text { Remove }\end{array}$ & $\begin{array}{c}\text { Mol B } \\
\text { Removed } \\
\text { / Mol Mg } \\
\text { Added }\end{array}$ & $\begin{array}{c}\text { Solids } \\
\text { Formed } \\
\text { (g/L) }\end{array}$ \\
\hline 1 & \multirow{3}{*}{$\begin{array}{c}\text { Adsorp } \\
\text { tion }\end{array}$} & 11.06 & 0.93 & 0.76 & 0.17 & 18.3 & 0.034 & 0.6286 \\
\hline 2 & & 11.07 & 1.85 & 1.57 & 0.28 & 14.9 & 0.056 & 0.8354 \\
\hline 3 & & 11.12 & 2.78 & 2.33 & 0.45 & 16.0 & 0.091 & 0.7150 \\
\hline 4 & \multirow{2}{*}{$\begin{array}{c}\text { Co- } \\
\text { precipit } \\
\text { ation }\end{array}$} & 10.83 & 0.93 & 0.60 & 0.32 & 35.0 & 0.066 & 0.8208 \\
\hline 5 & & 10.97 & 1.85 & 1.32 & 0.53 & 28.7 & 0.108 & 1.0428 \\
\hline
\end{tabular}

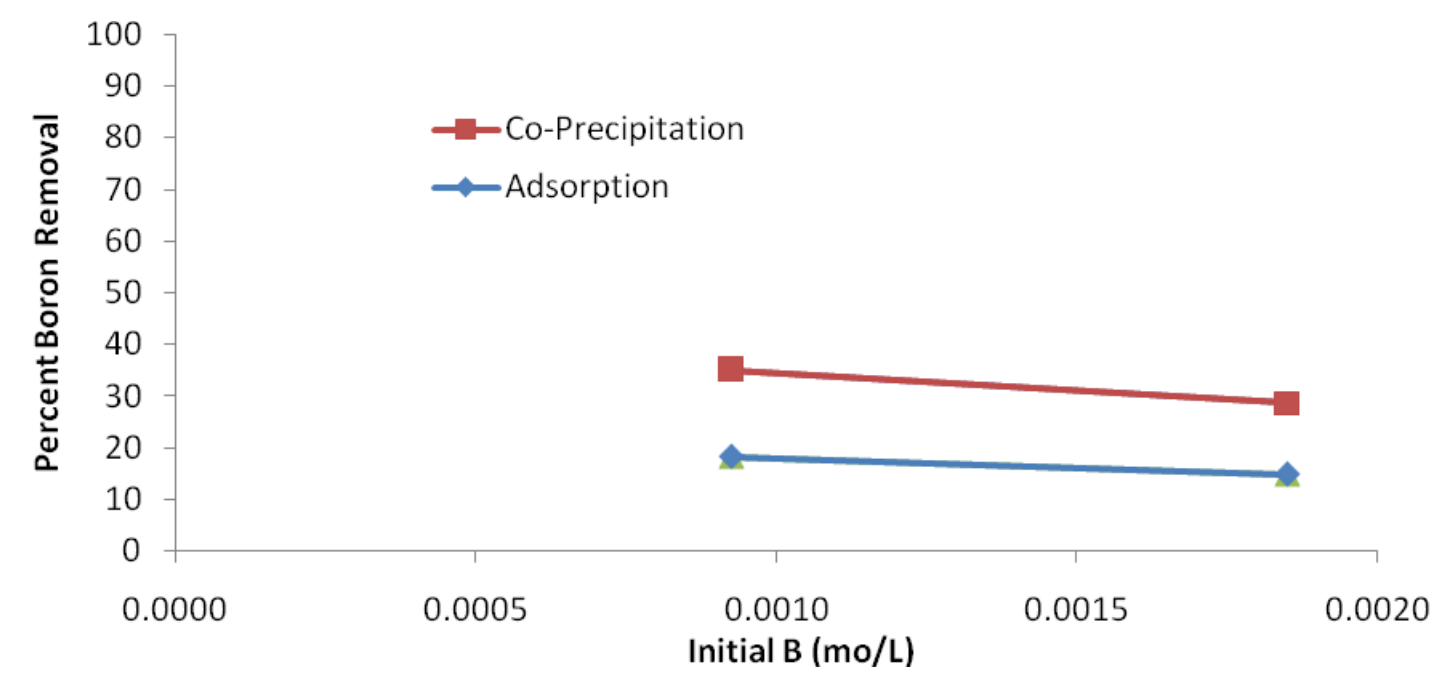

Figure 4-13 Boron removal for solutions in which solids were pre-formed (adsorption) versus formed after boron addition (co-precipitation). 


\subsection{Conclusions}

This study aimed to determine the feasibility of using magnesium chloride for boron removal from reverse osmosis concentrate generated from oil field produced water. It is necessary to balance economic as well as operational parameters. The amount of boron removal, costs of treatment and sludge disposal, availability of reagents, and environmental consequences must all be considered. Treatment of reverse osmosis concentrate instead of raw produced water has several potential benefits. First, the flow is significantly lower so facility and chemical costs will be reduced. Second, the concentration of boron is higher in reverse osmosis concentrate leading to an increased driving force for boron removal. This increased driving force should lead to lower sludge production because of higher boron content in the sludge.

The optimal $\mathrm{pH}$ for boron removal with magnesium chloride was found to be approximately 11.0, confirming previous results (Parks \& Edwards, 2007). Mixing time up to 1321 minutes did not have a significant effect on boron removal, establishing that equilibrium was reached during the standard 45-minute experimental procedures used in the current study. Isotherms for boron adsorption to the solids formed from magnesium chloride addition showed that boron adsorption was linear with respect to equilibrium boron concentration within the range of $2.5-55 \mathrm{mg} / \mathrm{L}$ equilibrium boron concentrations. This result shows that boron removal did not reach a saturation point 
for the boron-to-magnesium ratios 0.03 to 1.7 explored during this study, and treating reverse osmosis concentrate, as opposed to more dilute raw produced water, will increase the amount of boron removed onto magnesium solids.

In previous work by Wörlen (2008), the highest removal achieved using magnesium oxide on AG produced water during this study was $90 \%$ boron removal achieved with 30 $\mathrm{g} / \mathrm{L} \mathrm{MgO}$ at a $\mathrm{pH}$ of 10.3 and $66^{\circ} \mathrm{C}$. This dose of magnesium oxide corresponds to a molar magnesium concentration of $0.744 \mathrm{~mol} \mathrm{Mg} / \mathrm{L}$ (Worlen, 2008). By comparison, the highest removal observed during the current study was over $86 \%$ using $5 \mathrm{~g} / \mathrm{L}$ of magnesium chloride at a $\mathrm{pH}$ of 11.10 and temperature of $21^{\circ} \mathrm{C}$. This dose of magnesium chloride corresponds to a molar concentration of only $0.025 \mathrm{~mol} \mathrm{Mg} / \mathrm{L}$, which is a little less than one thirtieth of the magnesium concentration needed when magnesium oxide was used. This demonstrates that magnesium chloride is a more efficient treatment reagent than magnesium oxide. Magnesium chloride treatment decreases chemical consumption, as well as having less severe temperature sensitivity. Despite these advantages, magnesium chloride treatment, as developed thus far, will be costly. Using $1.0 \mathrm{~g} / \mathrm{L}$ of magnesium chloride leading to a boron removal of approximately $30 \%$, the resulting RO concentrate would contain about $20 \mathrm{mg} / \mathrm{L}$ of boron. Magnesium chloride was estimated to cost about $\$ 540$ a ton (2008 - 2009 prices). Assuming $75 \%$ recovery through reverse osmosis and a treatment plant flow rate of 2 MGD, 500,000 gallons of water would need to be treated daily. This would require 1.8 tons of magnesium 
chloride and cost $\$ 1000$ a day. Almost all of this weight would become dry weight sludge, the disposal of which would represent additional cost.

Solids produced by magnesium chloride and magnesium oxide were compared using $\mathrm{x}$ ray diffraction analysis. Solids resulting from magnesium oxide treatment were mainly magnesium oxide (either reformed or undissolved original solids) with other amorphous solids. For magnesium chloride treatment, the solids were mainly magnesium chloride hydroxide, brucite, and amorphous solids. Chemical composition differed between the treatments as well. Since it is not known how much $\mathrm{MgO}$ dissolved and reformed, it is not known whether co-precipitation with $\mathrm{MgO}$ occurred. It is likely that much of the MgO residual was undissolved reagent that could remove boron only by adsorption. Therefore, it cannot be determined if $\mathrm{MgO}$ is fundamentally worse at co-precipitation of boron when compared to $\mathrm{MgCl}$ 2. A conclusion as to which solids in suspension are better for boron removal can only be indirectly made based on the results of other experiments. In order to determine which solids in fact adsorbed greater quantities of boron would require further research.

For a given dose of magnesium chloride, boron removal was two times greater for coprecipitation than adsorption. In situ co-precipitation led to greater boron removal 
probably because more sites were available for boron entrapment on freshly precipitating solids than on pre-formed crystalline material.

In this study, high temperatures led to a decrease in boron removal from $12 \%\left(30^{\circ} \mathrm{C}\right)$ to just over $2 \%\left(70^{\circ} \mathrm{C}\right)$ at a $1 \mathrm{~g} / \mathrm{L}$ magnesium chloride dose. The warmer temperature also led to a decrease in the settleability of the solids. Since RO concentrate is expected to be cool $\left(50-60^{\circ} \mathrm{C}\right)$ compared to raw produced water $\left(70-80^{\circ} \mathrm{C}\right)$, magnesium chloride would be the recommended reagent.

Several anions were tested for their possible effect on boron removal. The first was sodium chloride. Sodium chloride exhibited minimal effects on boron removal. Sulfate was also tested as a compound found in the RO concentrate and was also shown to have almost no effect on boron removal.

In previous research (Parks \& Edwards, 2007), silica was found to play a significant positive role in boron removal. In fact, silicon removal was required for boron removal in these studies. In contrast, the current research found that boron removal was better in the absence of silicon. Thus, removal of silicon prior to magnesium chloride treatment 
would be beneficial. In addition, removal of silicon prior to reverse osmosis treatment would decrease scaling of the membranes.

In summary, the maximum observed boron removal efficiency observed in this work was $87 \%$ at a pH of 11.1 using $5.0 \mathrm{~g} / \mathrm{L}$ of magnesium chloride. Even considering the relatively low RO concentration flow, this high dose of magnesium chloride would result in high reagent costs and production of large quantities of sludge, which would be expensive to dispose of.

If lower boron removal efficiencies could be tolerated, lower magnesium chloride doses could be used. For example, with a silicon concentration of $13.7 \mathrm{mg} / \mathrm{L}$, as much as $31 \%$ boron was removed from solution using $1.0 \mathrm{~g} / \mathrm{L}$ of magnesium chloride at ambient temperatures. This translated to a removal of approximately $10 \mathrm{mg} / \mathrm{L}$ boron, and the process would produce a little less than $1 \mathrm{~g} / \mathrm{L}$ of dry solids.

Further research is required to make this process more cost effective. Several possibilities exist for achieving this. First, boron could be removed from RO reject by adsorption to sludge produced upstream in the lime-softening of the raw produced water. Since this sludge would necessarily be produced in the proposed treatment 
scheme (Figure 1-1), this method would not result in any increases in sludge. Experiments using such sludge could be used to determine the feasibility of this method and also to explore adding materials such as magnesium chloride to the lime sludge to enhance boron removal. This method could work if a magnesium precipitate is formed in a thin layer over existing solids, more adsorption/co-precipitation surface would then be available than if than same mass were "balled" up on a tiny nucleating site.

Another possibility is the use of poly-aluminum chloride instead of magnesium chloride as the treatment reagent. Although aluminum sulfate has been used before with unsatisfactory results (Konstantinou, Kasetta, \& Pashalidis, 2006), aluminum electrocoagulation has been reasonably successful (Yilmaz, Boncukcuoglu and Kocakerim 2007). Due to their decreased requirement for mixing compared with aluminum sulfate in coagulation processes (Crittenden, et al. 2005), chlorinated aluminum compounds could possibly form more effective adsorbents for boron than aluminum sulfate. 


\subsection{Works Cited}

Adams, Roy M. Boron, Metallo-Boron Compounds and Boranes. New York: Interscience Publishers, 1964.

Blevins, Dale G., and Krystyna M. Lukaszewski. "Boron in Plant Structure and Function." Annual Review Plant Physiology and Plant Molecular Biology 49 (1998): 481-500.

Bouguerra, W., A. Mnif, and M. Dhahbi. "Boron removal by adsorption onto actiated alumina and by reverse osmosis." Desalination 223 (2008): 31-37.

Camacho-Cristobal, Juan J., Jesus Rexach, and Agustin Gonzales-Fontes. "Boron in Plants: Deficiency and Toxicity." Journal of Integrative Plant Biology 50 (2008): 12471255.

Crittenden, John C, R. Rhodes Trussell, David W. Hand, Kerry J. Howe, and George Tchobanoglous. Water TreatmentL rincipes and Design. 2nd. Hoboken, New Jersey : Wiley, 2005.

Eaton, Andrew D., Lenore S. Clesceri, and Arnold E. Greenberg. Standard Methods for the Examination of Water and Wastewater. 19th. Washington, DC: American Public Health Association, American Water Works Assoc., Water Environment Federation, 1995.

Eaton, Scott V. "Effects of boron defficiency and excess on plants." Plant Physiology, 1940.

EPA. 2006 Edition of the Drinking Water Standards and Health Advisories. Office of Water, US Enviornmental Protection Agency, 2006.

Garcia-Soto, M. Del Mar de la Fuente, and Eugenio Munoz Camacho. "Boron removal by means of adsorption with magnesium oxide." Separation Purification Technology 48 (2006): 36-44.

Goldberg, Sabine, and R. A. Glaubig. "Boron Adsorption and Silicon release by the Clay Minerals Kaolinite, Montmorillonite, and Illite." Soil Science Society of America Journal 50 (1985): 1442-1448.

Goldberg, Sabine, H. S. Forster, M. S. Lesch, and E. L. Heick. "Influence of Anion Competition on Boron Adsorption by Clays and Minerals." Soil Science 161 (1996): 99103. 
Harvey, David T. Modern Analytical Chemistry. McGraw Hill, 2000.

Hayes, Tom, and Dan Arthur. "Overview of Emerging Produced Water Treatment Technologies." 11th Annual International Petroleum Environmental COnference. Albuquerque, 2004.

Jacob, Cyril. "Seawater Desalination: Boron Removal by Ion Exchange Technology." Desalination 205 (2007): 47-52.

Jahiruddin, M., R. Smart, A. J. Wade, C. Neal, and M.S. Cresser. "Factors regulating the distribution of boron in water in the Rlver DEE catchment in north east Scotland." The Science of the Total Environment 210 (1998): 53-62.

Jiang, Jia-Qian, Y. Xu, K. Quill, J. Simon, and K. Shettle. "Mechanisms of Boron Removal with Electrocoagulation." Environmental Chemistry 3 (2006): 350-354.

Kitano, Yasushi, Minoru Okumura, and Masatoshi Idogaki. "Coprecipitation of borateboron with calcium carbonate." Geochemical Journal 12 (1978): 183-189.

Konstantinou, Maria, Glykeria Kasetta, and loannis Pashalidis. "Boron adsorption on alumina and magnesia in aqueous solutions: a comparative study." International Journal of Environmental Technology and Management 6 (2006): 466-479.

Kostick, Dennis S. Boron. 2006 Minerals Yearbook, United States Geological Survey, 2006.

Kostick, Dennis S. Boron. Mineral Commodity Summaries, U.S. Geological Survey, 2008.

Magara, Yasumoto, Akihisa Tabata, Minoru Kohki, Mutsuo Kawasaki, and Masahiko Hirose. "Development of boron reduction system for sea water desalination." Desalination 118 (1998): 25-34.

McNeill, L.S., and M. Edwards. "Predicting as removal during metal hydroxide precipitation." Journal of American Water Works Assoc. 89 (1997): 75-86.

Mondal, S., and S. Ranil Wickramisinghe. "Produced water treatment by nanofiltration and reverse osmosis membranes." Journal of Membrane Science 118 (2008): 162-170.

Muetterties, Earl L. The Chemistry of Boron and its Compounds. New York : John WIley \& Sons, Inc. , 1967. 
Nielsen, Forrest H. "Boron in Human and animal nutrition." Plant and Soil 193 (1997): 199-208.

Parks, J. and M. Edwards. "Boron in the Environment." Critical Reviews in Science in Technology 35 (2005): 81-114.

Parks, Jeffrey L., and Marc Edwards. "Boron removal via formation of magnesium silicate solids during precipitative softening." Journal of Environmental Engineering 133 (February 2007): 149-156.

Parks, Jeffrey L., and Marc Edwards. "Precipitative Removal of As, Ba, B, Cr, Sr, And V using Sodium Carbonate." Journal of Environmental Engineering 132 (2006): 489-496.

Pastor, M. Rodriguez, A. Ferrandiz Ruiz, M. F. Chillon, and D. Prats Rico. "Influence of pH in the elimination of boron by means of reverse osmosis ." Desalination, 2001: 145-152.

Pokrovsky, Oleg S., and Jacques Schott. "Experimental study of brucite dissolution and precipitation in aquous solutions: Surface speciationa nd chemical affinity control." Geochimica et Cosmochimica Acta 68 (2004): 31-45.

Pokrovsky, Oleg S., Jacques Schott, and Alain Castillo. "Kinetics of Brucite Dissolution at $25 \mathrm{C}$ in the presence of ORganic and Inorganic Ligands and Divalent Metals." Geochemica et Cosmochimica Acta 10 (2005): 905-918.

Polyak, Desiree E. Boron. U.S. Geological Survey Minerals Yearbook, United States Geologic Survey, 2007.

Ravina, Louis. Everything you want to know about Coagulation and Flocculaton, 4th Edition . Staunton : Zeta-Meter , 1993.

Receoglu, O., and U Beker. "A preliminary study on boron removal from Kizildere/Turkey Geothermal Waste Water." Geothermics 20 (1991): 83-89.

Remy, Patricia, Herve Muhr, and Imen Ouerdiane. "Removal of Boron from Wastewater by precipitation of a sparingly soluble salt." Environmental Progress 24 (2005): 105-110.

Ross, V F, and J. O. Edwards. "The Chemistry of Boron and Its Compounds." In The Chemistry of Boron and its Compounds, by Earl L. Muetterties, 155-207. Wilmington: John Wiley and Sons, Inc., 1967.

Sheridan, Margaret. California Crude Oil Production and Imports. Staff Paper, California Energy Commission, 2006. 
Skoog, Douglas A., James F. Holler, and Stanley R. Crouch. Principles of Instrumental Analysis, 6th edition. Belmont: Thomson HIgher Education , 2007.

Stumm, Werner, and James J. Morgan. Aquatic Chemistry: Chemical Equilibria and Rates in Natural Waters; Third Edition. New York: Wiley Interscience , 1996.

Tanaka, Mayuki, and Toru Fujiwara. "Physiological Roles and Transport mechanisms of boron: Perspectives from plants." European Journal of Physiology, 2008: 671-677.

Turek, Marian, Dydo Piotr, Jolanta Trojanowska, and Adam Campen. "Adsorption / Coprecipitation - reverse osmosis system for." Desalination 205 (2006): 192-199.

USEPA. Drinking Water Health Advisory for Boron. Health Advisory, Washington DC: USEPA, 2008.

USEPA. Fact Sheet: Final Regulatory Determinatins for Second Drinking Water Contaminant List. United States Environmental Protection Agency , 2008.

USEPA. Health Effects Support Document for Boron. Support Document, United States Environmental Protection Agency, 2008.

USHHS. Draft Toxicological Profile For Boron. Toxicological Profile, Altlanata: United States Department of Health and Human Services, 2007.

Veil, John A., Markus G. Puder, Deborah Elcock, and Robert J. Redwick Jr. A White Paper Describing Produced Water from Production of Crude Oil, Natural, Gas, and Coal Bed Methane. White Paper, United States Department of Energy, 2004.

Weber, Walter J., Paul M. Mcginley, and Lynn E. Katz. "Sorption Phenomena in subsurface systems: Concepts, Models and Effects on Contaminant Fate and Transport ." Water Research, 1991: 499-528.

WHO. Boron Drinking Water. Background Document for development of WHO Guidlines for Drinking-water Quality, Geneva: World Health Organization, 1998.

Wiberg, Egon, Nils Wiberg, and Arnold Holleman. Inorganic Chemsitry. San Diego: Academic Press, 2001.

Woods, William G. "An Introduction to Boron: History, Sources, Uses, and Chemistry." Environmental Health Perspectives 102 (1994): 5-11. 
Worlen, Cecilia. Co-Precipiration . Adsorption of Boron for Treatment of Produced Water at the Arroyo Grande Oil Field, California. Thesis, San Luis Obispo: Dept. of Civil and Environmental Engineering, Cal Poly, San Luis Obispo, 2008.

Yilmaz, A. Erdem, Recep Boncukcuoglu, and M. Muhtar Kocakerim. "A quantitative comparison between electrocoagulation and chemical coagulation for boron removal." Journal of Hazardous Materials 149 (2007): 475-481. 